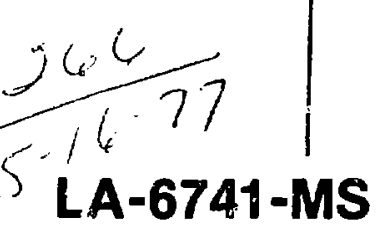

Informal Refort

vc-41 $2 n, 0,5$

Issued: April 1977



\title{
An Examination of the Pathways from Soil to Man for Plutonium
}

by

J. W. Healy 
This work was supported by the US Energy Research and Development Administratiois, Division of Safety, Standards, and Compliance.

\author{
Printed in the United States of America. Available from \\ National Technical Information Service \\ U.S. Department of Commerce \\ 5285 Port Royal Road \\ Springfield, VA 22161 \\ Price: Printed Copy $\$ 5.00$ Microfiche $\$ 3.00$ \\ Thiw report who prepored an an acruant of work yponaored

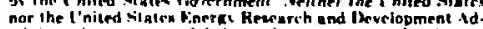 \\ minixts : lion, nur ans of iheir emplusers. nor ans of their con.

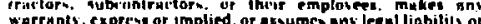

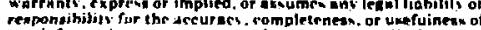

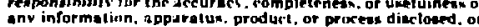

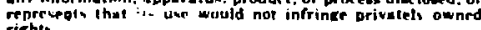 \\ rishis.
}


AN IXAMLATION OF 'HHS PATHWAYS FROM SOIL TO MAN FOR PLUTONIUS

by

J. W. Healy

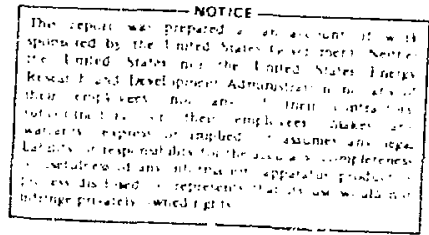

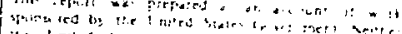

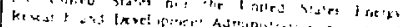

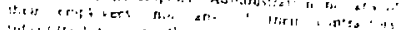

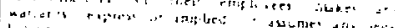
are

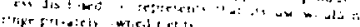

\begin{abstract}
The data available on resuspension and ingestion as pathways of plutonium froii soil to man were reviewed and a recommended limit based lipon a conservative interpretation of the National Courcil on Radiation Protection and Measurements (NCRP) recommendations for limiting values was derived. Wind resuspension appeared to be the least limiting value with mechanical resuspension and pica in children among the more important. Ingestion of food. stuffs could also be an important pathway if it is assumed that all food is produced in the contaminated area.
\end{abstract}

\title{
I. INTRODUCTION
}

The derivation of a limit for plutonium in soils is difficult because of the widely differing concitions in wich it may be applied. Thus, when the vegetated areas of the East with relatively heavy rainfall are contrasted with the farm lands of the middle of the country or with the arid and semiarid regions of the West, the conditions are so different that it is difficult to find a common ground. If, then, the differing uses of the land, which range from pasture through agriculture or forests to the building of town and cities, are included, the situation becomes almost hopeless. It is for this reason that many people feel that one should not attempt to derive a specific guide for soils but should examine each case on an ad 
hoc basis. There is considerable merit to this vienpoint but this means that the battle for acceptance and concensus must be fought anew for each of these cases and it may be difficult to explain to a public not used to this type of an approach the details of why different values are acceptable at different locations.

For these reasons, we have tried to derive a numerical value for plutonium in soils which is believed to be safe at any location. It would be ideal to believe that this could be used as a "decision lovel," 1 or a level above which further investigation and decision is needed taking into account the existing conditions, thereby combining some of the advantages of a fixed value with the advantages of an ad hoc determination. It is apparent to the author, however, that the forces of society are such that this type of flexibility will not be accepted and we must resign ourselves to the fact that any value accepted will be used throughout. However, we must also recognize that the approach used here is not unique in its problems or the method of handling although this may be an extreme example. For examp1e, the present limits for radioactive materials in air or water involve the reduction of a large number of variables to single numbers that represent a "safe" 1 imit.

This analysis was prepared for a particular purpose: to give guidance as to leveis on properties to be returned to the public after potential contamination from nuclear work. This limits our consideration to areas where the contanination has been present for some time since it is unlikely that an area would be disposed of immediately following an accident that resulted in contamination. While many of the same considerations nay be of importance in a limit to be used following an airborne deposition, the primary factor of possible mobility of the fresh deposit will not be present here.

It is assumed that the property, once sold, is subject to no further control so that it could be used for any purpose: homes, farms, pasture, a factory, or any similar use. It can be seen that this eliminates the variable of use, since che limitation 
must be gauged to the use with highest probability of intake. It is possible that restrictions could be places in the deed at the time of sale so that certain uses are forbidden. Such a practice nay be the wisest choice when the darage to the environment is such as to destroy valuable resouris. It must be remembered that cleaning of soil contaminatior requires removal of the contaminated soil and replacing with cian soil from anochar location. A less drastic measure is ploning but even this can cause damage in some cases. Since the soil is the basic support for all terrestrial ecosystems such "decontamination" can severely affect an ared. Areas with endangered species or those which have fragile ecosystems that may not recover for centuries deserve special attention with the wisest course, possibly, to not decontaminate so that the conseguent disruption does not occur. Such a decision must be made at the time by responsible officials.

Jince the considerations in this report were primarily based upon the population being in close proximity to the contaminated area, the values derived here should not be considered as applicable to areas still under control of access. Such 1 imitations should be based primarily on airborne transport (or in some aieas water transport) to the surrounding population.

In accidince with gocd radiation protection practice and as recommended by the NCRP, the value given should be regarded as the maximum allowe? with values reduced to as far below this value as is practicable before disposal. While this requires a value judgment on the part of both the disposer and the recipient, this principle, in general, can be defined as removal of contamination to a level where further reductions would be exorbitantly expensive or would result in unacceptable damage to the property or the environment.

The limitation is not intended to be translated into an "acceptable" value for the release of plutonium as based on land contamination. With present controls on the design and operation of plutonium-handling facilities, it is believed that land 
contaminatios ia the future will occur only in the event of ar accident. In $\therefore$ hases, where the land is under the control of an operator, it is considered good prastice to clean up any contamination to the extent practicabie and, if possible, to below the 1 imitation given, always with respect for the practical degree to which cheanup can be accomplished without completely destroying what cne is trying to protect.

\section{I. SOIL CHARACTERISTICS PERTINENT TO PLUTONIUN TRANSFER}

The properties of plutonium in soils and the possibilities of movement are ralated to the characteristics of the soil as well as to the method whereby the plutonium was originally deposited. While considerable attention has been paid to the preserice of oxide particles as a result of accidents or safety tests, it must be realized that other methods of soil contamination, such as adsorpition from liquids, do occur. In the case of the oxide particles, they will have an initial particle size characteristic of the method of formation and deposition. They wil1 undoubtedly be degraded in size with time by the normal method of soil formation. However, for the area contaminated with plutonium in solution, the absorption will be chiefly on the smaller particles in the soil, the clays. These particles are normally present in the soils as aggregates or fastened to the larger sand particles although the degree of aggregation depends upon the soil type, humus content, and moisture content.

Since the scil and its properties play an important part in the interactions with plutonium, we have reproduced in the remainder of section II, a discussion on soils and wind erosion by J. Nyhan from a previous report. ${ }^{2}$

A. Wind Erosion in the U.S.

Although few regiors in North America are entirely free from wind erosion, several regions exhibit high activity. Figure $l$ 
Shows that the erosion of soil by wind has been the worst in the Great Plains, as well as the Columbia River plains, and some parts of the pacific Southwest, and the Colorado Basin. Ocher general regions of interest include the muck and sandy areas in the Great Lakes region and the sands of the Gulf and Atlantic seaboards. ${ }^{3}$ It is useful to consider three factors influencing the mechanic: of wind erosion: wind, soil, and the nature of the croding surface.

Regions in the U.S. With relatively high average surface wind velocities (I:ig. 2) correspond to areas of high soil erosion by wind. This is not surprising since the intensity of wind erosion apparently varies as the cube of wind velocity. ${ }^{4}$ The wind factor is centered around the wind velocity pattern near the soil surface, its effect on the initiation of soil movement, and the transportation and deposition of soil particles.

The soil factor involves the influence of soil moisture and soil structure on the severity of wind erosion. Periods of drought, wind erosion, and dust storms have occurred simultaneously in the Great Plains, and the intensity of wind erosion varies inversely as the square of either moisture at the soil

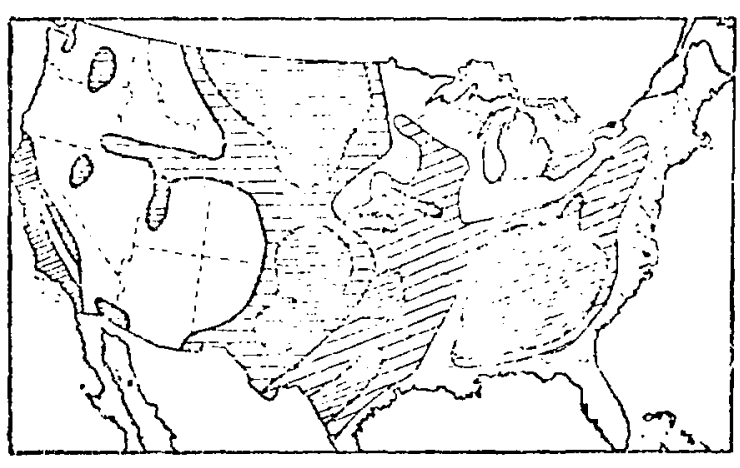

Fig. 1. A generalized map (101) showing the chief large areas of high soli erosion by wind (horizontal shaciing) or runoff islanting shading).

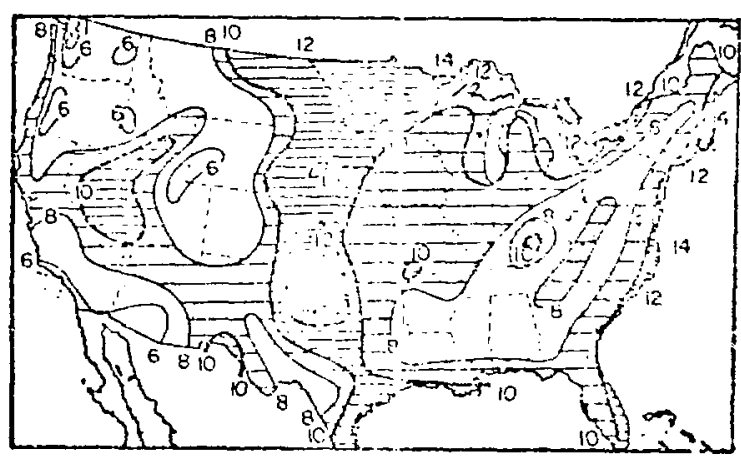

Fig. 2. Generalized map (101) of average surface wand velocity (mpla). 
surface or effectiva precipitation. 4 Again, a good correlation exists between geographic regions of intense hind erosion (lig. 1) and areas where cvaporation i! usually in excess of precipitation (Fig. 3 ). These observations are related to the fact that there are very few winds that have surficient velocities to overcome the very large cohesire forees of moisture at a tension of 15 atmospheres in an air-uricu soil. 5,0 Soil structure, or the arrangement of individual sand, silt, and clay particles with respect to each other, also influences soil resuspension. Soil structure is in turn affected by the particle size distribution of the soil, as well as the organic matter and polyvalent cation content of the soil components important in binding the particles together. Although enormous forces are necessary to break the covalent bonds involved in these soil-cation-organic molecule complexes, winds can move groups of these aggregates in the form of clods less than 840 um in diameter.' The stability of these structural units is decreased by tillage operations and by freeze-thaw and wetting-drying cycles at the soil surface.

The nature of the eroding surface is another factor which influences the mechanics of wind erosion. Surface conditions which affect wind erosion are the surface roughness and the degree of protection by surface cover. The erosion decreases with increasing surface roughness, when this rorghness is due to nonerodible structural units, mainly because of the diminished wind velocity at the soil surface. Vegetation not only adds to surface roughness but also provides cover for the soil surface. Regions of the U.S.A. where the vegetation is minimal (grassland or desert) also exhibit a potential for significant wind erosion (Fig. 1) compared with the minimal wind ercsion in prairie-forest or forest zones (Fig. 4). Vegetation effectiveness as a wind barrier depends primarily upon its density, width in the wind direction, porosity, and orientation with respect to the prevailing winds. 


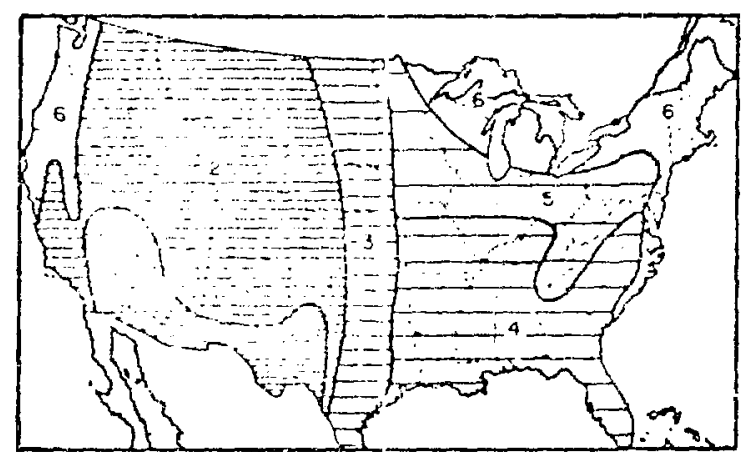

F1E. 3. Evaporation reftans:

1. evaporaticn riush in excess of prec1piation

2. evaporation conslderably in excess of precipitation

3. evaporation usua 13 ar exaess of prectpiza:ion

4. evaporalich in excess of prec1pliation in wam montis

5. precte1tat in in exaess of evaporation in cooier months

5. preclp1tsitor Eereralij in excess of eveporation (10:).

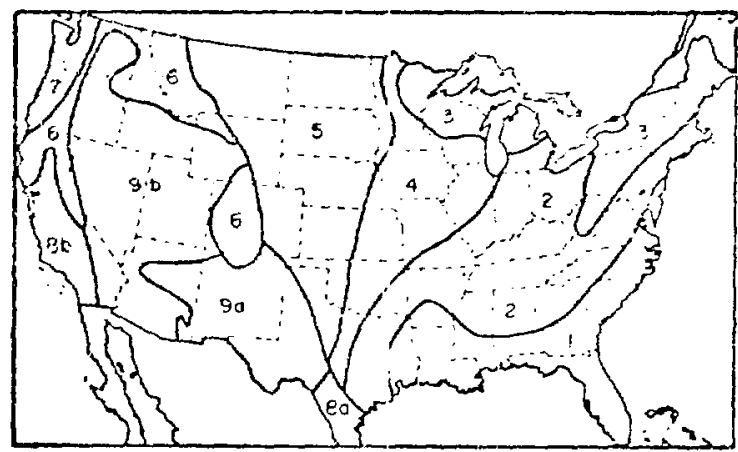

F1g. 4. Gereralized teet:

1. sourtedater anest

2. dections ackest

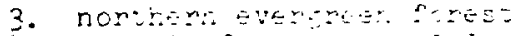

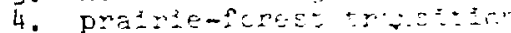

5. $5 x \leqslant 5 s i s x 2$

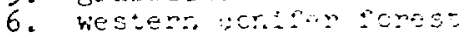

7. northwasm ander tanes

8a. desert sirits

8b. sertiesent struits

9a. semideser:

9b. desert

B. Variations in Soil Properties Which Influence Erosion

In order to understand the natural variability of soil properties affecting wind erosion, an understanding of some factors in soil formation is helpful. The five factors of soil formation that influence, have influenced, or may influence soil genesis are as follows: parent material, organisms, climate, relief (topography), and time (Fig. 5). When considering soil variations throughout an area as large ss the Great Plains, it is useful to relate the scale of action of these five factors to soil variability within this large region. Climate and organisms tend to be relatively uniform across distances of tens or hundreds of miles (kilometers), whereas parent materials are fairly uniform over miles of distance. Almost al1 of the shortdistance changes in soil type are related to the topographic factor.

The five soil formation factors are responsible for general patterns of soils occupying positions on contemporary landscapes within the wind-eroded areas in Fig. 1. Transects across the 


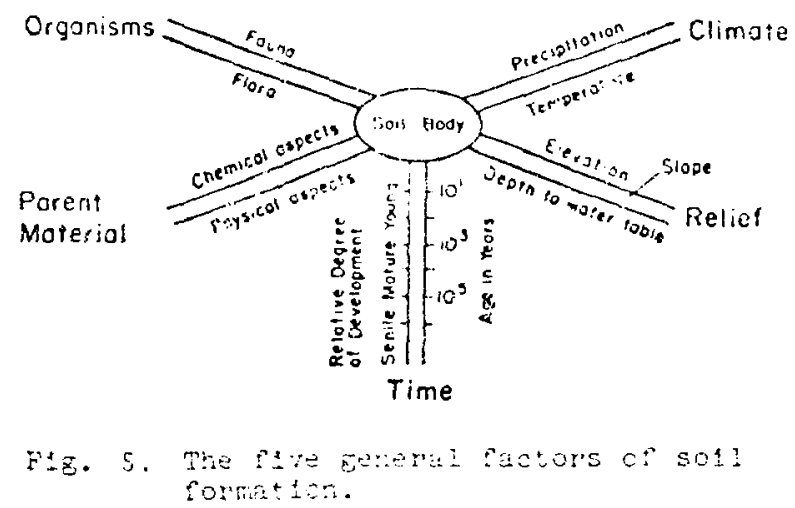

northern and southern Creat plains exhibit large areas of entisols* and aridisols** in the western regions, grading into vast areas of mollisols*** to the east. These soils are also the major soils in the areas of Washington, Nevada, California, and Arizona where high wind erosion activity exists. scils belonging to the Entisol order of the U.S. Comprehensive soil Classification system ${ }^{8-10}$ represent the simpler end of the soil continuum relative to soil development and usually occur in mouniaincus, desert, and alluvial floodplain regions. These soils are morphoiogically similar to their parent materials, partially due to the immobilization of clay illuviation by inert materials, highly siliceous sediments, and carbonates. The entisols are similar to soils of the Aridisol order in that they both contain light-colored topsoils with less than $1 \%$ organic matter. However, the aridisols, the soils of the arid regions, are more weathered than the entisols and exhibit minimal clay illuviation, maximum carbonate accumulation, and many times a surface "pavement" of gravel. The mollisols, the darker colored grassland soils of the prairies, contain greater than $1 \%$ organic matter in the top 7 in. $(18 \mathrm{~cm})$ of their profiles. Several

\footnotetext{
*Newly formed soils. ** Soils of arid regions. ***Grassland soils of steppes and prairies.
} 
pedogenetic processes are involved in mollisol profile development that are minimized in entisol-aridisol profiles: ll: the process of darkoning of sojl by organic matter additions, (2) accelerated cluriation and illuriation of clays, and ( $\bar{i}$ ) loess aditions to the topsoils of some mollisols.

Jenny ${ }^{1}$ has allocated a scheme for comparing soils or individual soil properties. This scineme is based on the principle of comparing a given goil property among soils when one soil formation factor is dominant and the other four are inerfective. Jenny took soil samples along an $11^{\circ} \mathrm{C}$ isotherm in the arid-humid transition belt extending from Colorado through kansas to western Nissouri, and correlated natural variations in soil properties with annual rainfall. ${ }^{12}$ The results (lis. 6 ) indicated that the depth of the carbonate horizon and hydrogen-ion concentration depend most sensitively on rainfall, with nitrogen content (related to organic matter content) and clay concentrations less influential. Since these soil properties influence soil structure directly, wind erodibility will be inversely related to this climatio factor.

The particle size distribution of a soil is an important factor contributing to soil aggregate formation. The U.S.D.A. has developed a system of classifying soils relative to their texture, i.e., the relative proportions of sand (5:1- to $2000-1 \mathrm{~m}-$ diam particles), silt (2-to $50-\mu m-d i a m$ particles) and clay (particles with diameters less than $2 \mathrm{\mu m}$ ). These 12 classes are usually presented as a soil-texture triangle (Fig. 7 ). These 12 classes can be further grouped into coarse-, medium-, and finetextured soils as in Table $\mathrm{F}$.

Natural variations in particle size distributinns of surface soils [i.e., top inch $(2.5 \mathrm{~cm})$ of soil] have not received much attention, mainly because the top $15-30 \mathrm{~cm}$ of soil is usually the important unit for agricultural and soil classification reasons. However, it is known that climatic factors have a large influence on the particle size distribution af surface 


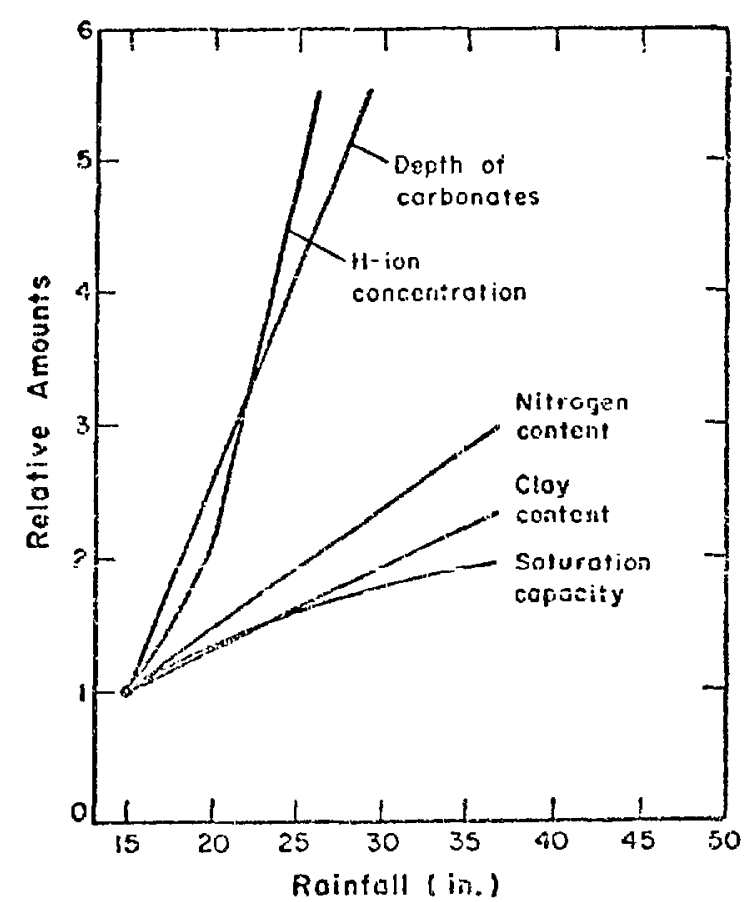

FIE. 6. Ralative soil property-rainalil curves for some soils in the ureat Plains (69).



Fig. 7. The soli texture triangle (USLA).

soils, a factor involved in aggregate formation. With increasing aridity, physical processes assume relatively greater significance than chemical forces in the disintegration of rocks. Thus, aridisols bear a closer relation to thejr parent materiai than mollisols. However, reduction in size of sand and silt particles is performed largely by physical weathering via differential thermal expansion of minerals, frost action, and by erosion and deposition by water, ice, and wind. In contrast, clay particles have relatively large surface areas that are able to react relatively fast via chemical reactions, all of which require the presence of water.

In order to observe the net result of physical and chemical weathering processes on parent materials, the particle size distributions of selected textural types of soils is presented in Fiss. 8-13 and Table II. This compilation of resulcs for over 
TABLE I

SOIL-TEXTURE CLASSIEICATION

Coarse-textured

Medium-textured soils

Fine-textured soil.s
1. Sands and loamy sands

2. Sandy loams

3. Loamy soils

4. Moderately heavy soj.1s

5. Clays and silty clays
Sand

Joamy sand

Sandy loam

Fine sandy loam

Very fine sandy loat! Loam

silt loam

silt

Sandy clay loam

clay loam

silty clay loam

Sandy clay

silty ciay

C.3 ay

40 soil types ${ }^{13-27}$ is presented as graphs of percentages of particles (by weight) smaller than a specified particle size. Whenever the data are available, the mechanical composition of "typical soils," as given by one author 28 is also plotted for comparison (solid lines).

Figures 8-13 incicate that very few soils have appreciable amounts of sand particles greater than $500 \mu \mathrm{m}$ in diameter. This seems to substantiate the observation that many soil materials, notably those in glaciated areas where much of agricultural science developed, tend to have a mininum in particle size distribution around $1000 \mu \mathrm{m} .{ }^{29}$ At the other end of the spectrum, many soils ilay consist of over $30 \%$ by weight of particles smaller than $0.2 \mu \mathrm{m}$ in diameter; this represents a documented, 5 

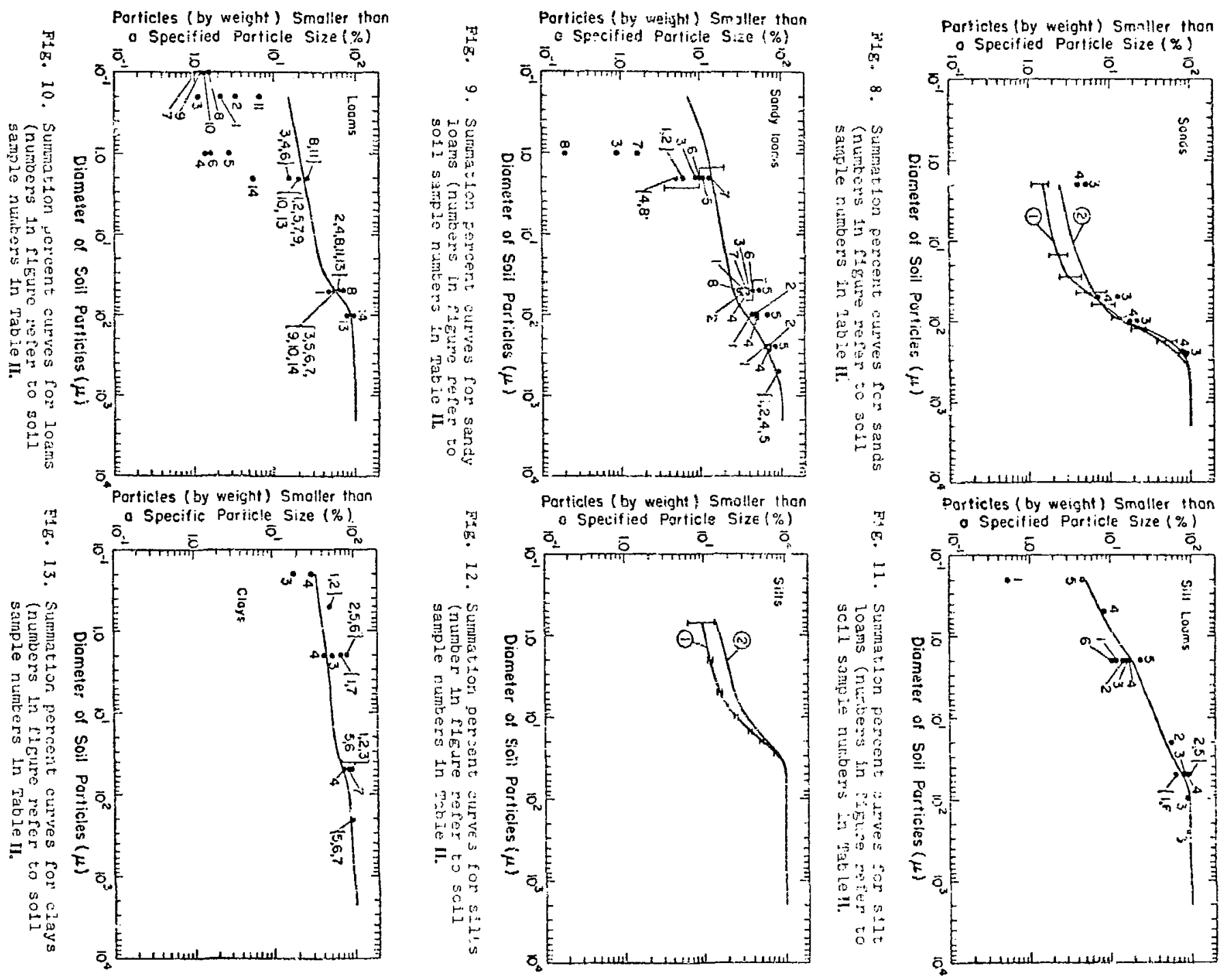
T'ABLE II

IDFNIIPICATINA OP SUILS IN PIGUEES $B-13$ BY TEXTUAAL CLKSSES

\begin{tabular}{|c|c|c|c|c|c|c|}
\hline $\begin{array}{l}\text { Texiliral } \\
\text { ClasB } \\
\end{array}$ & $\begin{array}{l}\text { Sample } \\
\text { Number in } \\
\text { Fisire }\end{array}$ & $\begin{array}{l}\text { So11 } \\
\text { TyLe }\end{array}$ & 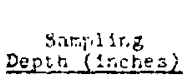 & Lacat:on & Comineris & Reference \\
\hline & \multicolumn{6}{|c|}{ A. Coarse-zextured so118 } \\
\hline Sand & i & 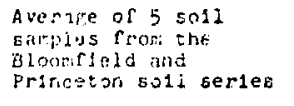 & $\begin{array}{l}\text { Varted rrom } \\
40-200\end{array}$ & Indiana & $\begin{array}{l}\text { Sampies rrom C hordigoma } \\
\text { of watagh River tratsect }\end{array}$ & 13 \\
\hline sand & 2 & $\begin{array}{l}\text { Average of } 7 \text { solz } \\
\text { 8amieg from the } \\
\text { aloomilezd and } \\
\text { Princeton sosl series }\end{array}$ & $\begin{array}{l}\text { Yar1ed Eror. } \\
53-136\end{array}$ & Indtana & 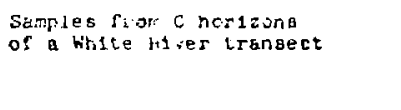 & $j . j$ \\
\hline Sand & 3 & Not clansiried & $0-2$ & $\begin{array}{l}\text { Northern } \\
\text { Aiaska }\end{array}$ & 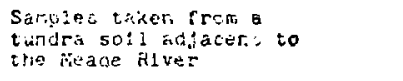 & 24 \\
\hline \multirow[t]{2}{*}{ Sand } & 4 & not ciassiridd & $0-5$ & $\begin{array}{l}\text { Sorthertl } \\
\text { Alsoka }\end{array}$ & $\begin{array}{l}\text { Sarpies taren in sand } \\
\text { duris adjacent to the } \\
\text { Heade ilver }\end{array}$ & 14 \\
\hline & \multicolumn{6}{|c|}{ B. Mediun-textured so11日 } \\
\hline $\begin{array}{l}\text { Sandy } \\
\text { loan }\end{array}$ & 1 & Sc1tuate baridy loam & $0-9$ & $\begin{array}{l}\text { New } \\
\text { tispatire }\end{array}$ & $\begin{array}{l}\text { Sample taken at crest } \\
\text { of a druailn }\end{array}$ & 15 \\
\hline $\begin{array}{l}\operatorname{Sandy} \\
2 \operatorname{com}\end{array}$ & 2 & $\begin{array}{l}\text { Scituate rine sandy } \\
\text { Loam }\end{array}$ & $0-7$ & $\begin{array}{l}\text { Wis } \\
\text { liangshire }\end{array}$ & $\begin{array}{l}\text { Samplis token in midule } \\
\text { slope region of ditimiln }\end{array}$ & 15 \\
\hline $\begin{array}{l}\text { Sandy } \\
\text { 20ali }\end{array}$ & 3 & $\begin{array}{l}\text { Greenfleid sine } \\
\text { bandy Ioam }\end{array}$ & $0-20$ & $\operatorname{ca} 21 \operatorname{cosn} 1 \mathrm{~s}$ & & 16 \\
\hline $\begin{array}{l}\text { Sandy } \\
\text { loam }\end{array}$ & 4 & Ilmoaliute sards soam & 0.2 & vitah & Samples from ardd reainn & 17 \\
\hline $\begin{array}{l}\text { Sardy } \\
\text { jonm }\end{array}$ & 5 & $\begin{array}{l}\text { Eacalante riue } \\
\text { Bandy loam }\end{array}$ & $1-12$ & Utah & Samples from arld region & 17 \\
\hline $\begin{array}{l}\operatorname{sand} y \\
\text { leam }\end{array}$ & $\epsilon$ & $\begin{array}{l}\text { Auncape of } 7 \text { Ptarmigan } \\
\text { banty loans }\end{array}$ & $0-8$ & Montana & $\begin{array}{l}\text { Located cri bteep-gentie } \\
\text { mountain oiopes }\end{array}$ & 18 \\
\hline Sandy loan & $\tau$ & Mussitk sandy loam & $0-6$ & Caliroris & Podzol1C EOAI & 19 \\
\hline Sandy loan & 8 & Caspar sandy joam & $0-6$ & callornda & rodzolie soll & 19 \\
\hline Loam & 1 & $\begin{array}{l}\text { Inclassified but in } \\
\text { the oabow soil } \\
\text { association aroa }\end{array}$ & $0-7$ & Saskstchewan & Coth1c Black Sold & 20 \\
\hline Loain & 2 & $"$ & $0-7$ & Sashatichewan & Podzolic Orthic Dark Grey Sol1 & 20 \\
\hline irr:m & 3 & $\begin{array}{l}\text { Unclassjsled, but in } \\
\text { Whit tewood Agsociazion }\end{array}$ & $0-4$ & Saskat chewan & Podro21c Dark Grey hooded soll & $2]$ \\
\hline Loam & 4 & Tehama loan & $0-8$ & Cal1romia & - & 16 \\
\hline Loam & 5 & Nimball loam & $0 \therefore 4$ & Gelleornie & - & 16 \\
\hline Lonom & 6 & San Jpaquin loan & $0-6$ & Cazisomia & - & 16 \\
\hline
\end{tabular}


TABLE II (cont)

ZDENTIFICATION OF SOILS IN PICURES 8-13 BY TEXTURAL CLASSES

\begin{tabular}{|c|c|c|c|c|c|c|}
\hline $\begin{array}{l}\text { Toxiural } \\
\text { Class } \\
\end{array}$ & $\begin{array}{l}\text { Sample } \\
\text { Number In } \\
\text { Pigure } \\
\end{array}$ & $\begin{array}{l}\text { So11 } \\
\text { Type }\end{array}$ & $\begin{array}{c}\text { Sampling } \\
\text { Depen (1nches) }\end{array}$ & Lacat10n & Comments & Peference \\
\hline Lean & 7 & Garnea loam & $0-6$ & $\begin{array}{l}\text { North } \\
\text { Dakota }\end{array}$ & $\begin{array}{l}\text { Publicaldor. soli " S5jND-2-1 } \\
\text { Srum antral North Dakota }\end{array}$ & 21 \\
\hline Loam & 8 & Barnes Loam & $0-2$ & $\begin{array}{l}\text { North } \\
\text { Dakota }\end{array}$ & 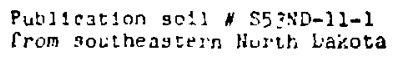 & 21 \\
\hline Loam & 9 & Earnes loar. & $0-5$ & $\begin{array}{l}\text { Worth } \\
\text { Daknes a }\end{array}$ & $\begin{array}{l}\text { Publication soli } 454: \text { DD-10-2 } \\
\text { From northeastern Horh Datota }\end{array}$ & 21 \\
\hline Loufn & 10 & Aestad Loan & $0-6$ & $\begin{array}{l}\text { North } \\
\text { Daxota }\end{array}$ & $\begin{array}{l}\text { Grassland soll rrom central- } \\
\text { eascetal hosin Dakuta }\end{array}$ & 21 \\
\hline Loam & 11 & Mappanee Loara & $0-8$ & Ohio & lake plain sample & 22 \\
\hline Loan & 12 & Nappanee ioam & $0-8$ & M1ch1gan & glacial till plain sample & 22 \\
\hline LOB & 13 & Redraedd loam & $0-6$ & U:ah & aliuvial soll in an arid region & 17 \\
\hline Lónm & 14 & Jvada 2.oam & $0-1$ & vtah & - & 17 \\
\hline Loan & 15 & Melbourne loam & $0-7$ & Cailfornia & Lateritic soll & 19 \\
\hline silt 20em & 1 & Not classiried & $0-1$ & Sagkatchewan & Orthle Grey Hooded soll & 20 \\
\hline silt $108 \pi$ & 2 & Hogmer s1lt loam & $0-8$ & Illno1s & loesg-derlued podzolic soll & 23 \\
\hline S11t loan & 3 & $\begin{array}{l}\text { Ante lope Springs } \\
\text { silt Loam }\end{array}$ & $0-3$ & U:ah & - & 17 \\
\hline silt $300 m$ & 4 & Coroptne s11t loata & $0-6$ & $\begin{array}{l}\text { Br!tish } \\
\text { GuIana }\end{array}$ & podzol1c costal soll & 24 \\
\hline S11t Ioam & 5 & Fasroidge sit loan & $2-3$ & $\begin{array}{l}\text { British } \\
\text { Columb1a }\end{array}$ & - & 25 \\
\hline S13t $30 a n$ & 6 & Hopleys silt loam & $0-6$ & Montana & Alpine soll & 18 \\
\hline silt & 2 & $\begin{array}{l}\text { Averibe of } 5 \text { soll } \\
\text { samples from the } \\
\text { Alrors. Magsdale and } \\
\text { Sylvall serles }\end{array}$ & $\begin{array}{l}\text { varied from } \\
40-140\end{array}$ & Indiane & $\begin{array}{l}\text { Sanples room } c \text { horizons of a } \\
\text { Wabsh River transect }\end{array}$ & 13 \\
\hline \multirow[t]{2}{*}{ s12t } & 2 & $\begin{array}{l}\text { Average or } 4 \text { soli } \\
\text { samples from the } \\
\text { Alford, pagadale, and } \\
\text { Hosmer serieg }\end{array}$ & $\begin{array}{c}\operatorname{var} 1 e d \\
52-76\end{array}$ & Indlana & $\begin{array}{l}\text { Samples from } c \text { horizons of a } \\
\text { White River transect }\end{array}$ & 13 \\
\hline & \multicolumn{6}{|c|}{ c. Fine-iextured go113 } \\
\hline clay & 2 & Prontland clay & $0-6$ & $\begin{array}{l}\text { Britgsh } \\
\text { Gutana }\end{array}$ & $\begin{array}{l}\text { Coastal so11, unleached } \\
\text { phase }\end{array}$ & 24 \\
\hline clay & 2 & Prontland clay & $0-6$ & $\begin{array}{l}\text { Brit1gh } \\
\text { Gulara }\end{array}$ & $\begin{array}{l}\text { leached and cultivated } \\
\text { phase }\end{array}$ & 24 \\
\hline Clay & 3 & Albernt clay & $0-2$ & $\begin{array}{l}\text { Brftigh } \\
\text { Columb1a }\end{array}$ & - & 25 \\
\hline Ciay & 4 & $\begin{array}{l}\text { Average of } 3 \text { Thoeny } \\
\text { clays }\end{array}$ & Unspectried & Montana & Samples from B horizonB & 26 \\
\hline Clay & 5 & $\begin{array}{l}\text { Princes town } \\
\text { clay }\end{array}$ & $0-6$ & Wegt Indies & - & 27 \\
\hline clay & 6 & Carbon frail clay & $0-6$ & West Indies & - & 27 \\
\hline clay & 7 & Pltahes clay & $0-6$ & West Indies & - & 27 \\
\hline
\end{tabular}


orders of magnitude difference in soil particle sizes. The results of summation curves for 560 German soils 30 indicated that: (1) particle size distributions were normally distributed when the log of the particle size was plotted on the abscissa, (2) every particle size range has one maximum size distribution, and (3) certain distributions did not occur natural1y. Examples of soils that were not found were soils with less than $20 \%$ silt and greater than $30 \%$ clay and soils with less than $65 \%$ sand, less than $5 \%$ clay and more than $30 \%$ silt.

C. Classification of Soils Into Wind Erodibility Groups

Eolian materials were described in a recent review 3.1 by their pathway of transportation in the atmosphere, persistence in the atmosphere, and particle size (Table III). More specifically, we are interested here in the air concentrations from the soil surface to about $2 \mathrm{~m}$ above the soil surface. Chepil $32-34$

TABLE III

CLASSIFICATION OF EOLIAN MATERIALS

\begin{tabular}{|c|c|c|c|c|}
\hline \multirow[b]{2}{*}{ Type of Material } & \multirow{2}{*}{$\begin{array}{c}\text { Dominant } \\
\text { Particle } \\
\text { Size } \\
(\mu \mathrm{m}) \\
\end{array}$} & \multicolumn{2}{|c|}{ Transport } & \multirow{2}{*}{$\begin{array}{c}\text { Persistence in } \\
\text { Atiosphere }\end{array}$} \\
\hline & & Patrivay & Range $(\mathrm{km})$ & \\
\hline Dune sand & $400-200$ & $\begin{array}{l}\text { At or near } \\
\text { ground level }\end{array}$ & $10^{-3}$ to $10^{\circ}$ & $\begin{array}{c}\text { Highly transient } \\
\text { phase }\end{array}$ \\
\hline Loess & $50-10$ & $\begin{array}{l}\text { Lower tropo- } \\
\text { sphere }\end{array}$ & $10^{-1}$ to $10^{2}$ & Transient phase \\
\hline Aerosolic dust & $10-1$ & $\begin{array}{l}\text { Middle and } \\
\text { upper tro- } \\
\text { posphere }\end{array}$ & $10^{4}$ to $10^{6}$ & $\begin{array}{l}\text { Residence time } \\
\text { depends on pre- } \\
\text { cipitation fre- } \\
\text { quency but is } \\
\text { thought to be } \\
\text { days to weeks }\end{array}$ \\
\hline $\begin{array}{l}\text { Stratospheric } \\
\text { dust }\end{array}$ & $<1$ & Stratosphere & $210^{9}$ & $\begin{array}{l}\text { Residence time, } \\
\text { years }\end{array}$ \\
\hline $\begin{array}{l}\text { Extraterrestrial } \\
\text { dust }\end{array}$ & $40-0.01$ & $\begin{array}{l}\text { Interplanetary } \\
\text { space }\end{array}$ & $210^{13}$ & Undetermined \\
\hline
\end{tabular}


has documented the dynamics of wind movement of arable soils in this zone via surface creep, saltation, and suspension, involving progressively smaller soil particles.

After the violent wind erosion in the Great plains in the 1930 s and 1950s, criteria were needed to determine the capability classification of soils in these areas-criteria based on more than land use experience. In 1957 Coover and Moldenhauer 35 used a formula, which expressed soil loss rates as a function of a soil "erodibility index," plant surface residue, and surface roughness, to quantitatively evaluate the wind erosion in capability classifications for Texas soils. In 1960 Chepil ${ }^{36}$ developed the more generalized relationship between actual soil loss rates and his soil erodibility index, based on many wind tunnel and field measurements, for Garden City, Kansas. Chepil late: developed a wind erosion climatic index for application of the Kansas experiments to many geographical regions. ${ }^{4}$ The final accomplishment came in 1963 when Chepil and Woodruff 37 published the wind erosion equation, which expressed the many factors involved in soil losses from erosive wind effects:

$$
E=f\left(\begin{array}{lllll}
I & C & K & L & V
\end{array}\right)
$$

This equation expresses the annual soil loss in tons per acre (E) in terms of the soil erodibility index (I), the climatic index (C), soil surface roughness $(K)$, the unsheltured field width (L), and the equivalent quantity of vegetative cover (V).

The Soil Conservation Service (S.C.S.) has recently deve1oped criteria for grouping soils into "wind erodibility groups" as described in Tables IV and $V .{ }^{38}$ The procedure is to collect about $2 \mathrm{~kg}$ of dry soil from the surface inch of the field, sieve the soil through an $0.84-\mathrm{mm}$ square-opening sieve in the field, and relate the percentage of nonerodible soil aggregates greater than $0.84 \mathrm{~mm}$ to the wind erodibility group and soil erodibility index (the $I$ factor in the wind erosion equation). When large areas of 1 and must be classified and sieving is not a feasible 
TABLE IV

RILLA IONSHIP OF DRY SOIL AGGRIECATES >0.84 mi.

'TO SOIL ERODIBBILITY INDEX (I) AND WINI) ERODIBILITY' GROUP

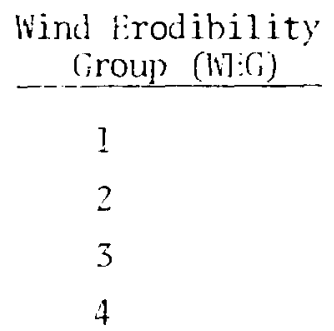

$+1$.

5

6

7

8
Dry Soil Aggregates

$>0.84 \mathrm{~mm}-$ percent

$0.5-1.5$

$5.0-15.0$

$16.0-34.0$

$15.0-35.0$

$15.0-35.0$

28.0-52.0

$36.0-54.0$

$36.0-64.0$
Soil Frodibility

Index tons/acre/year

$340-280$

$180-117$

113-67

$117-65$

$117-65$

$79-33$

$63-29$

$63-17$

procedure, the wind erodibility group can be roughly estimated by the texture by feel method. Once the wind erodibility group has been estimated, site-specific information on the other four factors of the wind erosion equation can be collected to estimate the potential amount of wind erosion for a given field under local climatic conditions.

This work has many direct applications to the problems of coricern, especially because the S.C.S. has already collected these data for many soils. The total amount of soil loss per year, as predicted by the wind erosion equation, does consist of about $90 \%$ soil loss via saltation (and minimal surface creep) and about $10 \%$ soil loss in suspension - on the average. 39 Thus, many large soil particles would move via saltation close to the soil surface ( $90 \%$ below a height of one foot), 3 and would initiate suspension of smaller soil particles (silt, clay, and aggregates) in the respirable size range. This represents no small amount of soil - estimates of up to $277 \mathrm{million}$ tons per year were found in suspension over the Great Plains in the 1950s. 39 


\section{TABLE V}

GUIDE FOR ESTIMATING WIND ERODIBILITY GROUP

FROM APPROXIMATE SOIL TEXTURES

Texture of Surface Inch

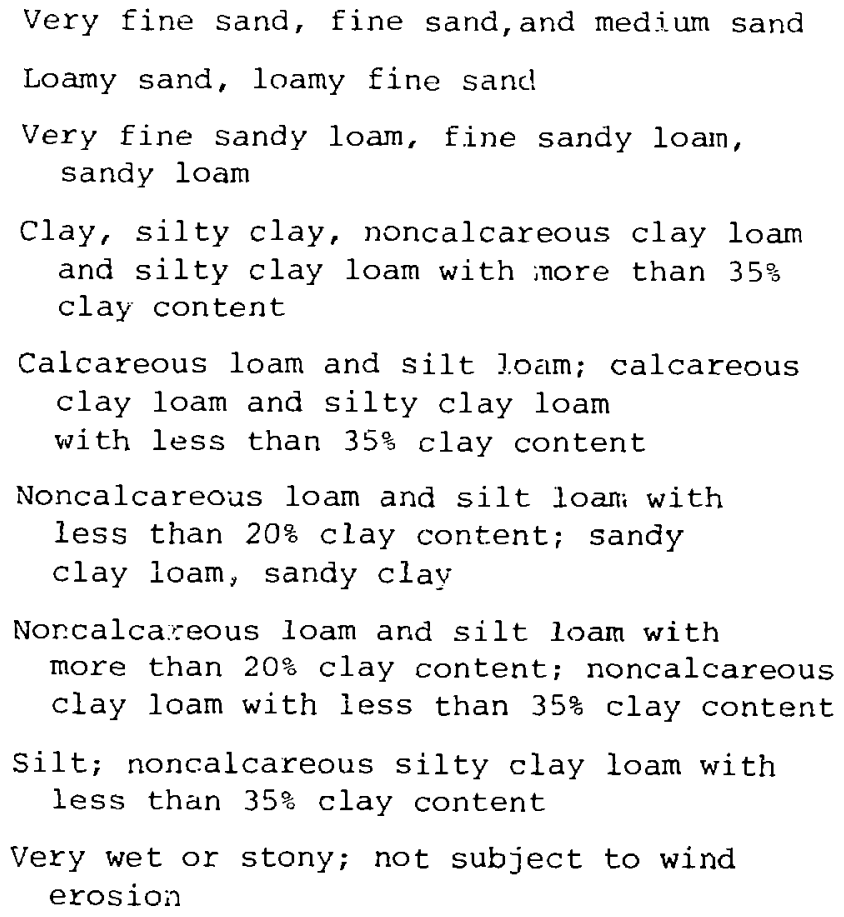

Wind Erodibility Group

1

2

3

4

$\Delta \mathrm{L}$

5

0

7

8

\section{MECHANISMS OF EXPOSURE}

The radiations emitted by plutonium are nonpenetrating so that any potential health hazard from plutonium in the soils must result from transfer from the soils into the body. Material transferred to the surface of the body is also of little importance except that this may serve as an intermediate step in the intake to the body. In a previous report, ${ }^{40}$ we considered the following mechanisms of transfer.

1. Absorption through the skin or wounds. The absorption factors derived were based primarily on the plutonium being applied as a solution rather than in the form of insoluble 
oxide or soluble plutonium absorbed on soil particles. Eren ther, it was cstimated that the amount of plutonium-bearing soil on the skin could be as high as $1300 \mathrm{dis} / \mathrm{min} / \mathrm{g}$ (590 pCi/gj continually carried throughout life. This is believed to be a very conscrvative estimate, perhaps by several orders of magnitude when the form of the plutonium on the soils and occupancy factors for the contaminated area are considered. Since there have been ino additional data on skin absorption obtained in the interim, we will not consider this mechanism further in this report.

2. Inhalation as a result of general resuspension. General resuspension is considered to be that due to either winds or mechanical disturbance that results in relatively widespread air contamination with the meteorological dispersion characteristics of the area an important factor.

3. Inhalation as a result of local resuspension. Local resuspension is considered to be that due to mechanical disturbance that produces a high local concentration in the breathing zone of the individual. It also includes the production of local resuspension following transfer to another medium, for example, the production of high concentrations during the removal of clothing that was contaminated in the area. The latter mechanism could, perhaps, be better labeled as a "transfer-local resuspension" but we will continue to include it in the local resuspension category.

4. Ingestion as a result of eating plant material raised in the contaminated area nr. animal products from the cortaminated area. In genei:l, this mechanism was earlier judged to be relatively minor, but it will be reviewed again in 1 ight of the more recent data.

5. Casual ingestion of soil by individual sorking in the area or as a result of dust derived from the area. 
6. Deliberate ingestion of soil by children living on the contaminated area.

In general, the pathways explored in this report are similar to those in the previous report. Little additional data are available on the local resuspension problem but there have been a relatively large number of experiments on wind resuspension which have icd to increased understanding of the problem although there still remains a paucity of data with which to really provide a quantitative estimate for areas different from those investigated.

1V. I:ITAKE LIMITS

In recent years, particularly since the issuance of the BEIR report, ${ }^{41}$ there has been a trend toward the derivation of estimated numbers of health effects under assumed conditions to arrive at the consequences of a given action, such as establishing a new program or a new limit. The uncertainties of such a procedure in converting an estimated dose to numbers of cancers or genetic defects are well known and were emphasized in the body of the BEIR report. In fact, the NCRP in a review of the current state of radiation protection policy stated: 42 "The NCRP wishes to caution governmental policy-making agencies of the unreasonableness of interpreting or assuming upper limit estimates of carcinogenic risks at low radiation levels, derived by linear extrapolation from data obtained at high doses and dose rates, as actual risks, and of basing unduly restrictive policies on such an interpretation or assumption. The NCRF has always endeavored to insure public awareness of the hazards of ionizing radiation, but it has been equally determined to insure that such hazards are not greatly overestimated. Undue concern, as well as carelessness with regard to radiation hazards, is considered detrimental to the public interest." 
In the present study, the uncertainties in estimating the intake and resulting doses far outweigh the uncertainties of even the calculations referred to above. Thus, measurements from which resuspension rates can be derived are relatively few and only in selected areas. The behavior patterns of children with respect to playing in the soil are poorly defined and even the latest data on foodstuff contamination tends to be indicating higher transport than was previously believed.

We could have proceeded by producing a mathematical "model" including known methods of intake and metabolism and used best guesses as to the transfers. However, this would also involve chwosing one or two model locations so that the conditions could be related to the location. Our experience indicates that such an approach tends to mask uncertainties and produces numerical values that are commonly regarded as having validity far beyond their true uncertainty. For this reason we have analyzed each of the potential pathways of exposure separately, attempting in each case to carefully delineate uncertainties and to explain assumptions but, at the same time, using conservative assumptions so that it is extremely probable that accumulations in the body, even in extreme conditions, will not reach the limit chosen.

The NCRP has recommended that for individuri members of the public not occupationally exposed that "the dose :imit for the critical organs (whole body) of the individual...shall be 0.5 rems in any one year, in addition to natural radiation and medical and dental exposures." 43 This 1 imit is based on possible somatic effects. For genetic considerations they recommend that: "The dose equivalent to the gonads for the population of the United States as a whole from all sources of radiation other than natural radiation, and radiation from the healing arts shall not exceed a yearly average of 0.17 rem...per person." (emphasis added) In considering this limit they point out that: "With an intended limit of 0.5 rem per year for most, if not all situations, the average incremental dose to population groups 
from radiation plants and installations would probibly easily stay below 0.1 rems per year, comfortably lithin the limit that consideration of genetic effects sets tor the whole population." lie lill, therefore, in general, base our consideritions on a dose to the critical organs of the maximum individual of 0.5 rems/year. This, of course, is lower by a factor of 5 than is recommended by the ICRP ${ }^{44}$ for most critical organs of an individual but does correspond to their limit for the average of a population group.

The basic strategy in the examination of the indiridual pathways was to estimate the dose to a maximum individual in any environment. Thus, the mechanical resusponsion was considered for a farmer tilling his ficlds and this pathway may be of much lower importance in other situations. Some other pathway may be of greater importance in other environments. The dose limits from the NCRP are to cover al1 sources of man-made radiation aside from medical. This, of course, can change from year to year and from place to place depending upon fallout conditions as well as the use of devices producing $x$ rays. The degree of conservatism in the derivation of the plutonium limits as well as the focus on the maximum individual, leads to the conclusion that any allowance for other exposure is not necessary unless such exposure reaches a major fraction of the 500 mrem per year.

The primary sources of intake and subsequent exposure are ingestion and inhalation. Ausorption through the skin was considered in the earlier report 40 and appeared to be of little consequence even with assumed absorption rates higher than appear reasonable. Since no new information has been obtained, this potential pathway will be ignored in this study.

Following ingestion the ICRP 45 summarizes the absorption as follows: "...following ingestion of relatively insoluble material, such as $\mathrm{PuO}_{2}$, the absorbed fraction may be taken to be about $10^{-4} \%$. For more soluble compounds (e.g., plutonium nitrate) the absorption is also low, due to hydrolysis; the absorbed fraction may be assumed to be about $3 \times 10^{-3} \%$. This fraction may be increased substantially if the ingested material is administered 
to immature animals or is in a strongly acid solution. Absorption of chemically stable, soluble complexes le.g., Pu-DIPA chelates) from the gastrointestinal tract may be as high as $2 \%$ of the amount administered." However, in reference to the high absorption hith complexed plutonium they point out that if the complex is highly stable and the complexing liqujd is of high stability, as is ITPA, disassociation of the complex in the body will be minimal and excretion of the absorbed complex will be rapid and over $99 \%$ will be excreted in 2 days. Weaker complexes, such as the citrate, however, will be metabolized and the retained fraction may be considerably higher than following a soluble salt, such as the nitrate, by perhaps one or trio orders of magnitude. It must be remembered, hovever, that these studies on complexing agents are done with plutonium already complexed and usually with an excess of complexing agents so that behavior in environmental situations may be different.

Both the ICRP 46 and the NCRP 47 in derivation of drirking water MPCs have used an absorption from the G.I. tract typical of a soluble salt, such as the nitrate, of $0.003 \%$. While this is appropriate for water, there is some question whether this value should be used for foods. Adequate studies have not been done on the absorption of plutonium which has been metabolized in plants or animals, and in prepared foods there are many addi. tives (although in small quantities) which could aifect the uptake from the G.I. tract. For these reasons, we have chosen an uptake value ten times that used in setting MPCs for drinking water, or $0.03 \%$, for use in ingestion of foodsturfs. However. for ingestion of soils we have used the value for the saluble salt or $0.003 \%$. If the plutonium in the soil is in the form of plutonium dioxide, as would occur from most atmospheric dispersals, this value is undoubtedly high, perhaps by one or two crders of magnitude depending upon particle size. If the pluto. nium is absorbed on the clay fraction and if desorption in the G.I. tract occurs it may behave as the soluble salt. No allowance ras made over and above these considerations for incrused 
absorption by childrer because the age perind during which this is important is small and any additional accuniulation during this period will be within the range of uncertainty when the ful 1 ifetime accumulation is considered.

In assessing the permissible ingestion rate we consider the critical organs of concern as the bone and the liver. The ICRP, for inhalation, recommends that the quantity of plutoniun in these two organs be partitioned equally since, in the extreme case, this will. not result in ar error of more than a factor of 2 to cither organ. 45 In the ingestion case it appears 1 ikely that the quantity going to the bone will be greater than that to whe 1 iver. However, we wil1 consiler the ICRP recommendation on inhalation to apply for ingestion since this is well within the other uncertainties in the study. Thus, of that absorbed to the bioodstream, it is assumed that $45 \%$ deposits in bone, $45 \%$ in liver, and the remaining $10 \%$ is distributed to the remainder of the body. Again following the ICRP, ${ }^{45}$ the half-life in the skeleton is taken as 100 years and in the 1 iver as 40 years. The permissible intake lias based upon accumulating a quantity in the budy which would result in 0.5 rems per year to the critical organ at the end of a 70-year exposure period. For a liver weight of $1700 \mathrm{~g}$ and a G.I. tract absorption of $0.03 \%$, this permits an ingestion of $44 ! n \mathrm{pCi} / \mathrm{day}$ to result in a final 1iver content of $880 \mathrm{pCi}$ after 70 years. For an absorption of $0.003 \%$, the intake would be $4400 \mathrm{pCi} / \mathrm{day}$. For a $7000-\mathrm{g}$ skeleton, the amount to give 0.5 rems per year is $730 \mathrm{pCi}$ and the corresponding intakes for 70 years would be $270 \mathrm{pCi} / \mathrm{day}$ for $0.03 \%$ absorption or 2700 for $0.003 \%$ absorption when the "dose distribution factor" of 5 is included. It is noted that the bone limit is different in origin from the liver limit in that it was derived by biological comparison with radium and these data were used to derive the dose distribution factor. ${ }^{48}$ The NCRP 43 did not address bone as a critical organ except for a footnote "For most alpha particle emitters deposited in bone, the bone itself may be the overriding critical organ with respect to bone cancer." 
The detailed study of the question of the application to bone was deferred to a study of internal emitters.

Inhalation is normally considered the most nrobable method of intake of a relatively insoluble material which is poorly absorbed through the G.I. tract. The ICRP Task Group on Lung Dynamiss 49 has provided a detailed review of information on deposition of particulates in the lung and the subsequent elimination and transfer to other organs. A Task Group of Committee 2 of the ICRP has proposed revisions to the behavior of plutonium following deposition in the lung. 45 To estimate the intake which would produce 0.5 rems per year at the end of a continuous exposure for 70 years, we have calculated the dose to the lung, skelaton, and liver Lor various particle sizes of both the Class $Y$ (retained in the lung for long times) and Class $W$ (retained in the lung for intermediate times) plutonium. The more soluble material represented by Class $D$ is not believed to be representative of plutonium compounds. The lymph nodes were not included since the evidence with animals indicates that they are insensitive to the long term effect of cancer production and dose limits have not been derived for these organs.

The deposition in the three parts of the respiratory tract considered were read from the curves of the ICRP Task Group 49 and are given in Table Vl.

The relatively high deposition in the pulmonary region (3-9\%) for particles above $10 \mathrm{~km}$ AMAD is presumable due to the presence of smal1 particles in the distribution although the Task Group does not discuss this point. It may be noted that the values for the larger particle sizes total more than $100 \%$ deposition. These were the values estimated from the curves in the Task Group report and were retained rather than attempting adjustment. For the smaller particle sizes the difference between the deposition and $100 \%$ represents the fraction exhaled without depositing.

While we have used the model by the ICRF ${ }^{45}$ for movement into the bloodstream, it should be noted that there is some question 
'IA:IIE' VI

DEPOSITION IN RESPIRATORY TRACT

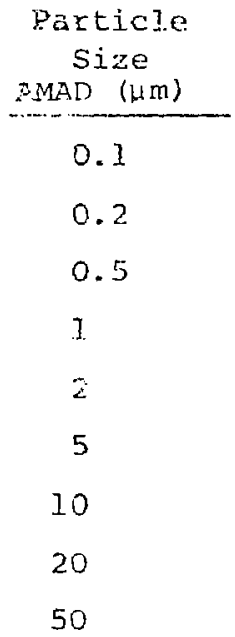

\begin{tabular}{c}
$\frac{}{\text { Nasopharmyx }}(\dot{\rho})$ \\
\hline 1 \\
4 \\
15 \\
30 \\
50 \\
75 \\
83 \\
87 \\
99.5
\end{tabular}

Deposition

\begin{tabular}{cc}
$\begin{array}{c}\text { Tracheobronchial } \\
(8)\end{array}$ & $\begin{array}{c}\text { Pulnonary } \\
(8)\end{array}$ \\
\cline { 2 - 2 } 8 & 50 \\
8 & 40 \\
8 & 30 \\
8 & 25 \\
8 & 20 \\
8 & 12 \\
8 & 9 \\
8 & 5 \\
8 & 3
\end{tabular}

about the values of transfex from the upper respiratory tract to the blood. These were included in the model to account for the relatively rapid jnitial transfer to the body noted in nany experiments. However, the absorption appears to be very high as compared with, for example, the absorption from the G.I. tract. This, as will be seen, produces high quantities absorbed to the body from large particles deposited in the upper respiratory tract. If this initial kigh transfer were due to a small fraction of higher solubility material deposited in the deep lung, then the absorption from the upper tract would be an artifact and not representative of actual absorption. We have, however, used the model as given rather cnan attempting a revision. Table VII gives the results of these calculations in terms of the quantity that could be inhaled each day to limit the final dose rate after continuous exposure for 70 years to 0.5 rem per year.

The relatively small change with particle size for the material transferred to the skejeton and liver reflects the deposition and absorption to the biood from the upper respiratory tract. This model would say that the particle size is relatively 
TABLE VII

QUANTITY OF PLUTONIUM INHALED PER DAY

TO RESULT IN 0.5 REMS/YR AFTER 70 YEARS (PCi;

\begin{tabular}{l} 
Particle \\
Size-AMAD \\
$(\mu \mathrm{m})$ \\
\hline 0.1 \\
0.2 \\
0.5 \\
1 \\
2 \\
5 \\
10 \\
20 \\
50
\end{tabular}

\begin{tabular}{ccc}
\multicolumn{3}{c}{ Clacs Y } \\
\hline Skeleton $\begin{array}{c}\text { Liver } \\
\text { (pCj./day) }\end{array}$ & Lung \\
\hline 1.9 & 1.5 & 2.4 \\
1.5 & 1.8 & 3.0 \\
1.7 & 2.4 & 4.0 \\
2.0 & 2.7 & 4.8 \\
2.7 & 3.2 & 6.0 \\
3.2 & 4.5 & 10 \\
4.4 & 5.3 & 13 \\
5.0 & 7.2 & 24
\end{tabular}

\begin{tabular}{ccc}
\multicolumn{3}{c}{ Class $w$} \\
\hline $\begin{array}{c}\text { Skeleton } \\
\text { (pCiver day) }\end{array}$ & Lung \\
\hline 0.57 & 0.94 & 24 \\
0.65 & 1.1 & 30 \\
0.70 & 1.2 & 40 \\
0.67 & 1.1 & 11 \\
0.61 & 1.0 & 60 \\
0.57 & 1.0 & 1.00 \\
0.57 & 0.94 & 130 \\
0.58 & 0.97 & 240 \\
0.55 & 0.91 & 400
\end{tabular}

unimportant for materials which can be transferred to the blood. stream. Thus, the choice of a general number to represent the intake by inhalation depends upon an assessment of the form of the plutonium in the soil and its probability of transfer to the bioodstream following inhalation. Certainly when high-fired ${ }^{239} \mathrm{PuO}_{2}$ is present, the class $Y$ is most appropriate for, at least, the immediate problem. However, possible changes in the form of the plutonium with time have not been defined. Heat source plutonium $\left({ }^{238} \mathrm{Pu}\right)$ appears to be more soluble than ${ }^{239} \mathrm{pu}$ because of its high specific activity. For these reasons, we have chosen to use a limiting intake of $0.7 \mathrm{pCi} / \mathrm{day}$ to represent tha general situation. This will provide 0.5 rems per year to the skeleton after 70 years of continuols exposure and a sizable safety factor for the lung in the event the actual material is more insoluble than is defined by the 500-day half-life of the class $Y$ material. This amounts to a continuous air concentration of $3.5 \times 10^{-14} \mu \mathrm{Ci} / \mathrm{ml}$ over this time period. 


\section{GENERAL RESUSPENSION}

General resuspension is defined as the process or processes by which concentrations are produced over a reasonably large area and are strongly affected by the existing meteorological conditions. The driving force for this type of resuspensior can be either winds or mechanical disturbances of the soils with the resulting dust carried and dispersed by the winds.

\section{A. Wind Resuspension}

The movement of soils from agricultural fields has been studied for many years. The processes responsible have been classed as surface creep (for larger particles), saltation (for intermediate size particles), and susperision (for smaller particles that can be carried by winds, often to long distances). The suspended fraction consists of the smaller particles that are respirable and usually of most interest. However, if Table VII is correct, some interest must be attached to the larger particles, particularly if the plutonium is somewhat soluble in body fluids. The surface creep and saltation are usually dominant in terms of the mass of soil moved (at least under erosion conditions) and can be an important element in moving soil (and contaminant) from one area to an adjacent one. However, under the assumptions of this study, such movement is not an important element. If the levels are low enough to mect the criteria in the original area, movement to another area with resulting dilution should result in the rew area meeting the criteria.

In our previous repori 40 we assumed, on the basis of very meager evidence, that the rate of pickup of contaminant particles increased as the square of the wind speed. Since this time, important studies have been done that have shown this assumption to be incorrect and have further illustrated the importance of such factors as aggregation in the soil and corresponding sizes of dust particles in the atmosphere. We also assumed that a surface layer was the source of the wind-blown 
material and that the rate of pickup could be characterized by that of Ireshly deposited zinc sulfide particles. While there may still be merit in the idea of a surface layer, the more recent data on weathering and consequent agglomeration, as well as the apparent stabilization of an area by particles moving into a position where they are sheltered from the wind, indicate that the situation is extremely complex and any useful definition of a surface layer must await further studies. In this report we will review only a few of the more pertinent aspects which are directly applicable to the estimation of general resuspension by winds.

Gillette 50,51 has calculated the vertical flux of 0.5 -toloHm dust particles during erosion episodes in agricultural fields from the vertical profiles of dust and wind speeds. In tio soils, having a silt and clay fraction of $4-4.5 \%$, he fourd that the vertical flux increased as the 5.14 power of the friction velocity above a threshold while, in another having a sand anci silt content of about $19 \%$, the vertical flux increased as the 9.67 power of the friction velocity. This increase of vertical flux with wind velocity was greater than the increase of the horizontal flux of sand. He attributed these observations to the production of small particles in the breakup of aggregates under "sandblasting" from the particles ir saltation. Shinn et al. 52 by measurements of dust profiles and a simplified and generalized model similar to Gillette's, have measured the dependency on wind speed of the resuspension rate at the GNX area in Nevada and at a recently cultivated agricultural field in Texas. Characteristics of the area and fluxes derived from the measurements are given in Table VIII.

Since the saltation in the urdisturbed soils at the Nevada site is low while that in the disturbed soil in Texas was high, these resuits appear to be in good agreement with those of Gillette and confirm the conclusion that under conditions of erosion the resuspension rate increases rapidly with wind speed. one can also speculate from the results of Gillette that the 
TABLE VIII

\section{SHINN'S VALUES FOR TWO SITES}

\begin{tabular}{|c|c|c|c|}
\hline SITE & $\begin{array}{l}\mathrm{zo} \\
\mathrm{cm}\end{array}$ & $u_{x^{\prime}} u^{(a)}$ & $\begin{array}{c}\text { Flux } \\
\text { rncs }{ }^{\prime}\left(m^{2} \cdot s\right)\end{array}$ \\
\hline GMX & 2.0 & 0.1 & $0.73 u_{*}^{3.09}$ \\
\hline Texas & 0.044 & 0.05 & $62.6 u_{\star}^{7.38}$ \\
\hline
\end{tabular}

(a) $u_{x}$ is friction velocity and $u_{2}$ is the wind speed at $2 \mathrm{~m}$ height.

actual rate: of increase may be a function of the soj 1 composition. In fact, Shinn 52 has proposed a tentative relationship between the soil erodibility index 53 and the race of increase with wind speed.

The resuspension rate from several contaminated areas or from tracers has also been measured. Ansbaugh et al. 54 have measured the resuspension rate from the plutorium in the cill area using an ultrahigh volume sampler. In this area, the plutonium was deposited about 20 years ago following chemical explosions with plutonium present. fis results showed values of the resuspension rate which varied from $2 \times 10^{-12}$ to $6.5 \times 10^{-11_{s}}-1$ with one outlier at about $4 \times 10^{-9} \mathrm{~s}^{-1}$. When these results were normalized by dividing by the cube of the friction velocity, the values ranged from $2 \times 10^{-11}$ to about $10^{-10} \mathrm{~s}^{2} / \mathrm{m}^{3}$. Selımel, 55 in a correiation of air sampler results from a station near Rocky Flats, found that the measured concentration at one station varied as the 2.1 power of the wind speed, which implies that the pickup rate varies as the 3.1 power of the wind speed since the dilution increases at the first power of the wind speed. Michels, ${ }^{56}$ by integrating the quantity of plutonium in a line of samplers downwind from a contaminated area at Rocky Flats, estimated that about $7.3 \times 10^{-4}$ of the plutonium on the area was carried by winds in a 14-month period. This amounts to an average pickup rate of $2 \times 10^{-11}$ per second, a value within the 


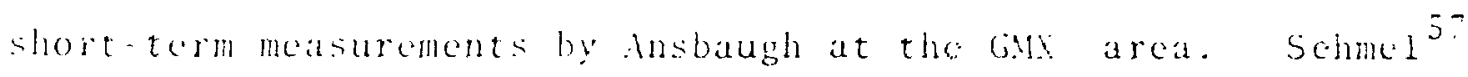
measured resubpension rates using a subnicrometer calcium nolyhate sprayod in a 29 m radius circle in a lightly rogetated area at llanford. The arerage resuspension rates were $10^{-10} \mathrm{~s}^{-1}$ over a period of $t$ months with no apparent uecrease. In a more recent report 58 he indicates that the rates varied from $11^{-1}$ to $10^{-8} s^{-1}$ over an 8 -month period with little sign of decrease with time. In one expiriment the samplers were turned on and off as a function of lind speed at $2.1 \mathrm{~m}$ abote the ground. Using the midpoints of the three wind-speed rangos for calculation, the rate of pickup increased bith wind speed to a police ranging from 2.5 to 3.1 . If the third power of the wind speod is used, the rate of pickup can he axpressed as $1 x 1^{-11}$ $u^{5}$ with the constant, craluated from this one experiment, ranging from 9.2 $x 10^{-12}$ to $1.5 \times 10^{-11}$. These ralues appar to be somewhat lower than those moasured elscwhere for freshly deposited sources. This ma! well be due to the method of appication or to the small particle size, either of which could promote aggregation.

The data from the zinc sulphide experiments used earlicrto were re-examined with the conclusion that they indicate an increase in resuspension rate as the square of the hind velocity. However, in view of the evidence that a cube relation nar be more viable they liere fitted to this with the resuit that they indicate a resuspension rate of $5 \times 10^{-9} \mathrm{u}^{3}$.

The various measurements have been drawn together in Table IX with some liberties taken with the data. Where the values were given in units of the friction velocity they were converted to wind speed using a ratio of $\vec{u} / u_{*}$ of 0.1 in the GMX area and 0.05 in the Texas experiment. The final value marked as "extrapolated" was obtained by assuming that the ratio of resuspension of soils in the GMX and Texas areas was the same as the ratio of resuspension of the plutonium in these two areas.

These values illustrate well the wide variations possible. However, we will explore the meaning of some of these variations in a practical situation in later discussion. 
WIND SPEED DEPENEENCY OF RESUSPENSION RATE

\begin{tabular}{|c|c|c|c|c|}
\hline \multirow{2}{*}{ Source } & \multicolumn{2}{|c|}{ Based on } & \multirow[b]{2}{*}{ Units } & \multirow[b]{2}{*}{ Material } \\
\hline & $\begin{array}{l}\text { Priction } \\
\text { Velocity }\end{array}$ & $\begin{array}{r}\text { hind } \\
\text { Specel }\end{array}$ & & \\
\hline G:: : & $K u_{*} 5.1+$ & & $m g /\left(m^{2} \cdot s\right)$ & nisturhed soit - 10 Cincs (a) \\
\hline Gillette & $\mathrm{Ku} u_{*} 9.6^{*}$ & - & $m g /\left(m^{2} \cdot s\right)$ & listurbed coil - 19\% fines \\
\hline Shing & 0.7314 .3 .09 & $6 \times 10^{-4} \mathrm{u} 3.09$ & $m g /\left(m^{2} \cdot s\right)$ & soil - axx \\
\hline $\operatorname{shinn}$ & $52.0 \quad 4 * 7.38$ & $.6 \times 10^{-8} u_{*} 3.09$ & $m y /\left(m^{2} \cdot s\right)$ & nisturbed soil - Texas \\
\hline Anshaugi & $10^{-19} 1_{1 *} 3$ & $10^{-1 \tilde{z}_{u} 3}$ & $s^{-1}$ & $p_{11}-a n$ \\
\hline Senmel & - & $\mathrm{K} \mathrm{u}^{3} \cdot 1$ & $s^{-1}$ & Pu - Rocky Flats \\
\hline $5 e !: n=1$ & - & $10^{-11} \mathrm{id}^{3}$ & $s^{-1}$ & $\mathrm{CaMoO}_{4}-$ llanfori \\
\hline$\therefore \operatorname{al} y$ & $\cdot$ & $5 \times 10^{-9} \mathrm{u}^{3}$ & $s^{-1}$ & Ens - Hanfors \\
\hline Extranolated & $10^{-8} \mathrm{u}_{*}^{7} \cdot 38$ & $2 \times 10^{-18} \mathrm{u}^{7.38}$ & $s^{-i}$ & Pa - disturbed soil - Texar \\
\hline
\end{tabular}

The extrapolated value for plutonium in disturbed soil was obtained by the ratio of Shinn's two coefficients for GMX and Texas and multiplying by the coefficient for plutonium found by Ansbaugh at GMX.

As can be seen, the values available are for a few limited areas characterized by either undisturbed, semiarid conditions or by disturbed agricultural lands. However, it is precisely in these types of areas that wind-driven resuspension could be of importance so that the use of these values should describe the areas of most interest for this pathway.

The question of the particle size of the plutonium contaminant in the soil and its influence on the resuspension rate or the relative concentration of dust in the air as compared to soil is one discussed in the previous report. Gillette ${ }^{50,59}$ has studied the clay fraction in the soil and its existence under 
several conditions. In one case he noted that the size distribution for particles $<1 \mathrm{\mu m}$ in the resuspended fraction implied a fraction of $<0.1 \%$ of the soil mass in the range $0.3 \leq \mathrm{r} \leq 1$ im while the analysis of the soil indicated $13.7 \%$ by mass of the soil in the clay fraction $(\mathrm{r}<1 \mu \mathrm{m})$. However, the clay fraction was determined by use of a detergent to obtain an ultimate separation of the clay particles from the larger soil particles. The comparison of the aerosol size fraction with the soil size distribution indicated that less than $0.8 \%$ of the submicron soil particles were available to produce the submicron portion of the aerosol. Photomicrographs showed the larger soil particles to have a coating of clay particles which may be several layers thick. From these studies he concluded that aerosol derived from soil has a size distribution which seemingly follows the size distribution of the soil except for $r<1 \mu \mathrm{m}$ where soil agglomeration is effective. 59 Thus, for particles of $\mathrm{PuO}_{2}$ in the soil one wculd expect that those $<1 \mu \mathrm{m}$ in radius (aerodynamic diameter if spherical $\sim 6 \mathrm{~mm}$ ) would be associated with the larger soil particles and would behave in an aerosol similar to these particles. fs the $\mathrm{PuO}_{2}$ particies decrease in size from $1 \mathrm{\mu m}$, the agglomeration forces become much stronger and the probability of disassociation by "sandblasting" in saltation or otherwise separating into discrete particles becomes much lower. In the case where the plutonium enters the soils from solutions the absorption occurs chiefly on the smaller soil particles (clays) which in turn are subject to agglomeration. Thus, while one tends to think of discrete particles of $\mathrm{PuO}_{2}$ in the soil and air, this is probably true only in the size range at the upper end of the respirable range and above. Such agglomeration of the smaller particles and association with the larger soil particles is undobutedly an important part of the weathering process, although the speed with which it occurs, as compared to other actions which tend to shelter the particle from the wind, is unknown. 
One of the concerns expressed by many is the possibility of large air concentrations and subsequent largc intikc of plutonium during periods of high winds and resulting dust storms. Certainly the concentrations of soil in the air are high under these conditions. Orgil1, 60,61 by correlations of visibility measurements with dust concentration, has estimated the frequency of dusty hours from 343 weather observations in the continental U.S. His results indicate that a large area in the southcentral U.S. exceeds $1 \stackrel{\circ}{0}$ of the time in which the dust concentration is in excess of $3-5 \mathrm{mg} / \mathrm{cm}^{2}$. On the east coast the frequency is low ranging from $0.005 \%$ to about $0.1 \%$. The west coast, west of the mountains, is similar to the east coast.

Information is not available to fully relate these lindings to potential plutonium concentrations, particularly írom relatively small contaminated areas. In general, one would expect that as the wind speed increases, to produce these dusty conditions, larger and larger particles would be carried by the winds in suspension. That this may be so is indicated by data of Chepil and Woodruff 62 in which the "average equiralent diameter" (determined by the settling rate) was measured from some dust storms in Kansas and Colorado. Here the average equivalent diameter at $20 \mathrm{ft}(26 \mathrm{~m})$ above the ground was about $0.05 \mathrm{~mm}(50 \mathrm{\mu m})$ increasing to about $65 \mathrm{\mu m}$ at $2 \mathrm{ft}(20.6 \mathrm{~m})$ above the ground. Porch, 63 while measuring the short-term dust concentration fluctuations in a desert area with a light scattering instrument, had two dust devi 15 pass directly over the instrument. On neither occasion was a detectable reading observed. This he tentatively ascribed to the fact that the sampling lines would effectively eliminate particles larger than $5 \mu \mathrm{m}$ and that it was possible that the sand transported by the dust devils was too large to get into the instrument. Sinclair ${ }^{64}$ measurea the particle size distribution from a small dust devil by use of petri dishes coated with vaseline. His results indicated a mass median diameter of about $80 \mu \mathrm{m}$ with $70 \%$ of the mass as particles greater than $50 \mathrm{\mu m}$. Some $10-12 \%$ of the mass was associated with 
particles less than $10 \mathrm{im}$. He indicated that the results sugsest that dust devils remove essentially the same number oi small particles ( $10-j \mathrm{~m}$ diam) that are removed by larger scale resuspension mechanisms and that smal1-to meäium-size dust devils are capable of removing and verticaliy transporting sand particies as large as approximately $350 \mathrm{~m}$ from a hide range of desert surfaces. He further estimated that during a dust devil season of 45 days, for a typical southwestern desert area, some 157 tons per day are transported over an area of $285 \mathrm{~km}^{2}$. llowever: due to the area ratios and duration times, the dust storm mean daily dust transport differs from this by a factor of $10^{7}$.

General information on the concentrations in the air near contaminated areas is available from several current studies. In each of these cascs, the plutonium has been in place for one to two decades so that they satisfy the criterion for aged sources.

At the GME sitc at the Nerada Test Station, the contamination occurred irough dispersion of plutonium which was intimately assuclated with explosive charges. Size distribution anaiyses of the soil particles in two samples indicated that only $1-2 \%$ of the plutonium is associated with soil particies with diametcr less than $5 \mu \mathrm{m}$ while about $90 \%$ was associated with particle sizes of 20 to $250 \mathrm{~km}$. $^{6}$ Profile samples have shown that greater than $90 \%$, probably $95 \%$, of the plutonium is in the first $5 \mathrm{~cm}$ depth from the surface. 66 The area of study is ahout $240000 \mathrm{~m}^{2}$ with an estimated total depositon of $2.5 \mathrm{Ci}$ of plutonium. 66,67 Thus, the average contamination is about $10 \mathrm{\mu Ci} / \mathrm{m}^{2}$ or about $0.25 \mathrm{nCi} / \mathrm{g}$ in the top $2.5 \mathrm{~cm}$. The contamination over the area is decidedly nonuniform, however, with one area of 1400 $\mathrm{m}^{2}$ surrounding ground zero having an average level of 530 $\mu \mathrm{Ci} / \mathrm{m}^{2}$.

Ai: samples were taken at the fence around the area in a NE and SW direction for 17 months. ${ }^{68}$ If one estimates an average resusponsion factor using the average deposition in the area, the sample to the NE showed a value of $6 \times 10^{-10} \mathrm{~m}^{-1}$ while the one 
to the sir gave a value of $5.8 \times 10^{-11} \mathrm{~m}^{-1}$. Whese results bere casentially confirmed by shorter time periol samples in the Sl. and NW directions. The higher value to the Xl correlates well with the direction of the higher wind speeds even though the total frequency of winds in both directions was about tho salle. If we express these results in a different manner, the ingher value corresponds to $2 .+\times 10^{-5} \mathrm{~g} / \mathrm{m}^{3}$ (ratio of the air concentration to the average quantity per unit weight in the soil). Jive cascade impactors were also operated for a periol of 30 days in the summer of 1972.68 These impactors were located 250 fit lrom ground zero on an arc to the she (the direction of maximum wimal speeds). The contaminated area upwind of this point hils much smaller but contained the bulk of the plutonium. A rough estimate from Ref. 6 ? Indicated the area to be about 17541 ' $^{2}$ with a total of about $1.8 \mathrm{C}_{1}$ of plutonium. This would make the average about $100 \mathrm{HCi} / \mathrm{m}^{2}$ or, in the first $2.5 \mathrm{~cm}$ depth in the soil, some $2.5 \mathrm{nCi} / \mathrm{g}$. However, it was only about $150 \mathrm{ft}$ to an area of $1400 \mathrm{~m}^{2}$ that averaged $550 \mathrm{LCi} / \mathrm{m}^{2}$. The impactor samples averaged between $1 \times 10^{-14}$ u $\mathrm{Ci} / \mathrm{ml}$ and $3.9 \times 10^{-4}$ m $\mathrm{Ci} / \mathrm{ml}$ with an arerage of $2.5 \times 10^{-14}{ }_{\mu} \mathrm{Ci} / \mathrm{m} 1$. If we use the average concentration upwind this amounts to a resuspension factor for this smaller area of $2.3 \times 10^{-10} \mathrm{~m}^{-1}$. On the mass basis, the average value was about $10^{-5} \mathrm{~g} / \mathrm{m}^{3}$ with the maximum about 1.5 times greater. Of course, if one used the average for the entire area (much of which was downwind during periods of high winds) then the resuspension factors would be ten times greater because of the smaller average deposition. The average soil particle size in the air from the study was $1.6 \mu \mathrm{m}$ with a $\sigma_{\mathrm{g}}$ of 15 while the AMAD for the airborne plutonium was $3.0 \mu \mathrm{m}$. It was noted that this latter distribution indicated that only about $20 \%$ of the plutonium was of a size that would undergo pulmonary deposition according to the formulations of the ICRP Task Group on Lung Dynamics. 49

The contamination at the Rocky Flats Plant occurred when drums containing oil, previously contaminated with plutonium in 
machining operations, leaked onto the ground. The contamination was then, presumably, spread to neighboring areas during a fieri. ol of clcanup since downwind air samples showed high readings during this period. The actual area of drum storage was later covered with an asphalt pad to immobilize the highest levels of plutonium in the soil. Micheis 56 indicates that an on-plant test section (including the area around the pad) of $172001 \mathrm{~m}^{2}$ contained $0.63 \mathrm{Ci}$ of plitonium for an average of $3.7 \mu \mathrm{Ci} / \mathrm{m}^{2}$. krey and llardy ${ }^{69}$ estimate the total pluronium off the plent land and extending downwind to the $3-\mathrm{mCi} / \mathrm{km}^{2}$ contour (about $7-8$ miles) to be about $2.6 \mathrm{Ci}$. In this survey, samples were taken to a depth or 8 in. ( 220 ciil) and eight profile samples indicated that about 50-60\% of the plutonium is in the top $5 \mathrm{~cm}$ (range 39 to $91 \%$ ). In a more recent study, krey ${ }^{70}$ reports the plutonium off-site to be $3.4 \pm 0.9 \mathrm{Ci}$. HASL 71 aiso estimates the 241 fm to grow in from the decay of ${ }^{24}$ pu to a maximuri in the year 2035 of: about $18 \%$ of the ${ }^{239} \mathrm{Pu}$ activity.

Johnson, 72 of the Jefferson County Health Department, rook a series of samples by sweeping dust from the ground surtace. These samples were size separated by water elutriation and the $<5-4 m$ portion analyzed for piutonium. The results, in comparison with those from the Colorado Health Department who sampled to a depth of $1 / 8$ in. $(20.3 \mathrm{~cm})$ and did not do particle size separation, were higher at similar locations by factors ranging from 4 to 285 indicating that a significant portion of the plutonium is associated with the smaller particles of the soil. Nathans and Hol1and ${ }^{73}$ measured the size distribution, by the use of fission track autoradiography, of the "equivalent $\mathrm{PuO}_{2}$ diameter particle" from two air samples taken in the area. They noted that there were a large number of single and double tracks in the sample indicating the possible presence of parijcles smaller than $0.1 \mu \mathrm{m}$ or the shielding of the alpha tracks by the sand grains. The size distributions of the particles with activity equivalent to $\mathrm{PuO}_{2}$, measured by the number of tracks radiating from a point, were characterized by median dianeters 
of 0.15 and $0.13 \mu \mathrm{m}$ with $\sigma_{\mathrm{g}}^{\prime} \mathrm{s}$ of 1.7 and 1.6 . The size distributions of the soil particles on the filters were characterized by median diameters of 10 and $8.7 \mu$ with $\sigma \mathrm{g}$ 's of 2 and 2.1. Volchok, ${ }^{74}$ using both a horizontal elutriator and a cyclone to pass particles proportional to the respirable fraction, estimated that about $25 \%$ of the airborne plutonium was respiraole. This is in agreement with the size distribution measurements of the airborne soil particles, but much lower than would be expected from the " $\mathrm{PuO}_{2}$ equivalent" particles. However, the sample size on the autoradiography study was small so that the results may represent only a portion of the population of particle sizes. Sehmel, ${ }^{75}$ from the ratio of plutonium coliected on an impactor and a high-volume air sampler, concluded that the material collected on the air sampler contained nonrespirable particles with the respirable fraction at $2 \mathrm{~m}$ height about $20 \%$. This fraction increased with height, but his studies showed that this was due to an extraneous source not associated with the resuspension. From these data, it appears that the plutonium in the soils at Rocky Flats is primarily present in or on the smaller particle size of the soil, possible as aggregates with the soil particles.

A number of air sampling stations are located downwind from this contaminated area. For this comparison we have used the values of the Colorado State Health Department for Station $0-3$, which is downwind from the test area described by Miche1s and about at the downwind edge. This station for the period 1970 to $1974^{76}$ showed a concentration, adjusted for the backgrouna from fallout, of $6 \times 10^{-9} \mathrm{\mu Ci} / \mathrm{m}^{3}$. Other data indicate this to be close to the maximum station at this distance. If we compare this with the average deposition found by Michels 56 for the test area, we find a resuspension factor of about $2 \times 10^{-9} \mathrm{~m}^{-1}$. If we further assume that about $40 \%$ of the plutonium is in the top $2.5 \mathrm{~cm}$, the resuspension factor based on quantity per unit weight of the soil becomes about $1.6 \times 10^{-4} \mathrm{~g} / \mathrm{m}^{3}$. 
The data from these contaminated areas indicate the concentrations from wind resuspension to be relatively small even for areas such as the GMX area where the quantity of plutonium in the soil is significant. However, the very rapid increase in resuspension rate with wind speed noted in agricultural soils raises some doubt as to what would happen if these areas were contaminated with plutonium.

It must be remembered that the concern with plutonium in the air (as with other long-lived radioactive materials) is with the average concentration over a long period of time, such as one year, and not with the instantaneous concentration, which is represented by the measurements giving the rapicincrease with wind speed. To determine the effect of wind speed on the average concentration, we calculated the concentration at the edge of a 10 000-n-wide strip infinite in the crosswind direction assuming that the wind is blowing continualiy across the field directly at the receptor. However, to assess the importance of frequency of various wind speeds, we used the frequencies given by wind roses in three locations.

The concentration at the edge of such a source, uniform $1 y$ contaminated, was given in our previous report 40 as

$$
x=\frac{k \Omega \sim}{V u}\left[\exp \left(-\frac{4 V}{\sqrt{\pi} \mathrm{C}^{\mathrm{n}}} \mathrm{x}_{1}^{\frac{\mathrm{n}}{2}}\right)-\exp \left(-\frac{4 \mathrm{~V}}{\sqrt{\mathrm{n} C_{z^{n}}}} \mathrm{x}_{2}^{\frac{\mathrm{n}}{2}}\right)\right]
$$

When $K$ is the rate of resuspension, $\Omega^{\prime \prime}$ is the quantity of plutonium per unit area, $\bar{u}$ is the wind speed, $C_{z}$ is the diffusion coefficient in Sutton's formulation, $n$ is Sutton's stability parameter, $x_{1}$ is the distance to the nearest boundary of the area and $x_{2}$ is the distance to the farthest boundary. We have changed the equation slightly by defining $V$ as equal to $V_{d} / u$ where $V_{d}$ is the deposition velocity. The rationale for expressing the deposition velocity as a function of the wind velocity 
was discussed in the previous report. ${ }^{40}$ Iqquation (1) was derived for a height above ground of zero and provides an unrealistically high answer if the near bcundary of the area is close to the receptor. To provide a more reasonable value, the contribution of the near area was solved by numerical integration using the equation for an infinite line source upwind and a height of $1 \mathrm{~m}$.

$$
x=\frac{2 k \cdot}{\sqrt{\pi} c_{z} \bar{u} x^{\frac{2-n}{2}}}\left[\exp -\left(\frac{z^{2}}{c_{z}{ }^{2} x^{2-n}}+\frac{4 v}{\sqrt{\pi} c_{z} n} x^{\frac{n}{2}}\right)\right],
$$

where $\Omega^{\prime}$ is the plutonium deposition per unit length of line. Since the wind roses available were brcken down into frequency by stability classes, we chose to do the calculations for three stability classes: stable, unstable, and near neutral. Where the data were broken into pasquill categories, we combined $A$ and $B$ as unstable, $C$ and $D$ as near neutral, and $E$ and $F$ as unstable. One would predict that the rate of pickup for a given wind speed would differ depending upon the stability and turbulence of the atmosphere. Data on this factor are not available. However, as an approximation we assumed that the pickup coefficients were measured under neutral conditions (true in Texas) and applied a correction factor, $s$, based upon the change in deposition velocity with stability estimated in the previous report. 40 Intuitively one would believe these factors to be similar since they depend upon much the same factors. Coefficients used ara given in Tab1e $X$.

The results of the calculations are given in Table XI. As can be seen, there is little overall difference in the average concentration although if one compares the contribution from each wind speed it is apparent that the importance of the higher increase with wind speed is important in the $\bar{u}^{7}$ column since the 
TABLE X

COEFFICIENTS EOR CALCULATION

$\begin{array}{cccc} & \text { Stable } & \text { Neutral } & \text { Unstable } \\ \mathrm{c}_{\mathrm{z}} & 0.07 & 0.1 & 0.3 \\ \mathrm{n} & 0.5 & 0.25 & 0.2 \\ \mathrm{~s} & 0.33 & 1.0 & 2.3\end{array}$

largest contribution is in the higher wind speeds. It is probable that the $\bar{u}^{7}$ values at the lower wind speeds are low since Gillette ${ }^{51}$ has used a threshold value of $\overline{\mathrm{u}}$ of $0.18 \mathrm{~m} / \mathrm{s}$ which, assuming a $z_{0}$ of 0.04 , would correspond to a wind speed of 3.6 $\mathrm{m} / \mathrm{s}$. Calculations assuming the GMX relationship to apply below this threshold indicate little difference in the average. This type of calculation, on the average, tends to minimize differences in extreme values, such as for wind speeds well in excess of the "greater than" values. We have tried to mininize this by choosing a relatively high value for the wind speed in the category above the top range, but this factor may result in a somewhat higher answer for the higher wind speeds. It is doubtful that it would be as much as a factor of 2 .

The absolute values are of interest since this type of calculation, assuming the wind blows in the same direction continuously, would be a maximum. If we assume, as in the GMX area where the coefficients were.measured, that the plutonium is in the top $2.5 \mathrm{~cm}$, then $1 \mu \mathrm{Ci} / \mathrm{m}^{2}$ amounts to a level of about 20 $\mathrm{pCi} / \mathrm{g}$. The soil concentration to give an MPC in air of $3.5 \mathrm{x}$ $10^{-14} \mu \mathrm{Ci} / \mathrm{cm}^{3}$ would be between 2400 and $4700 \mathrm{pCi} / \mathrm{g}$ for the LASL winds, 1300 and $1800 \mathrm{pCi} / \mathrm{g}$ for the Hanford winds, and 960 and $2400 \mathrm{pCi} / \mathrm{g}$ for the Pittsburgh winds. It should be noted that the Hanford wind rose, measured at $200 \mathrm{ft}$ ( $261 \mathrm{~m}$ ) represents wind speeds much higher than those at the ground which will tend 
APPLICATION OF POWER LAW INCREASE IN RESUSPENSION RATE TO SOURCE INFINITE IN Y AND 10 OOO $\mathrm{M}$ WIDE IN $\mathrm{X}$. SOURCE $1 \mathrm{HCi} / \mathrm{m}^{2}$

LASL Winds ${ }^{77}$

\begin{tabular}{|c|c|c|c|}
\hline \multirow{2}{*}{$\begin{array}{l}\bar{u} \\
\mathrm{~m} / \mathrm{s}\end{array}$} & \multirow{2}{*}{$\begin{array}{l}\text { Freq } \\
\\
\\
\end{array}$} & \multicolumn{2}{|r|}{$x$} \\
\hline & & $\begin{array}{l}10^{-13} \mathrm{u}^{3^{(\mathrm{a})}} \\
\underline{\mathrm{C} \mathrm{C} / \mathrm{cc}} \\
\end{array}$ & $\begin{array}{l}7 \times 10^{-18} \mathrm{u}^{7 \mathrm{a}} \\
\underline{\mu \mathrm{Ci} / \mathrm{cc}}\end{array}$ \\
\hline $0-1.3$ & 45 & 4. $2 \times 10^{-18}$ & $5.9 \times 10^{-23}$ \\
\hline $1.3-2.7$ & 18.4 & $1.7 \times 10^{-17}$ & $1.9 \times 10^{-20}$ \\
\hline $2.7-5.4$ & 23.2 & $9.0 \times 10^{-17}$ & $1.6 \times 10^{-18}$ \\
\hline $5.4-8$ & 8.7 & $9.1 \times 10^{-17}$ & $1.2 \times 10^{-17}$ \\
\hline $8.0-10.7$ & 2.43 & $4.9 \times 10^{-17}$ & $2.7 \times 10^{-17}$ \\
\hline $10.7-13.4$ & 0.60 & $2.4 \times 10^{-17}$ & $3.4 \times 10^{-17}$ \\
\hline$>13.4(16)$ & 0.21 & $1.6 \times 10^{-17}$ & $7.4 \times 10^{-17}$ \\
\hline Total & - & $2.9 \times 10^{-16}$ & $1.5 \times 10^{-16}$ \\
\hline
\end{tabular}

Hanford $-200 \cdot(.1 \times \text {. HE })^{78}$

\begin{tabular}{|c|c|c|c|}
\hline \multirow{2}{*}{$\begin{array}{l}\bar{u} \\
\mathrm{~m} / \mathrm{s} \\
\end{array}$} & \multirow{2}{*}{$\begin{array}{c}\text { Freq } \\
\frac{2}{0}\end{array}$} & \multicolumn{2}{|c|}{$x$} \\
\hline & & $\begin{array}{l}10^{-13} \mathrm{u}^{3(a)} \\
\mathrm{LCi} / \mathrm{Cc}\end{array}$ & 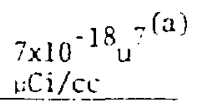 \\
\hline $0-1.3$ & 14.3 & $1.2 \times 10^{-18}$ & $1.6 \times 10^{-23}$ \\
\hline $0.3 \cdot 3.1$ & 24.4 & $1.8 \times 10^{-17}$ & $4.7 \times 10^{-20}$ \\
\hline $3.1-5.4$ & 22.3 & $5.0 \times 10^{-17}$ & $1.4 \times 10^{-18}$ \\
\hline $5.4-8$ & 17.8 & $9.7 \times 10^{-17}$ & $1.6 \times 10^{-17}$ \\
\hline $8.0-10.7$ & 8.33 & $8.9 \times 10^{-17}$ & $5.3 \times 10^{-17}$ \\
\hline$>10.7(15)$ & 4.86 & $1.4 \times 10^{-16}$ & $4.9 \times 10^{-16}$ \\
\hline & & - - & \\
\hline & & $3.7 \times 10^{-16}$ & $5.6 \times 10^{-16}$ \\
\hline
\end{tabular}

\begin{tabular}{|c|c|c|c|}
\hline \multicolumn{4}{|c|}{ Pittsburgh 79} \\
\hline $\begin{array}{l}\bar{u} \\
\mathrm{~m} / \mathrm{s}\end{array}$ & $\begin{array}{l}\text { Freq } \\
\frac{q}{9} \\
\end{array}$ & $\begin{array}{l}10^{-13} \mathrm{u}^{3}(\mathrm{a}) \\
\mathrm{Ci} / \mathrm{Cc}\end{array}$ & $\begin{array}{l}\frac{x}{7 x 10} \cdot 18 u^{7}(a) \\
\mathrm{Ci} / \mathrm{cc} \\
\end{array}$ \\
\hline $0-1.5$ & 11.3 & $8.5 \times 10^{-19}$ & $2.1 \times 10^{-23}$ \\
\hline $1.5-3.1$ & 28.8 & $3.4 \times 10^{-18}$ & $3.1 \times 10^{-20}$ \\
\hline $3.1-5.2$ & 33.6 & $1.8 \times 10^{-16}$ & $4.7 \times 10^{-18}$ \\
\hline $5.2-8.2$ & 22.2 & $3.5 \times 10^{-16}$ & $5.8 \times 10^{-17}$ \\
\hline $8.2-10.8$ & 3.5 & $1.1 \times 10^{-16}$ & $7.2 \times 10^{-17}$ \\
\hline$>10.8(15)$ & 0.6 & $4.4 \times 10^{-17}$ & $1.6 \times 10^{-16}$ \\
\hline & - & $7.3 \times 10^{-16}$ & $2.9 \times 10^{-16}$ \\
\hline
\end{tabular}


to make the estimates of resuspension much higher. The LASL wind rose was also measured at the top of a building about 50 ft $(\sim 15 \mathrm{~m})$ above the ground.

A final factor that must be cunsidered is the size oi the contaminated area. The above calculations were made for a very large area which does not seem credible for most conditions. If we assume the "infinite" dimension in the cross-wind direction to be $10000 \mathrm{~m}$, this area represents the deposition of $100 \mathrm{Ci}$ of Pu. We are currently deriving a method of calculating the average concentration downwind from the area source by use of the wind rose for an area, averaging over the appropriate sector and integrating by numerical means over the area. The results from use of the wind rose from MEAE and the resuspension factors from the GMX area $\left(K=10^{-13} \mathrm{u}^{3}\right)$ for square areas are given in Fig. 14. As can be seen, the maximum air concentration at the edge of the area is higher by a factor of about 7 for a 1000-m-square area than for a 20-m-square area. For the 1000-m square, the soil concentration corresponding to the $3.5 \times 10^{-14} \mathrm{uCi} / \mathrm{ml}$ limit, using a soil density of two and a $5-\mathrm{cm}$ sampling depth (thereby averaging the material on the surface through this depth) is $7600 \mathrm{pCi} / \mathrm{g}$.

\section{B. Mechanical Disturbance}

The mechanical disturbance of soils can provide forces which will cause resuspension of dust and associated contaminants during the period of the disturbance. Such disturbances can range from the relatively mild, such as animals grazing or an individual walking through the area, to the very severe, such as plowing or other agricultural operations or the use of earth moving equipment. In the latter case, the increased suspension can be noted by the dust cloud produced.

Suspension by mechanical means differs from wind resuspension in several respects. First, the driving force is a function 


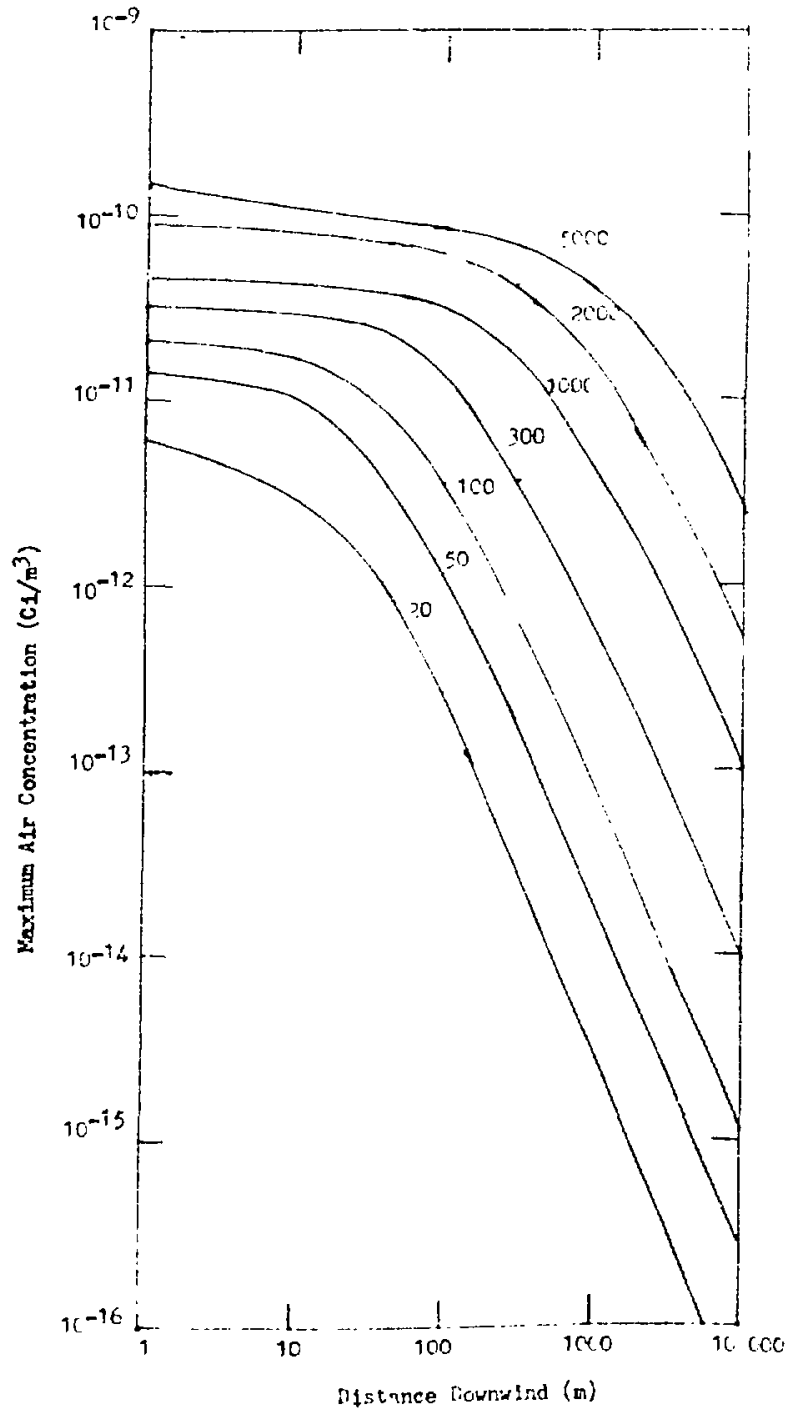

Fig. 14 .

Air concentrations downwind from square areas of dimensions given having a uniform level of one $\mathrm{Ci} / \mathrm{m}^{2}$. Pickup rate is given by $10-13_{\mathrm{u}} 3$.

of the action causing the suspension and can vary widely depending upon the magnitude of this action. In many cases, the disturbance is greater than that cau ed by the winds and is probably different in character since tho action can also disturb the 
subsurface and result in suspension of material from some distance below the surface, with this distance dependent upon the nature and magnitude of the disturbance. Note that we are here considering only the suspension at the time of the action; possible increases by winds following such a disturbance due to the change in the nature of the surface is covered by the cunsiderations in the previous section where the ultimate in aisturbed surfaces, a plowed field, was considered. Since the suspending force is divorced from the wind speed, it should be a constant depending only on the action. The concentration downwind will vary with the wind speed, being lower at the higher wind speeds because of the increased dilution.

The second difference arises from the localized nature of the mechanical disturbance and the resulting resuspension. In other words, the dust arises only from the very localized area or areas of disturbance rather than from the entire area and occurs only when the disturbance is active. Thus, a moving automobile or tractor will generate a dust cloud as it moves with resuspension dependent upon the speed of the vehicle as well as its size and the character and condition of the soll. This moving point source will average to a line source with the average resuspension rate and resulting average concentration downind dependent upon the time of averaging. A farmer plowing in a field will produce a point dust cloud which will average to an area source with the average resuspension rate from the area source again dependent upon the time of averaging.

A third difference is in the increased rate of mixing of contaminant in the surface layers with the soils underneath, at least for the more active disturbances. Thus, if excavating is in progress in the area, the contaminant in the top of the soil is mixed with the soil underneath. In the case where the contaminant is chiefly in the top layers, this will result in a dilution of the contaminant. This point is of interest even for aged contamination areas, since weathering usually results in a gradient with decreasing concentrations as one moves deeper in the soil. 
Some information is available on the effects of nechanical disturbance from trucks moving through contaminated arcas in arid country following dispersal of plutonium in safety tests. However, these experiments were done in freshly contaminated areas rather than the aged areas of interest here, and the results were expressed as resuspension ractors rather than in a form which can be used for analysis. It is of interest to note that the data from wind resuspension at Rocky flats include a certain undefined component of mechanical disturbance. This may be one factor in causing the somewhat higher resuspensions noted earlier in this area as compared to the GMX area in Nevada.

In our previous report, 40 data from Mork ${ }^{80}$ resulting from a vehicle driving through a freshly contaminated desert area were aralyzed. If a wind speed of $2 \mathrm{~m} / \mathrm{s}$ is assumed for this experiment, then out of seven values, four ranged between $2.6 \times 10^{-7} \mathrm{~s}^{-1}$ to $3.6 \times 10^{-7} \mathrm{~s}^{-1}$ while the other two indicated $2 \times 10^{-5}$ to $6 \times 10^{-5}$ $\mathrm{s}^{-1}$. The difference has not been resolved. It was also noted that the particle sizes resuspended must have been very large since the deposition velocities measured with sticky paper at the point of sampling ranged from 0.004 to $2 \mathrm{~m} / \mathrm{s}$ with only two of the seven values 1 ess than $0.1 \mathrm{~m} / \mathrm{s}$.

The study of Sehme1 81 of resuspension from an asphalt road due to passage of a car and the three-quarter ton pickup truck was alsc included in the previous report. ${ }^{40}$ Here the pickup rate varied from $10^{-8} \mathrm{~s}^{-1}$ to $8 \times 10^{-3} \mathrm{~s}^{-1}$ depending primarily on the speed of the vehicle since the resuspension rate was shown by Sehmel to be proportional to the square of the speed of the vehicle. Sehmel also indicated that the depletion of the resuspendable contaminant with any significant traffic would be significant. While these results are not directly applicable to the soil problem, since they represent fresh deposition on an asphalt surface, they dr indicate some maximum orders of magnitude for a hard surface and also indicate that such surfaces when heavily disturbed will not greatly affect the outcome of a contaminating event since they will serve only to 
provide a slight delay for the contaninant deposited on the surface before the contaminant continues downwind.

Sehme ${ }^{82}$ also measured the resuspension of $2 n S$ particles from the passage of a $3 / 4-t$ ton truck through an area covered with cheat grass at speeds of $8.05 \mathrm{~km} / \mathrm{h}, 24.14 \mathrm{~km} / \mathrm{h}, 48.28 \mathrm{~km} / \mathrm{h}$, and $64.37 \mathrm{~km} / \mathrm{h}$. The area was seeded with the particles, wind resus pension measured, and the truck passed through at $8.05 \mathrm{~km} / \mathrm{h}$. The other runs were made the following day. Results from the truck passage experiment are given in Table XII. The wind resuspension during the first day was $3.4 \times 10^{-8} \mathrm{~s}^{-1}$ for a $4.7 \mathrm{~m} / \mathrm{s}$ wind speed. Sehmel notes that this is a high value for the resuspension and probably reflects an increase due to resuspension of the particles from the upper portions of the cheat grass. The decrease after the first truck pass was attributed to the prior removal of the most readily resuspendible particles from the grass itself. Following this, there was an increase with truck speed although the resuspension rates at the higher speeds are one to two orders of magnitude lower than for the asphalt road.

In a recent paper, Milham et al. ${ }^{83}$ described the results of air sampling during the agricultural preparation of two fields

TABLE XII

MECHANICAL RESUSPENSION FROM TRUCKS

IN CHEAT GRASS AREA

Truck Speed

$(\mathrm{m} / \mathrm{s})$

2.2

6.7

13.4

17.9

\section{Resuspension}

\begin{tabular}{ll}
\hline per pass & per second \\
$2.5 \times 10^{-4}$ & $3.7 \times 10^{-5}$ \\
$9 \times 10^{-6}$ & $4.0 \times 10^{-6}$ \\
$9 \times 10^{-6}$ & $8.0 \times 10^{-6}$ \\
$8 \times 10^{-5}$ & $9.4 \times 10^{-5}$
\end{tabular}


having low levels of plutonium accumulated 25-30 years earlier as a result of an airborne release from a nearby stack. The measurements were made downwind 7.6 and $30.5 \mathrm{~m}$ from the edge of the field with six samples at face height; one located on the center line of the field width and the other two $7.6 \mathrm{~m}$ on either side. Results of this experiment are summarized in Table XIII witr the air concentrations being the average of the three sampleis at a given distance.

A somewhat similar experiment was done by Myers 84 at Livermore. The plutonium was applied to a small field $(10 \mathrm{~m} \times 17 \mathrm{~m})$ in the form of a digested sludge from a sewage plant. The sludge contained $2.8 \times 10^{-6} \mathrm{uCi} / \mathrm{g}$ of $\mathrm{Fu}$ and was applied to a depth of 7.5 to $10 \mathrm{~cm}$. The sludge was allowed to dry for 4 weeks during a period of no rain and the area was rototilled. The rototiller was 2 mide and was pulled behind a tractor with the dust cover open in order to maximize the escape of dust. Air sampling was done at one end of the plot with an Anderson cascade impactor. The soil after rototilling contained $4.3 \times 10^{-7}, \mathrm{HCi} / \mathrm{g}$ and the air sampler indicated an average concentration of $2.4 \times 10^{-8} \mu \mathrm{Ci} / \mathrm{m}^{3}$.

TABLE XIII

MECHANICAL DISTURBANCE RESULTS

FROM SAVANNAH RIVER

North Field

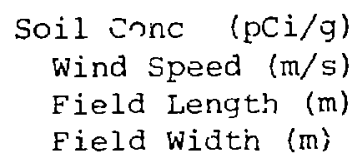

Air Conc $\left(\mathrm{pci} / \mathrm{m}^{3}\right)$

0.9

Sointh Fis:

2.7

7.6

105

30

5

30

145

Distance from Field Edge

\begin{tabular}{llll}
\hline $.6 \mathrm{~m}$ & $\underline{30.5 \mathrm{~m}}$ & $\underline{7.6 \mathrm{~m}}$ & $31.5 \mathrm{~m}$ \\
0.046 & 0.028 & 0.88 & 0.633 \\
0.02 & 0.011 & & \\
0.34 & 0.0052 & 0.029 & 0.0614 \\
0.01 & 0.0058 & 0.0089 & 0.002 \\
0.536 & 0.0062 & 0.014 & 0.012
\end{tabular}


About $50 \%$ of the plutonium in the air sampler was on the filter indicating a particle size in this fraction of < 1.1 w $A M A B$.

A resuspension rate was estimated from these data by integrating over the area using Sutton dispersion paramet_rs of $C_{y}=0.2, C_{z}=0.1, n=0.25$ and ratio of deposition velocity to wind speed of 0.005 . Since the wind speed was slightly off the axis of the field in each case, a correction was applied for this. These resuspension rates fromboth experiments are given in Table XIV.

From these data, a value of $10^{-7} \mathrm{~s}^{-1}$ to represent mechanical disturbance has chosen. Ideally one would like to have a sufficient number of values with different disturbances so that a reasonable pattern could be chosen and calculations made for each in assumed conditions. However, the paucity of data does not allow this. While some values in the table are higher than $10^{-7} \mathrm{~s}^{-1}$, many with vigorous disturbance are lower. Since we are trying to represent an average situation over a period of time, the choice appears justified and may be conservative when the full range of possible activities in an area is considered.

For application we considered the case where mechanical disturbance occurs repetitively year after year such as a farmer

TABLE XIV

$$
\text { ESTIMATED RESUSPENSION RATES }\left(s^{-1}\right)
$$

\section{SAVANINAH RIVER}

Bushhogging

Disking

Subsoiling

Fertilizing

Planting

LIVERMORE

Rototilling

\begin{tabular}{|c|c|c|c|}
\hline \multicolumn{2}{|c|}{ North Field } & \multicolumn{2}{|c|}{ South Field } \\
\hline $7.6 \mathrm{~m}$ & $30.5 \mathrm{~m}$ & $7.6 \mathrm{~m}$ & $30.5 \mathrm{~m}$ \\
\hline $9 \times 10^{-8}$ & $2 \times 10^{-7}$ & $1 \times 10^{-6}$ & $8 \times 10^{-8}$ \\
\hline $4 \times 10^{-8}$ & $6 \times 10^{-8}$ & - & - \\
\hline $7 \times 10^{-7}$ & $3 \times 10^{-8}$ & $3 \times 10^{-8}$ & $3 \times 10^{-9}$ \\
\hline $2 \times 10^{-8}$ & $3 \times 10^{-3}$ & $1 \times i 0^{-3}$ & $1 \times 10^{-8}$ \\
\hline $1 \times 10^{-6}$ & $4 \times 10^{-8}$ & $6 \times 10^{-7}$ & $2 \times 10^{-8}$ \\
\hline
\end{tabular}

$9 \times 10^{-8}$ 
plowing a field with the farm house or other ociudacy on the edge of the field. A series of square areas was considered upon which mechanical disturbance appropriate to the resuspension rate of $10^{-7} s^{-1}$ was carrical out for to h/y. The rosulting air cuncentrations at a height of one meter at the fowmind elge of the area was calculated by numerical integration using the lispersion coefficients previously employed for the wind resuspension calculation and the wind direstions and frequencies given for the $200-\mathrm{ft}(61-\mathrm{m})$ level at llanford in letcorology and ltonic Energy, 1968.78 The hemisphere with the maxtmum frequency of high wind speeds was chosen. These results are given in lable $\mathrm{Ni}$.

The vaiues for different depths are shown to indicate the difference resulting from depth of disturbance if the soil is uniformly contaminated to this depth and the disturbance is such that equal probability of resuspension occurs to all depths or the effect of different sampling depths if the contamination were all in the first centimeter.

TABLE XV

LIMITING SOIL CONCENTRATIONS AT EDGE OF VARIOUS SIZED AREAS UNDER MECHANICAL DISTURBANCE

\begin{tabular}{|c|c|c|c|c|}
\hline \multirow{3}{*}{$\begin{array}{l}\text { Area Size } \\
(\mathrm{m})\end{array}$} & \multicolumn{4}{|c|}{ DEPOSITION } \\
\hline & & & $\mathrm{pCi} / \mathrm{g}^{\mathrm{a}}$ & \\
\hline & $\mu \mathrm{Ci} / \mathrm{m}^{2}$ & $1 \mathrm{~cm}$ depth & $2.5 \mathrm{~cm}$ depth & $5 \mathrm{~cm}$ depth \\
\hline 20 & 140 & 7000 & 2800 & 1400 \\
\hline 50 & 60 & 2900 & 1200 & 580 \\
\hline 100 & 35 & 1800 & 700 & 350 \\
\hline 300 & 20 & 1000 & 400 & 200 \\
\hline 1000 & 14 & 680 & 270 & 140 \\
\hline
\end{tabular}


II. LOCAL RISUSTINSTOA

The concept of local resuspension was defined to permit the assessment of inhalation from activities which can produce concentrations over a smali volume in the vicinity of an individual or his nostrils and which is not measured by air samples taken in the immediate vicinity. It includes both inhalation from disturbance of the soil by the individual resulting in local concentrations and the more casual activities such as rencring clothing contaminated in the area or potential direct inhalation from contaninated skin or objects. The "resuspension factor" measured as the ratio of the air concentration to the quantity on the ground is a valid technique for estimating the mechanical disturbance since it relates the local air concentration to the local ground conditions. However, data on casual inhalation are meager, particularly if one must consider the transfers of contumination from the soil to the skin, clothing, or another contaminated object which is the agent carrying the contamination to the point of exposure.

For lcall resuspension, while an individual is outside working or playing in the soil, the important soil fraction would appear to be the smaller particle sizes which could remain suspended for a period of time in the absence of winds. If a wind strong enough and turbulent enoigh to hold larger particles wera blowing it would rapidly remove the material from the vicinity of the individual. Since the soils in the area of interest are unknown, we have considered several soils of varying clay content $(<2 \mu \mathrm{m}$ as determined by sedimentation following breakup of the aggregates) and assumed that all of the plutonium in the soil was on these fine particles. This is undoubtedly a worst case since the clays are normally strongly adsorbed on the sand particles or agglomerated. It is considered that an individual spends five $8-h$ days in vigorous activity on the contaminated area each year during periods when the soil is bare of vegetation and dry enough to produce dust. 
l)ata to fully justify a choice of resuspension factor for various activities are few. Experiments at Savannah River 83 demonstrated resuspension factors in the cab of a tractor during various agricultural operations of $4 \times 10^{-9} \mathrm{~m}^{-1}$ and $2 \times 10^{-7} \mathrm{~m}^{-1}$. At Livermore ${ }^{84}$ rototilling under maximum dust conditions with the plutonium in a dry sewage sludge on the surface gave a value of $6 \times 10^{-7} \mathrm{~m}^{-1}$. Stewait 85 has recommended a value of $10^{-5} \mathrm{~m}^{-1}$ for moderate activity in an arca of fresh deposition. For overall resuspension factors others have considered the value in an aged area to be $10^{-4}$ times that in a fieshly deposited area. 86 Considering the wide variance in activities in such an area, we nill use a value of $5 \times 10^{-7} \mathrm{~m}^{-1}$ for estimating the average exposure during periods of mechanical disturbance.

If $f$ is the fraction of smali particles in the soil (clays plus some fraction of the silts), d is the depth of the disturbance in the soil, and $\rho$ is the soil density, for a resuspension factor of $5 \times 10^{-7} \mathrm{~m}^{-1}$, the average concentration of soil in the air $\left(x_{s}\right)$ over a one-year period for the $40 \mathrm{~h}$ of activity is

$$
x_{S}=2.3 \times 10^{-5} \rho \mathrm{fd}
$$

The coefficient takes into account the resuspension factor, the conversion to $\mathrm{m}^{2}$, and the averaging of the $40-\mathrm{h}$ exposure over a one-year period. It may be noted that this equation assumes tiat only the small particle sizes are resuspendable. Thus, the resuspension factor does not correspond to the measured values where the total mass of contaminant or soil in the $1-m^{2}$ area is used in the denominator. In fact, this resuspension factor corresponds to the measured factor as $1 / f$. Thus, in an area where on 1 y $10 \%$ of the particles are available to be resuspended; the measured value would be 10 times the value used or $5 \times 10^{-6}$ $m^{-1}$. Since data on the relation between the resuspension factor and soil composition are not available to either justify or deny this assumption, this method was used as one technique to illustrate the possible effect of particle size. 
If we assume that all of the plutonium in the soil is in the fine particles, the concentration in the small particles to $1 \mathrm{im-}$ it the air concentration to $3.5 \times 10^{-14} \mu \mathrm{Ci} / \mathrm{m} 1\left(0.035 \mathrm{pCi} / \mathrm{m}^{3}\right)$ is

$$
\mathrm{pCi} / \mathrm{g}=\frac{0.035}{2.3 \times 10^{-5} \rho \mathrm{fd}}=\frac{1500}{\rho \mathrm{fd}}
$$

Values for the Iimiting soil concentration for several values of these parameters are given in Table XVI.

TABLE XVI

SOIL CONCENTRATION TO GIVE ANNUAL INHALATION

FOR VARIOUS DEPTHS OF DISTURBANCE OR SAMPLING

AND SOIL PARTICLES ( $\rho=2 \mathrm{~g} / \mathrm{cm}^{3}$ )

Soil Concentration in

Soil

Depth

(cm)

1

2.5

5

I

2.5

5

1

2.5

5

(a) During disturbance.

\begin{tabular}{ccc} 
Soil Concentration in & \\
$\begin{array}{c}\text { Fines } \\
(\mathrm{pCi} / \mathrm{g})\end{array}$ & $\begin{array}{c}\text { Total } \\
\text { Soil } \\
(\mathrm{pCi} / \mathrm{g})\end{array}$ & $\begin{array}{c}\text { A }{ }^{\mathrm{C}} \\
\text { Conc }\end{array}$ \\
\cline { 2 - 3 }$\left./ \mathrm{m}^{3}\right)$ \\
75000 & 750 & 100 \\
30000 & 300 & 250 \\
15000 & 150 & 500 \\
7500 & 750 & 1000 \\
3000 & 300 & 2500 \\
1500 & 150 & 5000 \\
2500 & 750 & 3000 \\
1000 & 300 & 7500 \\
500 & 150 & 15000
\end{tabular}


For the results in this table we have ignored aggregation arid have considered all of the clays and smail silt particles to be equally susceptible to resuspension. As was noted earlier, this is an unrealistic assumption since the snaller particles are absorbed onto sand particles or are aggregated with each other.

It is of interest that the value based on total soil is independent of the fraction in small particles although the concentrations in the fines, themselves, will vary widely depending upon the fraction present. If one considers the top one centimeter to be the layer of importance because of its susceptibility and there is no activity in lower layers, then the value given for the 2.5- and 5- cm depth as a sampling depth will be appropriate. Of course, if the activity has penetrated below $1 \mathrm{~cm}$, application of the value for the deeper sample will be adequate. It is noted that this type of calculation indicates one possible difference in the derived 1imit between a sampling based on total soil and on only the respirable fraction. It does, however, assume that the forces acting at $5 \mathrm{~cm}$ depth are as likely to resuspend the small particles as those at the suriace. This appears to be unilkely and is probably a conservative assumption for this sampling depth.

We attempted to derive a value for indirect transfer based upon dust in the home. However, no useful information on the amount of dust in the home that was derived from outdoor soil (as opposed to dust generated from other sources) was found to permit relating to a soil concentration. In a literature review of comparative concentrations indoors and outdoors, Benson et a1. 87 concluded that indoor atmospheric particulate concentrations appear to be generally lower than outdoor concentrations, especially at high outdoor levels, and the particulates indoors contain more organic material than those outdoors. The later finding would seem to indicate that a significant fraction of the indoor dust may originate from sources other than the soil. In two studies out of those reviewed, the conclusions were that 
the indoor activities were as important as the outdoor dust load and in one case a correlation was found between the number of people in a class room ard the dust loading.

This potential pathway must remain unsolved until better data are available. However, the comparison between atmospheric dust indoors and dust outdoors would sndicate that this pathway may not be limiting.

Dunster ${ }^{88}$ in a review of studies by others indicates that a recommended "safe" value of $0.1 \%$ of the material present on the hands inhaled during smoking of a cigarette is high comparec to the measured value by a factor of about 50. Thus, a reasonable fraction transferred would be $2 \times 10^{-5}$. Lepow ${ }^{89}$ has measured the quantity of dust on the hands of children as $0.011 \mathrm{~g}$. Since the hands of an adult are about four times as large as a two-yearold, this would imply $0.05 \mathrm{~g}$ on the adult assuming similar actions. If an individual smokes one pack per day the quantity of dust inhaled world be $2 \times 10^{-5} \mathrm{~g}$. For one pCi/day inhaled this would give a dust concentration of $50000 \mathrm{pCi} / \mathrm{g}$ or a concentration for the surrounding soil of $5000 \mathrm{pCi} / \mathrm{g}$. If we consider the actions of children, or other actions of adults, which bring the hands in proximity to the face, the increased proximity to the nostrils and the frequency of these actions would indicate that the value should be lower, perhaps by a factor of ten or twenty.

There are data on the concentration in the breathing zone as a result of wearing contaminated clothing. During the changing of cotton coveralls, Healy ${ }^{1}$ estimated from the data of Bruns kil1 $1^{90}$ that the quantity inhaled would be equivalent to that on $1-1 / 4 \mathrm{~cm}^{2}$ of the covera11. Butterworth and Donoghue ${ }^{91}$ studied the concentration resulting from contaminated coveralls while the individuais were carrying boxes, walking, and filing a metal rod. This resulted in a transfer equivalent to that on $0.3 \mathrm{~cm}^{2} / \mathrm{h}$ for $50 \%$ terylene - $50 \%$ cotton and $0.5 \mathrm{~cm}^{2} / \mathrm{h}$ for cotton covera.1s. If we consider a dust quantity on the clothing equivalent to that on the children's hands $\left(0.06 \mathrm{mg} / \mathrm{cm}^{2}\right)$ over a $12-\mathrm{h}$ period about $0.44 \mathrm{mg}$ would be inhaled. For an inhalation rate of 0.7 
$\mathrm{pCi} /$ day this would correspond to $1600 \mathrm{pCi} / \mathrm{day}$ of dust or 160 $\mathrm{pCi} / \mathrm{g}$ of the surrounding soil.

VII. INGESTION

Ingestion of plutonium is usually considered to be minimal hazard as compared to inhalation because of the low uptake from the G.I. tract. The G.I. tract itself is of even smaller concern since only a small fraction, if any, of the alpha radiation from the contents can reach the critical cells. However, it is necessary to reconsider the uptake for people living continually in a contaminated area since there will be mechanisms different from those encountered in occupational situations of less intimate contact.

In this section we consider the normal pathway of intake with food and elaborate somewhat on questions as to intake by children.

\section{A. Foodstuff $\mathrm{s}$}

The uptake bv plants from soils has been investigated in some detail. We will not, here, detail the results of these investigations since there are several reviews available. ${ }^{92,93}$ In normal soils, the uptake is low with the concentration factor (ratio of quantity per unit weight of plant macerial to quantity per unit weight of soil) of $10^{-4}$ or less. The application of chelating agents, such as FeDTPA, to the soil will increase this uptake greatly. Values of the concentration factor as high as 1 , or somewhat greater, have been obtained in pot culture by application of chelating agents in quantities well above those used for normal agriculture. There is no doubt, however, that the use of such agents in agriculture will increase plant uptakes.

One of the concerns with such measurements is that they may not se representative of the plant uptake after the plutonium 
has resided in the soil for some period of time. Here it is hypothesized that agents such as soil bacteria or natural chelating compounds will change the form of the plutonium to increase the uptake. There has been increased uptake noted in perennial plants cropped over a period of three to five years. However, Romney et a1. ${ }^{94}$ have pointed out that this may be due to increased root development so that a conclusive answer carnot be given. Schulz et al. ${ }^{95}$ grew wheat plant seedlings to maturity in pots containing a high-yielding forest soil, an agriculture soil from near Sacramento, and a fertile calcareous soil from the San Joaquin Valley. Plutonium, as nitrate or chloride, was intimately mixed with the soil. In this experiment it was anticipated that the uptake from the acid forest soil might be greater than from a neutral valley soil with low organic matter. However, with either the chloride or nitrate, the uptake in the forest soil was about one-fifth that of the valley soil.

However, the root uptake is not the only method of accumulation of plutonium in vegetation. Romney 95 has shown that the vegetation in the contaminated areas of the Nevada Test Site has dry weight concentration factors on the order of 0.05-0.2 due to the direct accumulation of soil on the surface of the plant. McLendon et al. ${ }^{97}$ at the Savannah River plant indicate that the average concentration factors between soil and camphor weed and honeysuckle (native plants) ranged from 0.07 to 0.22 on a dry weight basis with the lower values obtained offsite where the soil concentrations were lower. Since these were on a dry weight basis, they should be about a factor of 5 lower, or 0.014 to 0.044 , to represent the more applicable wet weight basis representative of the dier. On the same wet weight basis Romney's values would be 0.01 to 0.04 giving excellent agreement between these two widely different types of areas. Meyer et a1., ${ }^{84}$ at Livermore, grew vegetables in garden plots $10 \times 17 \mathrm{~m}$ fertilized with sewage treatment sludge containing small amounts of plutonium. They measured concentration factors, after preparing the vegetabies, ranging from $3 \times 10^{-5}$ to $2 \times 10^{-4}$ for corn, turnips, 
broccoli, and tomatoes. Interestingly, the crops grown on control plots with only fallout indicated higher uptakes ranging from $9 \times 10^{-3}$ to $1 \times 10^{-2}$. In each case, broccoli was highest. These values were again on a dry weight basis indicating that they should be reduced to $6 \times 10^{-8}$ to $4 \times 10^{-5}$ for the sludge enriched plots and to $2 \times 10^{-3}$ for the control plots.

The most pertinent data arise from a study of plutonium from fallout in the New York diet ${ }^{98}$ as discussed in the LMFBR Environmental Impact statement 86 since this includes a wide variety of foods grown in different conditions and a representative indication of the quantities of each eaten by the population. In this study, the cumularive plutonium fallout of 2.65 $\mathrm{mCi} / \mathrm{km}^{2}$ in 1972 at New York City was assumed to be representative of the fallout where the foods were produced. This plutonium was further assumed to be distributed through a $20 \% \mathrm{~cm}$ depth of soil of a density 2, again in the areas where the food was produced. These results were compared with the concentration in the diet for 1972 to arrive at concentration factors for each component of the diet. The fresh fish and shellfood were removed since our concern is with soil. These results are given in Table XVII.

These data indicate that the overall quantity of plutonium in plants used for food will be above that predicted from laboratory experiments on plant uptake. The data on fallout in the New York data are the most convincing since the results are for plants and plant products in a table-ready condition. The data on the native plants at Nevada and Savannah River give higher values than the New York City data, but these values are for plants directly from the area and not in a prepared form. It must be remembered that in the assessment of these lata, we are interested in the probable average uptake considering the full diet of plant material. That is, it is perfectly acceptabie to have a portion of the plant-derived food 10 times the value chosen as long as it is balanced by another food in equal quantity 10 times as low. In this consideration, however, the 
$\underline{\text { Food Item }}^{\mathrm{a}}$

Plant-Derived

Bakery Products

Whole Grain Products

Fresh Fruit

Dry Beans

Fresh Vegetables

Root Vegetables

Flour

Rice

Potatoes

Macaroni

Canned Vegetables

Fruit Juice

Canned Fruit
Plutonium

Concentration $\left(10^{-12} \mathrm{ci} / \mathrm{kg}\right)$
Per Capita Annual Intake

Conc Food

Factor (kg/yr) $\mathrm{Pu}\left(10^{-12} \mathrm{Ci} / \mathrm{yr}\right)$

Total Plant-Derived Diet

0.0085
0.0060
0.0051
0.0049
0.0043
0.0035
0.0028
0.0015
0.0013
0.0012
0.0009
$<0.0003$
$<0.0002$
0.0037

$\begin{array}{lr}1.3 \times 10^{-3} & 44 \\ 9.1 \times 10^{-4} & 11 \\ 7.7 \times 10^{-4} & 59 \\ 7.4 \times 10^{-4} & 3 \\ 6.5 \times 10^{-4} & 48 \\ 5.3 \times 10^{-4} & 10 \\ 4.2 \times 10^{-4} & 34 \\ 2.3 \times 10^{-4} & 3 \\ 2.0 \times 10^{-4} & 38 \\ 1.8 \times 10^{-4} & 3 \\ 1.4 \times 10^{-4} & 22 \\ <5 \times 10^{-5} & 28 \\ <5 \times 10^{-4} & 11 \\ 5.6 \times 10^{-4} & 314\end{array}$

0.37

0.066

0.30

0.015

0.21

0.035

0.095

0.004

0.048

0.004

0.019

$<0.007$

$<0.002$

Animal-Derived

$\begin{array}{lr}\text { Poultry } & 0.0033 \\ \text { Meat } & 0.0026 \\ \text { Eggs } & 0.0012 \\ \text { Milk } & <0.0003\end{array}$

Total Animal-Derived Diet $0.0010^{\mathrm{b}}$

Total Diet

$\begin{array}{lr}5 \times 10^{-4} & 20 \\ 3.9 \times 10^{-4} & 79 \\ 1.8 \times 10^{-4} & 15 \\ <5 \times 10^{-4} & 200 \\ 1.5 \times 10^{-4} & 314\end{array}$

$\overline{1.17-1.18}$

$a_{\text {Food categories and quantities are based on Department of Agriculture }}$ food purchase surveys.

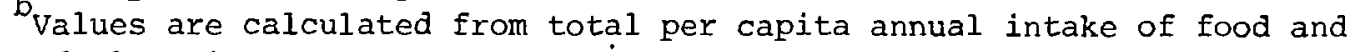
of plutonium.

question of variation in the makeup of the diet among individuals must play a prominent part.

From these data, overall concentration factors for foodstuffs as eaten (wet weight) over the concentration in soil are taken as $6 \times 10^{-4}$ for plants and $2 \times 10^{-4}$ for meat. With an allowable intake of $270 \mathrm{pCi} / \mathrm{day}$ based on $0.03 \%$ absorption from the 
G.I. tract, the soil concentration correspolsing to these concentration factors is $390 \mathrm{pCi} / \mathrm{g}$ for the total New York diet. If one considers that vegetarians eat the combined weight of meat and plant materials, the soil concentration would be $260 \mathrm{pCi} / \mathrm{g}$. Note that these values are based upon distribution of the plutonium through the cultivated layer of the soil and they further assume that al1 of the food consumed by the individual is obtained from the contaminated area. The home gardeners who grow their own fruit, vegetables, and potatoes are a more frequent occurrence. If we use these items from Table XVII, the quantity consumed is $158 \mathrm{~kg} / \mathrm{yr}$ and the soil limit becomes $1100 \mathrm{pCi} / \mathrm{g}$.

\section{B. Direct Ingestion}

The question of direct ingestion of the soil was introduced in the previous report ${ }^{40}$ as a potentially important pathway of exposure. This does not include the soil ingested with fruits or vegetables because this was included in the enhanced uptake used in the previous section. Here we consider direct ingestion as the actual consumption of soil either accidentally or deliberately.

There is considerable evidence available from the studies of lead accumulations and poisoning in people that children are the critical group for this element for several reasons including greater absorption into the body than adults, their ingestion of foreign materials such as paint chips, and of interest to this study, their greater contact with soil and household dust. While it is not possible to make direct comparisons of these data with plutonium intake because of the multiple sources of lead in the environment of children, the lack of a firm correlation at various ages between intake and blood leve1s, and the difference in metabolism of the lead and plutonium, there is considerable information of value for assessing the potential platonium problems in these studies. A brief review of the results applicable to casual ingestion by children will be followed by ari application to plutonium before addressing the deliberate ingestion question. 
Sayre ct a1. 99 noted that the data on ingestion of paint flakes could not account for the high fraction of inner-city children that had high blood levels of lead as compared to adults in the same region or suburban children of the same age group. He tested for the amount of lead on children's hands and on windowsills and floors of the play area. He indicated that a clear relationship was evident between individual hand and household levels. He also noted that blood levels are not commonly elevated until one year of age while children do not crawl until about eight months. The blood levels were fairly constant in children between 2 and 4 years of age $(40-50 \mathrm{ug} / 100 \mathrm{ml})$ and they then fell to $35 \mathrm{\mu g} / 100 \mathrm{ml}$ in children 5 years of age. He concluded from this that, although intensive mouthing decreases after 2 or 3 years of age, dirty hands are possibly more common and hand-to-mouth activities do persist to some degree. While they do not definitely implicate soil and dust, in contrast to others of the multiple sources of contamination, the authors do indicate that the results suggest dust ingestion as a possible mechanism of exposure.

Antopol et al.100 measured the reservoirs of lead in dust collected from the outer ledge of the southeast facing windows in Beth Israel Hospital as a result of automobile emissions. Concentrations ranging from 2000 to 50 00c ppm were found. They contrast this with the air concentrations of $3-5 \mu \mathrm{g} / \mathrm{m}^{3}$ in 1 ight traffic and $6-9 \mu \mathrm{g} / \mathrm{m}^{3}$ in heavy traffic and indicate that an individual might inhale $1 \mathrm{mg}$ or more of lead from the dust during several deep inspirations. They also note the observation that brain lesions are more froquent in preschool children and occur most often from late spring into early autumn. From this they suggest that this corresponds to the season when windows are oper and the preschool child's mouth and nose reach the level of the windowsil1 or just above it.

Lepow et al. 89 report that many of the urban children with 40-60 $\mathrm{gg} / 100 \mathrm{ml}$ blood levels attending the University of Connecticut clinics had no history of pica (a craving for nonfood 
substances) for paint nor was leaded paint ( $>1:$ lead) found in the dwellings. There was no rural counterpart for this group. They studied 10 children with chronically elevated lead levels $(40-120 \mathrm{\mu g} / \mathrm{ml}$ of blood). When a source of leaded paint had been found it was removed, and yet blood lead levels remained significantly eievated. Soil samples taken outside of 13 dwellings gave a mean of $1200 \mu \mathrm{g} / \mathrm{g}$. The levels were highest near the street and next to buildings. The mean level in household dust was $11000 \mathrm{\mu g} / \mathrm{g}$ with the highest concentrations on windowsills and in floor dust. The mean lead concentration of hand samples from 22 children was $2400 \mathrm{\mu g} / \mathrm{g}$ with the mean weight of hand sample $11 \mathrm{mg}$.

Landrigan et a1. ${ }^{101}$ in a study of a smelter in E1 Paso, Texas found lead concentrations in the soil within $200 \mathrm{~m}$ of the sme1ter of 560-11 450 ppm with a mean of $3457 \mathrm{ppm}$. The lead content was consistently higher at the surface. Household dust in Sme1tertown, a village with a population of 500 adjacent to the smelter gave a geometric mean of 22191 with a range in 53 samples of 2800-103750 ppm. The distribution of individuals with blood levels above a given value are given in Table XVIII.

This table clearly indicates the increased susceptibility for intake to children. It is difficult to ascribe the entire lead intake by the children to a given source since air concentrations were elevated and paint samples indicated the presence

TABLE XVIII

BLOOD LEVELï EY AGE GROUP IN SMELTERTOWN

\begin{tabular}{|c|c|c|c|}
\hline $\begin{array}{l}\text { Age Group } \\
(Y r)\end{array}$ & $\begin{array}{c}\text { No. } \\
\text { Measured } \\
\end{array}$ & $\begin{array}{r}\% 49-59 \\
\mu \mathrm{g} / 100 \mathrm{ml} \\
\end{array}$ & $\begin{array}{l}\%>60 \\
\mu \mathrm{g} / \mathrm{m} \ell \\
\end{array}$ \\
\hline $1-4$ & 49 & 55 & 14 \\
\hline $5-9$ & 101 & 34 & 11 \\
\hline $10-19$ & 109 & 25 & 6 \\
\hline $20+$ & 98 & 16 & 0 \\
\hline
\end{tabular}


of paint with a lead content greater than $1 \%$ in $30 \%$ of the homes. In a separate survey to better measure the sources of exposure, the geometric mean lead content of household dust was found to be 4022 ppon and a highly significant relation was found between the lead content of household dust and lead levels in the blood of children 1 to 19 yedrs old. Cilidiren with blood levels $240 \mathrm{~g} / 100 \mathrm{ml}$ (approximately the upper limit of "normal" values) lived in homes where the geometric mean lead content in dust was $6447 \mathrm{ppm}$ while those with levels less than $40 \mathrm{Hg} / 100 \mathrm{ml}$ lived in homes with $2067 \mathrm{ppm}$ in dust.

Roberts et a1. 87 in a study of two smelters in Toronto noted that the blood lead concentrations of children increased with proximity to the smelter although there was no significant trend for adults. In this case the soil concentrations near the smelters were 40000 and $16000 \mathrm{\mu g} \mathrm{Pb} / \mathrm{g}$ of soil trailing to an urban background of 100 to $500 \mu \mathrm{g} / \mathrm{g}$ at distances of about $400 \mathrm{~m}$. How ever, only $30 \%$ and $8 \%$ of the variation in b?ood lead could be attributed to this change with distance. Examination of head hair indicated the lead content did not vary significantly with distance along the hair from the head indicating that the rate of absorption of lead was fairly constant. While the air concentration was higher closer to the smelters than at a distance, $70 \%$ of this increase was attributed to large, nonrespirable particles and indoor concentrations during the winter months were on 1 y 20-30\% of those outside. From this, they conclude that poor personal hygiene and play habits of children living in the areas where the lead content of house dust, outdoor dust, and soil is elevated can result in excessive lead absorption. However, Randall et a1. 102 in studies with baboons has shown that the blood lead levels from inhalation of "coarse" particles (mean diameter $1.6 \mu \mathrm{m}$ ) is greater than from "fine" particles (mean diameter $0.8 \mu \mathrm{m}$ ) presumably due to lesser expiration of the coarse particles dnd subsequent absorption from the gut. The data are not. adequate to indicate whether the increased particle size near the smelters could explain a portion of the increased uptake. 
Vostal et a1. 103 measured the lead on floors and windowsills of homes along with the lead on the hands of children ia tic house by a smear technique. There was a definite correlation between the two in al inner city area where the levels were high enough to give reliable measurements. In one home where four measurements were made on one child by different investigators over a period of several months, the ratio of lead on the liands to the average of lead per $f \mathrm{t}^{2}$ on the floor ranged from 0.23 to 0.84 with an average of about 0.5 . They also measured the distribution of dust on a child's hands with the results shown in Table XIX.

Lepow et ai. 104 investigated the environmental and behavioral factors in 10 preschool children having high blood levels over the previous 6-25 month period. Readily accessible leacled paint had been eliminated as a significant source for at least three months before the study. The mean age of the children was 52 months. A11. but one had a previous history of pica and current pica was reported for four. They reported outdoor dirt with concentrations having 95\% confidence 1 imits of 700-1750 $\mathrm{\mu g}$ $\mathrm{Pb} / \mathrm{g}$ (mean 1200) while house dust had a $95 \%$ confidence limit range of 4900-17 000 $\mathrm{\mu g} / \mathrm{g}$ (mean 11000 ). In each case samples were taken with preweighed, self-adhesive labels pressed on the

TABLE XIX

DISTRIBUTION OF DUST ON THE HAND

$\begin{array}{lcc} & \begin{array}{c}\text { Right Hand } \\ \frac{\text { of total }}{0}\end{array} & \begin{array}{c}\text { Left Hand } \\ \text { of of total }\end{array} \\ \text { Thumb } & 14.9 & 11.9 \\ \text { Index finger } & 23.3 & 18.0 \\ \text { Middle finger } & 12.6 & 17.0 \\ \text { Ring finger } & 15.8 & 19.2 \\ \text { Small finger } & 66.3 & 12.5 \\ \text { Palm } & 17.8 & 21.3\end{array}$

6 
surface. The concentration in the dirt on children's hands had 95: limits of 650-4100 $\mathrm{mg} / \mathrm{g}$ (mean 2400), a value only twice that of the soil although the house dust was about 10 times. It was also noted that the difference between lead content on the hand samples obtained when children were playing outdoors was not significantly different from that obtained when they were playing inside of the dwelling. They point out that the higher leat concentration in house dust than outside may be due to a number of mechanisms including the presence of old pulverized paint indoors. Following observation of the 10 children it was concluced that a theoretical mouthing frequency of 10 times a day was an extremely reasonablo, if not conservative, estimate of the frequency of hands or nonfood items being placed in the mouths of these children.

Ter Haar et a1. ${ }^{105}$ measured the natural $210 \mathrm{~Pb}$ in various materials to use as a tracer as to the origin of lead in the feces and urine of children having $x$ rays showing opaque materials in the gut, a history of pica, elevated blood lead, or x-rays showing lead lines in the long bone. The ${ }^{210} \mathrm{pb}$ content of various materials was determined with the results given in Table $x x$.

TABLE XX

$210_{\mathrm{PB}}$ CONTENT OF NONFOOD MATERIALS

\begin{tabular}{lc}
\multicolumn{1}{c}{$\begin{array}{c}210_{\mathrm{Pb}} \\
(\underline{\mathrm{pCi} / \mathrm{g})}\end{array}$} \\
Paint chips & $0.005-0.07$ \\
Urban airborne particles & $60-150$ \\
Fallout dusit & $3-30$ \\
Vacuum cleaner sweepings & $0.4-1$ \\
Yard dirt & $0.3-2$ \\
Street dirt & $0.4-4$
\end{tabular}


The $210 \mathrm{pb}$ content of the excreta from chillren with signs of exposure and that of the children with low exposure was identical. Chelation treatment of one child with very high excretion of normal lead increased the stable lead output by a factor of 10- 30 but the $210 \mathrm{~Pb}$ did not increase. From these data the author concludes that children with pica (and other evidence of high lead intake) and normal children excreted identical amounts of $210 \mathrm{~Pb}$. Thus, dust and air-suspended particulate were not the sources of lead in these urvan children.

Baltrop et al. 106 measured the lead concentration in soils, in blood of children and mothers, and in feces of children in two towns where the lead content of the soil differed by a factor of about 2, in an aitempt to determine the importance of soil content in lead intake. Datis from the soil sampling are giver in Table XXI.

The similarity of the deep sample and surface sample in the grasslands at Matlock indicates that the lead may be of natural origin. The mean suspended particulate was $0.61 \mathrm{~g} / \mathrm{m}^{3}$ in Matlock and $0.29 \mathrm{~g} / \mathrm{m}^{2}$ in Buxton for a one-year period. This is low enough that the airborne lead was not contributing significantly to the intake. The results of the sampling of child and mother are given in Table XXII.

TABLE XXI

SOIL SAMPLING RESULTS - MATLOCK AND BUXTON

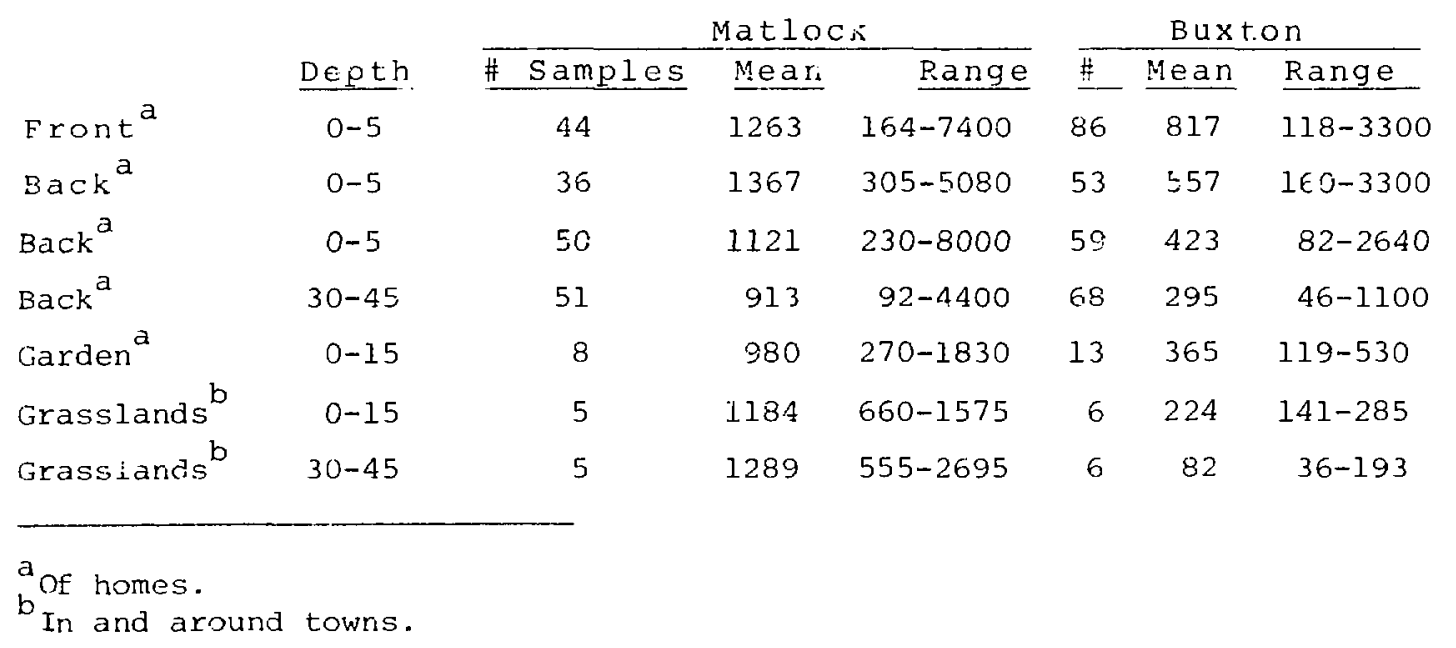

66 


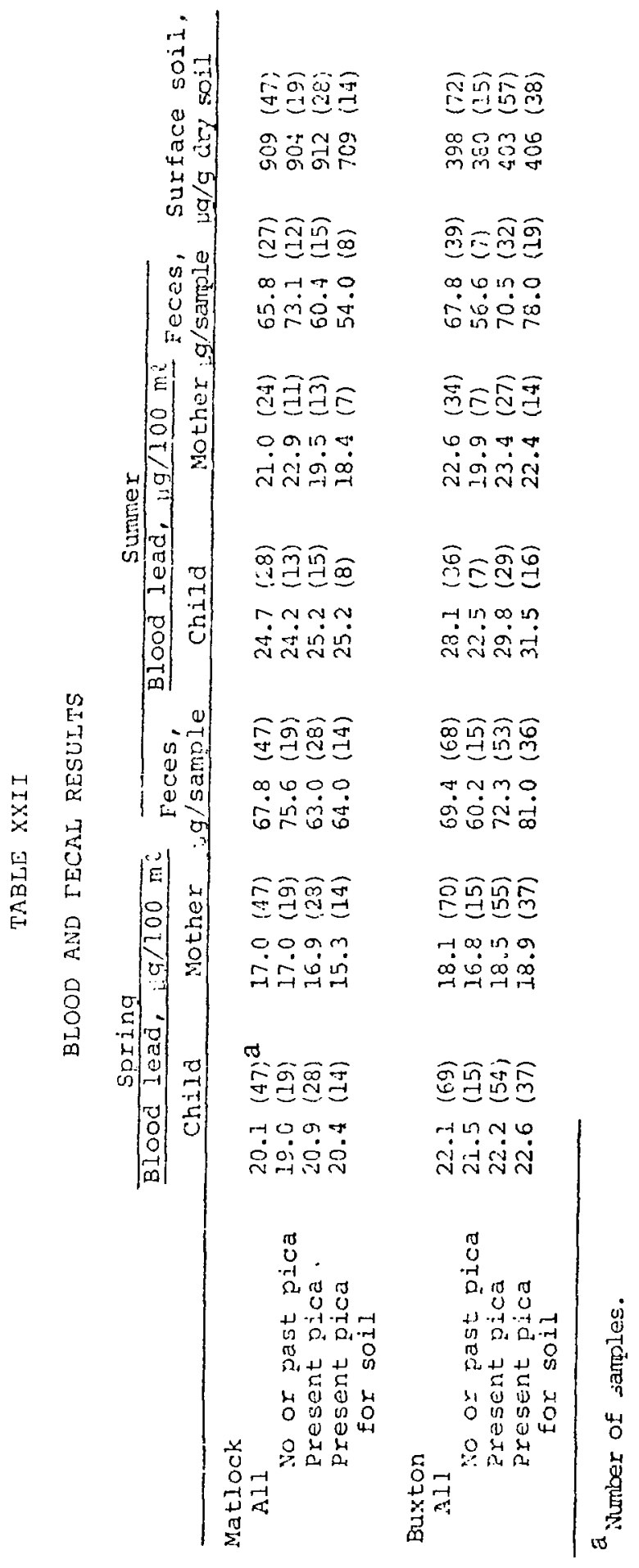


Both children and mothers had higher blood lead concentrations in the summer than in the spring and the children, both with and without pica, had higher biood lead concentrations than their mothers. The definition of pica used in this study included those children who habitualiy put fingers or toys in their mouths. Of the 119 children in both towns, only 11 of the 51 classified as having pica were definitely known to have swallowed soil. No statistically significant correlations were found between the blood, fecal, or hair lead values and the soil lead levels in the immediate environment of the child. In a further experiment, for which prelininary results are available, they compared two other villages where the mean soil lead concentrations are about $10000 \mathrm{ppm}$ and $500 \mathrm{ppm}$. The higher levels are in villages near old mine workings with some of the houses built on old waste material. The preliminary results of this study are given in Table XXIII.

TARLE XXIII

1973 SURVEY: PRELIMINARY BLOOD AND HAIR RESULTS

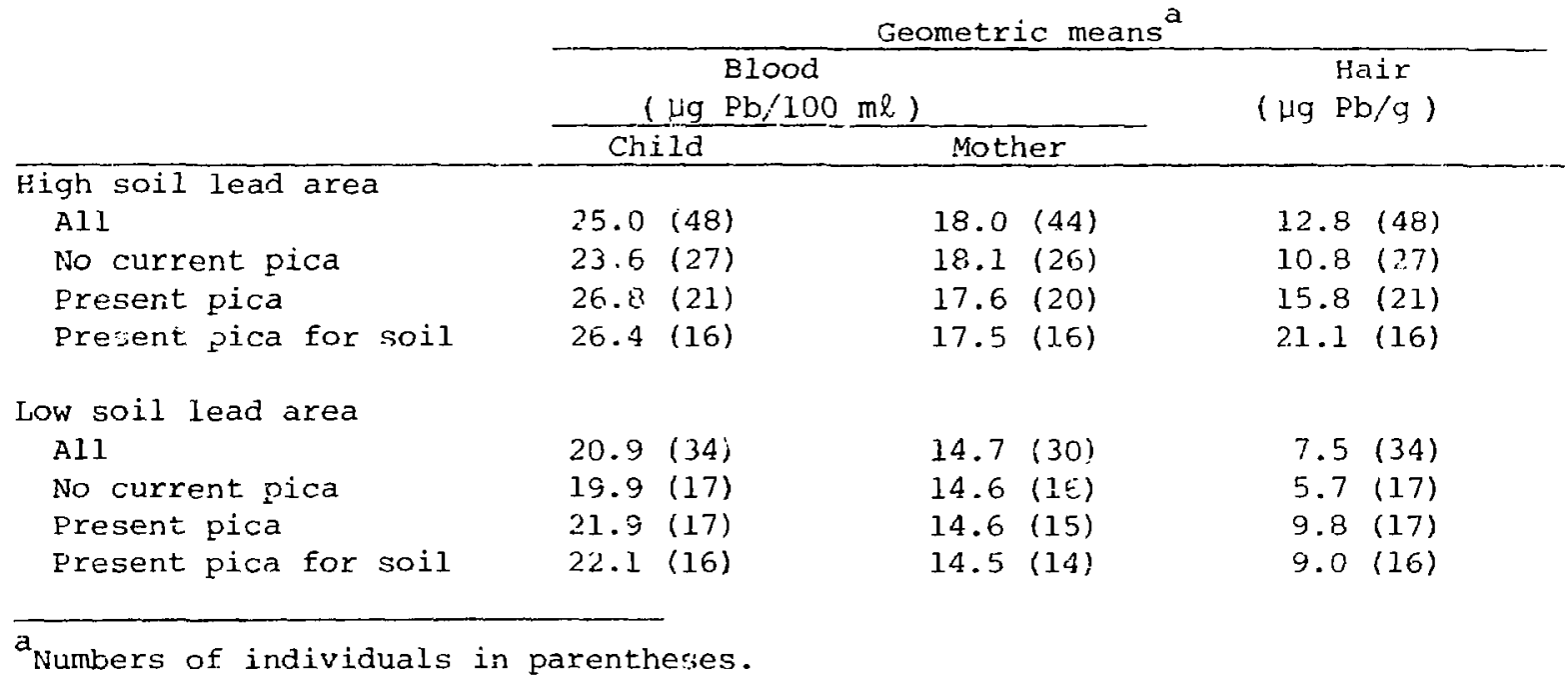


The blood values in the high soil lead area are higher than in the low soil lead area but are within the accepted normal range. Barltrop et al. concluded that the results to date suggest that local soil lead concentrations on the order of 10000 ppm are without major significance and, on present evidence, the concern with regard to contaminated soils in cities is not well founded.

We have not attempted to provide a complete review of the literature on lead or, even, to completely review the papers used. Instead, we have concentrated on the question of the hazard posed, particularly to children, by living in an area where the soil is contaminated with a toxic agent. As can be seen, there are different opinions. It appears that those who have made measurements on uptake in children along with environmental measurements feel that this pathway is not of major importance while those who have only made environmental measurements, and deduce the intake from these data, feel that it is of importance.

In applying these data to plutonium, it must be remembered that there are major differences between lead and plutonium in its behavior in the environment and its uptake in the body. The absorption of lead from the G.I. tract in adults is on the order of 5-10\% but for children can be considerably higher as is showr by studies with rats, Kostial et al. ${ }^{107}$ using $203 \mathrm{pb}$ in rats 5-7 days old showed absorption (and retention for $80 \mathrm{~h}$ ) of about $55 \%$. Forbes and Reina ${ }^{108}$ using carrier-free $212 \mathrm{~Pb}$ by gavage showed absorption and retention $8 \mathrm{~h}$ after administration of about $83 \%$ at 16 days of age dropping to about $15-16 \%$ at 32 days of age. These results would indicate that the greater susceptibility of children to lead poisoning as compared to adults is probably a function of the lower discrimination against lead as we11 as increased opportunity for intake.

There are two methods of assessing the hazard to cilildren of a contaminant in the soil: (1) by measurements of the environmental conditions and extrapolating to intake by using assumed 
or observed behavioral patterns, and (2) by measuring directly the resulting conditions in children actually living in a contaminated area. We will use both techniques in order to allow comparison.

It would appear that the hous ahold dust (or other dustfall) provides the chief pathway of concern since it appears to be elevated in concentration about a factor of 10 above the soils. Note that this conclusion is open to some question since many of the measurements were made largely in areas where the soil contamination resulted from atmospheric deposition in the vicinity of smelters and heavy highway traffic. It is possible, therefore, that sizable atmospheric concentrations still existed which would have served to increase household dust concentrations.) We will assume, following Lepow et a1., ${ }^{103}$ that the child places his hands in his mouth 10 times per day and ingests the full quantity of dirt which was removed by the label technique $(11 \mathrm{mg}$ ). Thus the dust ingestion would be $110 \mathrm{mg} / \mathrm{day}$. At a permissible intake of $2700 \mathrm{pCi} /$ day ( $0.003 \%$ absorption), the house dust concentration could be about $24000 \mathrm{pCi} / \mathrm{g}$. Given the factor of 10 between the soil and house dust, the limit for soil would be about $2400 \mathrm{pCi} / \mathrm{g}$. This calculation can be criticized on the grounds that such behavior on $1 y$ occurs for a short time in the life span and the accumulation during this period is sma11. However, if we assume a 5-yr period of mouthing, the accumulation is $8 \%$ of the liver burden and $9 \%$ of the bone burden for an adult. In relation to the organ size of a child, these produce larger doses. Since the limit is high compared to other pathways, we have not tried to refine it further.

From the results of Baltrop et a1. ${ }^{105}$ in the two English villages, one can arrive at an approximate value by several assumptions on the measured uptake. If we assume that the uptake came only from the soils and the feces to be a reasonable measure of the total intake, ther the children without pica in the village of Buxton with mean soil content of $400 \mu \mathrm{g} / \mathrm{g}$ had a daily intake of $60.2 \mu \mathrm{g} / \mathrm{g}$ in April and $56.6 \mu \mathrm{g}$ in July. Those in 
Buxton, where the soil concentration was about $900 \mathrm{\mu g} / \mathrm{g}$ had corresponding intakes of $75.6 \mathrm{\mu g}$ and $73.1 \mathrm{\mu g}$. Thus, for a difference of $500 \mu \mathrm{g} / \mathrm{g}$ in the soil, the differences in intakes were $15.4 \mathrm{\mu g}$ and $16.5 \mathrm{\mu g}$. These reduce to a daily intake of 0.03 and 0.033 of the quantity in one gram of soil. Again the permissible intake of $2700 \mathrm{pCi} /$ day would result from about $90 \mathrm{nCi} / \mathrm{g}$ in the soil. It should be noted that the values used in this calculation were not significantly different so that one cannot be assured that at conditions where an actual significant difference occurs the soil value may not be even higher. An additional uncertainty occurs in the assumption that the fecal content represents the full intake since the absorption of lead by children is not well known but is believed to be much higher than adults. However, even if the absorption is $50 \%$, one arrives at a value of $45 \mathrm{nCi} / \mathrm{g}$. 'ihe uncertainties in this calculation are such that the result should be viewed with caution. However, it does illustrate a potertially fruitful fieid for future investigation.

In addition to casual ingestion by mouthing of hands and other objects, we must be concerned with the deliberate ingestion of nonfood items, in this case soil, by a subgroup of children. The condition of craving such materials to the extent of going out of the way (often far out of the way), to obtain the nonfood item is called "pica." In many studies it includes any ingestion of foreign materials and even such acts as mouthing articles. However, unless it results in a health problem, such as the lead toxicity problems from ingesting chips of leaded paint or plaster, it often goes unnoticed. Robischon 109 notes several characteristics of pica upon which there is general agreement.

1. It is normal for a child to mouth and sometimes swallow nonedible substances in the first year and the beginning of the second year of life.

2. Although pica occurs in mentally defective children, it is found in the mentally normal as we11. 
3. Pica tends to be self-limiting in many instances. In these cases it has disappeared by the end of the preschool period.

4. Pica is commonly of a general nature with many types of substances ingested.

5. Pica is about evenly distributed between the sexes.

In general, pica which continues beyond the age of about two years is unusual and $i$ : regarded as abnormal. It is difficult to fully describe the incidence of pica in populations since the studies have generally been done with particular groups of individuals, often those known to have problems, and most frequently with children in run-down urban areas. Barltrop 110 indicates that soil and dirt consists of 23-44\% of al1 nonfood objects ingested. Obviously it is difficult to estimate the quantity of soil ingested but at least one study reports the ingestion of "handfuls" of soil every day in a severe case. 111 Layman et a1. 112 discuss another form of pica, the eating of clay, which is common practice in parts of the southeastern U.S., Indonesia, Australia, Africa, the West Indies, Central America, and some parts of South America. Different types of clay are eacen with the most popular being the red clay and the white clay. However, we have tended to discount this practice as a problem with piutonium because of the nonpermeable nature of clay banks and the consequent low probability of the contaminant penetrating to any depth into the clay. This does remain a potential problem under very unusual circumstances, however, and the health professional should be alert to this unusual condition.

There are numerous additional studies but none which give any quantitative information on the overall frequency or seriousness of the problem. Obviously, it could be, and in some circumstances is, a serious problem in modern society, particularly when the items ingested contain a high percentage of harmful substances, such as lead or bacteria, as from fecal matter. However, it is of interest that the studies of Barltrop ${ }^{105}$ and $\operatorname{Ter}$ 
Haar ${ }^{104}$ quoted earlier do not indicate a :erious problem with soil as a source among the children they studici.

To give some dimension to the problem, we will assume a child with a reasonably severe condition who ea:s 10 handfuls of soil per day with each handful containing $2 \mathrm{~g}$ of soil. The condition lasts over a period of 4 years froin the age of one to five. During this period the plutonium will accumulate in the bone but will approach only a small fraction of equilibrium. According to the ICRP, 113 the skeletal weight of a 5-year-old child is about $2.4 \mathrm{~kg}$ so that a dose of 0.5 rems per year would correspond to a burden of $250 \mathrm{pCi}$. Calculations indicate the skeleton to be more critical than the liver with an intake over the period of some $13000 \mathrm{pCi} /$ day required to reach this leve 1 at the end of 4 years. This calculation assumes adult parameters but the difference between children and adults are within the uncertainty of the other estimates. For an intake of $20 \mathrm{~g} /$ day over this period, the limit would be on the order of $650 \mathrm{pCi} / \mathrm{g}$. The total body burden would be $250 \mathrm{pCi}$, which, without considering elimination, would mean that the dose from this source would be only 0.15-0.2 rems/yr for the remainder of his life.

\section{I. DISCUSSION}

\section{A. A Reasonable Limit}

A listing of the limiting vilues for the individual pathways is given in Table XXIV. It must be recognized that the relative importance of each of these pathways will differ depending upon the particular area, its climate and habitation. In addition, the numerical values can have real meaning only when the source of the information and its use in deriving the value is understood. In the next part of this section we will attempt to indicate primary uncertainties, and where possible, degrees of conservatism or nonconservatism in relation to the chosen value so that the reader may better understand these important factors. 
TABLE XXIV

SUMMARY OF LIMITING VALUES

Pathway

Wind Resuspension

Infinite area upwind

$1000 \mathrm{~m}$ square area

Mechanical Resuspersion

$1000 \mathrm{~m}$ square area

Depth $1 \mathrm{~cm}$

$2.5 \mathrm{~cm}$

$5 \mathrm{~cm}$

Local Resuspension

Depth $1 \mathrm{~cm}$

$2.5 \mathrm{~cm}$

$5 \mathrm{~cm}$

Transfer to objects or clothing

Ingestion

Foodstufis - All grown on area

Foodstuffs - Home gardener

Casual

Deliberate (pica)
Soil Conc

$(\mathrm{pCi} / \mathrm{g})$

$960-4700$

7600

680

270

140

$75 \mathrm{C}$

300

150

$160-500$

260-390

1100

2400

650

A usefur limit must consider the following factors:

1) A numerical limitation;

2) the area over which it applies;

3) the depth in the soil to be considered.

These factors are, to a large extent, interdependent and can vary with the relative importance of the individual pathways in a given area. However, numerical values can be chosen for several pathways to be dependent on the depth chosen for sampling as is shown by the variation described for resuspension. For 
others, the depth is more indeterminate and depends upon the availability of the soil to the pathway. For agricultural crops one would consider the zone of cultivation to be appropriate. However, for pasture 1 and it would be the depth of the roots of the forage crops. For casual or deliberate ingestion, the depth would be that available for the pathway under the ambient conditions.

In arriving at a single number to represent a limit of concern we have considered the values for individual pathways in Table XXIV along with a qualitative estjmate of the probability of several pathways combining to increase the dose to the individual. This was not done on a formal basis, since as was noted above, this probability could vary depending upon the area use and habitation. However, a numerical value of $100 \mathrm{pci} / \mathrm{g}$ to a depth of $5 \mathrm{~cm}$ would appear to provide an adequate margin for the multiple pathway exposing the infrequent maximum individual in the region. We make no specific recomendation for deeper contamination although there is good reason to believe that the limit should be higher thasl above because of the low probability of exposure of people and the dilution that will occur when the material is exposed either by natural or artificial means. A study on appropriate limits for burial grounds currently in progress will shed some light on this question.

The appropriate area again differs with the pathway considered. Wind resuspension requires very large areas to allow the concentration to reach the values given. These are on the order of $1 \mathrm{~km}^{2}$ (250 acres) or greater. Smaller areas will make the wind resuspension less critical. Mechanical resuspension again requires a relatively large area primarily so that the very vigorous activities used as the basis will be carried out on the area year after year. Agriculture, in order to allow an area sufficient to provide food for the full year, requires a significant area. The limiting factor here would be a vegetarian maintaining a home garden or small farm and growing the large bulk of his food. The greatest limitation on an area would be 
the direct ingestion and possibly the local resuspension, it though it is unlikely that activities appropriate to the resuspension factors used would occur year after year in a very small area.

For these reasons, we have chosen an area over which the values can be averaged as equivalent to a play area or yard. While these can vary ir size, an area of $100 \mathrm{~m}^{2}$ or about 10000 $\mathrm{ft}^{2}$ was chosen as an appropriate averaging area. However, to assure that excessive exposure cioes not occur frem single hot spots, it is further recommended that the maximum value in any single sample not exceed $1000 \mathrm{pCi} / \mathrm{g}$. The problems of sampling to give reasonable assurance of meeting such a level will depend upon the form of the contamination (particulate or well dispersed). Simple techniques of direct alpha counting of soil samples usable in areas of moderate natural alpha activity in the soil are available to provide the ability to measure to this level in a large number of samples in a short time so that reasonable assurance is possible. 114

At the outset we addressed the question of the advisability of preparing recommendations for a limit such as this because of the sparse knowledge of many of the factors involved and the variations possible depending upon the nature and the use of the individual site. The following discussion of factors of conservatism as well as the analyses indicate that a general limit, such as recommended herein, will indeed provide great conservatism for individual sites. We recommend, therefore, that this limit be used for situations where knowledge is insufficient to provide better analysis of the individuad situation or where the cost of procuring such knowledge is excessive compared to the cost of remedy. In particular, we urge that decisions to destroy sensitive, unique, or important ecosystems be taken with considerable forethought and not be based solely on this limit. 
B. Major Uncertainties and Degree of Conservatism

The uncertainiies in the data are large, which is the reason for attempting to use reasonably conservative parameters. One of the largest uncertainties, which is difficult to assess, is in the wide variability of land use and actions on that land. we believe that it is obvious that levels in in uninhabited area with only occasional use, say for st land, could be considerably higher than we recomnend. Our basis has been to limit the maximum individual for any of the uses to which the land may be placed.

The data on wind resuspension is only in the past few years coming to the point of allowing coherent patterns to be derived. We have attempted to provide such a patters for the areas which have been studied but have not tried to extrapolate to unknown areas. Fortunately the studies that have been done are in areas where the problems with this pathway would be expected. The data on air concentrations around individual contaminated sites indicate that wind resuspension is probably a minor problem. Anspaugh ${ }^{115}$ has come to a simjilar conclusion by use of the mass loading approach in the GMX area since his limiting value is on the order of nanocuries per gram.

The dust storm as a mechanism for producing large concentrations in some areas was not well evaluated in this study because of the evidence that indicates the particle sizes to be relatively large. If, however, one believes that the plutoniun so suspended colld have the metabolic transfer properties of the Class $W$ in the ICRP models, then the particle size is unimportant as was shown earlier and, in areas where this can occur, this may be limiting. It must be remembered, however, that large areas are required for a dust storm to develop and the coniribution of dust from small contaminated areas will be small compared to the total dust from the entire contributory area.

The use of the total air concentration rather than the respirable fraction in deriving resuspension rates could add a factor of 2 to 5 conservatism to this pathway based on usual 
concepts. This will be discussed later in connection with the limits chcsen. However, the value chosen as a linit bysed on othe: pathrays is lower than the value we would choose for wind resuspension b: an order of magnitude or so, so that uncertainties in these values we not important.

The data for mechanicai resuspension are poor and the times chosen for their prevalence are arbitrary although we believe that the combination of resuspension,$\ldots$ and time spent per year would ocour only in unusual circumstance. Again, the resuspension raie chosen was representative of a violent action and did not filly account for the mixing action of tie first few years of the disturbance presumably resulting in lowe: concentrations in the future years. More study definitely needs doing for this patrway since, for the paraneters used herein, it may be one of the most limiting.

We have chosen a value for the local resuspension factor based upon the upper end of the disturbance level. In theory, there is a series of disturbances, or actions each of which can be characterized by resuspension factors in a given soil condition and by a time in which they occur. The proper value to use, then, would be a summation of the product of these. Until such values are available for the conditions appropriate to this study we cannot estimate any degree of conservaisism or rionconservatism although we believe that the analysis given here represents a reasonable worst case. A factor in applying the result is, again, the size of the area contaminated since this will have a bearing on the tine that a disturbance can occur in the area.

For the transfers to the person or the home we have used an earlier analysis since there appears to have been little, if any, study of the fuctors defining this important pathway in the intervening years. We have, however, added a factor of 10 be tween dust concentration in the home and surrounding soil concentration. This may well be a factor of conservatism since it arose from the lead data and not all studies showed this 
factor to exist. It was also notad that in many of the studies the source of the lead was from autumotive traffic which results in the lead being released to the atmosphere. Under these conditions it could adsorb directly on the particulates in the air resulting in high concentrations in airborne particles and dust. That is, under these conditions there may be some doubt as to whether the dust originated from the soil. In other studies, it was noted that the lead in the dust could have originated from crumbling paint in the home.

The ingestion, according to this analysis, provides a surprisingly strong component to the accumulation. For foods, thi.; is due to the use of a reasonable uptake factor in plants and animals, and the use of an uptake from the G.I. tract of the human of a value of 10 times the one normally used. We believe these to be appropriate considering the unknown behavior of plutonium in many soil types with time of residence and the unknowr. behavior of plutonium that has been metabolized in a plant or animal or processed with the preservatives and condiments now used. The values chosen are for a situation where all of the food for 70 years is grown in a contaminated area. While not an impossible situation it is unusual in this day of mass marketing of foodstuffs.

The pica question arises from somewhat unusual circumstances but not so unusual that it can be ignored. The history of lead. poisoning from ingestion of paint chips or plaster indicates the potential problem. The clioice of $20 \mathrm{~g}$ of soil as a daily quantity for ingestion appears reasonable for a relatively bad case but it could be exceeded in a very bad case. The absorption from the G.I. tract was taken to be the same as for a nitrate solution. Certainly for oxide particles the uptake would be lower by one or two orders of magnitude. The uptake from plutonium adsorbed on soil has not been determined but could, perhaps, be lower than the nitrate.

We have used the NCRP reconmendation of 0.5 rems/yit to the most exposed organ of the exposed individual, in our case the 
skeleton. It may also be noted that the $0.5 \mathrm{rems} / \mathrm{yr}$ was calculated to occur at the end of ihe 70-yr occupancy time so that the average dose over this period would be lower. We have also based our calculations on a contamination spread uniformly over the area. In accual situations there will be wide variability so that control to the limit stated will usually result in av. erages for the area lower than the estimated limit. One of the more conservative assumptions is that the individual uccupies this area for $70 \mathrm{yr}$ without leaving.

The conversion of the 0.5 rems/yr to the organ to the quantity inhaled was based upon the ICRP lung model as modified by the Task Group of Committee II on the metabolism of plutonium. This modification adds considerable emphasis to the absorption from the upper respiratory tract. The value chosen for intake was based largely on the more soluble plutonium (Class $W$ ), which we do not know will exist in soils.

Current1y, there is a movement toward reducing radiation limits on ad hoc basis using the principle of "minimum practicable." Thus, the EPA 116 proposed 1imits for the nuclear fuel cycle of 25 millirems per year to ail organs except the thyroid, skin, or cornel. For an individual at age 70, our limit was based on an exposure level 20 times that proposed by the EPA. We have attempted to base our limit on prevention of damage to health and not on the minimum practicable. We feel that such a limit is required before minimum practicable decisions are made since it sets an upper limit. We would also urge that the present 1 imit not be converted to a lower dose level by simple ratioing. Inscead, a new analysis should be made properly factoring in the degrees of conservatism required for such an assessment.

The primary basis in this derivation is the dose to the maximum individual which is a different basis than that used by most modelers who prefer to attempt to derive the average dose to a population or a segment of a population. It should be 
clearly recognized that, although we have not attempted to derive an average dose to the ropulation, it will be considerably lower than for the individual. The factor depends upon the relative importance of the various pathways in individual areas but is believed to be $1 \%$ or less of the maximum insividual in many areas.

\section{Sampling for "Respirable Fraction" in Soil}

In our previous report on this subject, 40 we introduced the concept of the "very surface layer" and recommended limitations based upon the smaller particle sizes. This was done in an attempt to apply the few experiments available to determine a resuspension rate. Recently, as a result of the finding that the plutonium concentration in the small soil particles at the ground surface in the vicinity of Rocky Flats is higher than the concentration in the total soil, 72 there have been recommendations to lower the existing Coiorado standard for developers by applying the numerical value to only the fraction smaller than $5 \mu \mathrm{m}$. This recommendation was not accompanied by any anaiysis showing an increase in the probability of intake. Instead, it appears to be tacitly assumed that if the piutonium was present on or in the small particles, they would be inhaled in proportior to this concentration rather than that in the total soil.

lie have not chosen such an approach but have based our proposed limit on the total concentration in the scil although we did examine the question in several of the anoropriate pathways. There are a number of reasons for the lack of acceptance. These are discussed briefly below.

1. The data available for the resuspension mechanisms are all based upon total content in the soil. If one assumes, as is implicit in the "respirable fraction" sampling techrique, that only the smaller particles are resuspended, then these resuspension riates and resuspension factors must be recalculated based upon the fraction of the plutonium (or other tracer) in the smaller particles. This is done essentially by multiplying the 
rate or factor by this fraction. When applied, the answer should be about the same since we are using a smaller factor to convert to air concentration with a higher soil value. In other words, if one is to make this change for the sampling procedure it should also be made for the initial data upon which the standard is based. Tables XIV and XV illustrate this change.

It is true that there can be differences in this factor in different soil types and it would be advisable to scart building a data base as to possible effect by making more detailed measurements of the soil characteristics in areas where measurements are being made so that more complete understanding of the phenomenon can be obtained. However, the data currently available do not indicate such an approach to be warranted.

2. The resuspension by winds is a complex phencmenon. Data on erosion indicate that the particle size undergoing saltation is a controlling factor. Such factcrs as the aggregation of the smaller particles and adsorption on the larger particles tend to minimize the importance of the small particle fraction in becoming airborne. This is well illustrated by those soils having a high fraction of clays where the agglomeration forces are such that they harden into rock-like structures when dry. On $1 ;$ the fraction that is abraded or otherwise removed is effective. It is probable that there is a soil composition which is most subject to erosion and resuspension but this must be based or relative composition of various sizes of particles as well as humus content and moisture content. In other words, we cannot relate the presence of only one fraction to the probability of becoming airborne.

3. The use of a thin layer at the surface raises many questions as to its meaning Such a sample is difficult to reproduce and represents only a temporary situation because of the ephem. eral nature of such a surface layer in most areas.

4. The use of only the small particle fraction in the soil provides only one component of the total answer required. The smaller particles in the soil originated by the breakdown of 
larger particles. We can expect this to happen for larger plutonium particles as well. Thus, even if we assume that the small particles are representative of the hazard, this will represent only present conditions and totally ignores potential future hazards .

5. The use of only the small particles and a curface sample is based on the assumption that inhalation is the only pathway. As we have seen, there are others, involving ingestion, that must be taken seriously. Thus, even if the "respirable fraction" at the surface is measured, additional samples to measure the total plutonium content are required. This will cause the number of samples and cost to be doubled.

It may be noted that the respirable fraction has not been neglected in this study. Instead we have incorporated it into the total soil limit. If the small fraction is to be used as a criterion for resuspension, then the limit should be increased by the ratio of the total soil to the small fraction.

D. Preliminary Ap?lication to ${ }^{241} \mathrm{Pu}$ and ${ }^{241} \mathrm{Am}$

Plutonium-24l is a beta-emitting isotope of plutonium that occurs to the extent of only about $0.5 \%$ in reapons plutonium but will be considerably higher, perhaps $15-20 \%$ in plutinium from high burnup plutonium. While it has a half-life of only 13.2 $y r$, it decays to produce ${ }^{241} \mathrm{Am}$, an alpha emitter with a halflife of $458 \mathrm{yr}$. The buildup of this daughter is such that a Inaximum is reached about $70 \mathrm{yr}$ after the purification of the plutoniun.

The low-energy betas from the ${ }^{241}$ pu add litile to the alpha dose so that this material can be ignored. However, the alpha particles from the Am can produce additional doses to the Iung, bone, and liver. Thus, any 1 imit for ${ }^{241} \mathrm{pu}$ must be related to a 1imit for the ${ }^{241}$ Am that it produces. About $0.025 \mathrm{Ci}$ of $241_{\text {Am }}$ will result from the decay of $1.0 \mathrm{Ci}$ of ${ }^{241} \mathrm{Pu}$.

The potential hazards from $241_{A m}$ have not been as well explored as have those of plutonium. The following summary is 
taken from Durbin. 117 It has a long retention time in the body and the liver and bone are the main sites of deposition once it reaches the blood stream. Studies of the carcinogenecity are in progress at Utah but have not continued long enough to give any comparison with radium or plutonium. However, the deposition in the bone is similar to that of plutonium so that the dose-equivlent calculation for the absorbed material should be similar to that for plutonium. The absorption from the 1 ung in compounds where the americium is not bound with plutonium may be somewhat higher than plutonium.

It is concluded that the calculations of permissibie intake for plutoniun by inhalation are reasonably indicative of americium. The possibly higher absorption from the lung may, in fact, indicate that ICRP model used may apply better to americium than co plutonium. We would, therefore, conclude that the inhalation pathways, as calculated for plutonium, are appropriate for americium.

However, for the ingestion pathway there is a different story. While data are considerably less for ancricium than for plutonium, there are sufficient available to indicate greater plant uptake and greater absorption from the gut. In a eritical review of data available, Thomas et ai. 118 found values of the concentration factor for diry plant tissue ranging from about $10^{-5}$ in the grain of wheat to about 0.2 in the leaves of bush beans. In average of 12 measurements indicated a concentration factor of 0.07 . However, the values were obtained from widely differing experimental conditions ranging from layering of the contamination in the pot to use of vermiculite to improve drainage to uniform contamination in the soil. It is difficult to assess a reasonable uptake value from these data because of the different cxperimental conditions, use of different soils, and use of different parts of the plant for analysis with only a few measurements on the portion used for foud. lie will use, as a preliminary basis until more returns are in, a value of $10^{-3}$ for 
the concentration factor on a wet weight basis. This corresponds to a value of perhaps $5 \times 10^{-3}$ to $10^{-2}$ on a dry weight basis.

The uptake from the G.I. tract also appears to be higher for americium than for plutonium. Durbin 117 indicates the best estimate of the uptake of trivalent actinides to be $10^{-4}$ to $6 \times 10^{-4}$. Thompson 119 provided a conservative estimate of $10^{-3}$. For our purposes a value of $5 \times 10^{-4}$ to $10^{-3}$ appears appropriate without being overly conservative. We will use $10^{-3}$ for estimates that wil1 give some allowance for direct accumulaticn on plant surfaces.

There is one other factor that will influence the potential dose from ${ }^{24 I_{A m}}$ in the environs. This is its greater mobility in soils that may make its long-term behavior in the environment different from plutonium. Marte $11^{120}$ has noted that this greater mcbility may result in increased movement away from the root zone of plants, thereby partial1y offsetîng the increased uptake.

In estimating a limit for ingestion we have not increased the uptake from the G.I. tract from food as was done for plutonium because of the uncertainty in value and the conservative value we have used for the uptake.

On the assumption that americ:um taken up into the body is distributed similarly to plutonium, the increased uptake will limit the dajly intake, either for foods or pica, to $80 \mathrm{pCi} / \mathrm{day}$. Assuming the uptake to the meat is increased in the same proportion as the increased uptake in the human G.I. tract, the food limits for the diet of Table XXIV become $70 \mathrm{pCi} / \mathrm{g}$ while a vegetarian living completely off the land would limit to $50 \mathrm{pCi} / \mathrm{g}$. The home gardener limit would be about $200 \mathrm{pCi} / \mathrm{g}$. The pica case, calculated for the ages of 1 to 5 in a manner similar to that used for plutoniun but with an uptake of $10^{-3}$ leads to a 1 imit of ahout $20 \mathrm{pCi} / \mathrm{day}$.

We will accept the $20 \mathrm{pCi} / \mathrm{g}$ as a recommended 1 imit based upon the possible occurrence of pica in children and to provide 
some factor of safety for the uncertain values used in the uptake calculation. However, it should be noted that the patiways for this isotope are limited with inhalation values about the same as plutonium. In this case, the average dose to the population will be a much smaller fraction of the riaximum dose than for plutonium.

In application to ${ }^{241} \mathrm{Pu}$, the limit for this beta emitter could be increased by a factor of 40 to allow for the decreased quantity of ${ }^{241} \mathrm{Am}$ remaining after decay. This would place the $241 \mathrm{Pu} 1$ imit at $800 \mathrm{pCi} / \mathrm{g}$.

\section{ACKNOWLEDGMENTS}

The assistance of $W$. J. Wenzel in searching out appropriate references, particularly those for the lead studies and wind resuspension, is gratefully acknowledged, as are the many helpful comments received from colleagues around the country following circulation of a draft of this document.

\section{REFERENCES}

1. J. W. Healy, "Surface Contramination: Decision Leve1s," Los Alamos Scientific Laboratory report LA-4558-MS (September 1971).

2. J. W. Healy, "Contamination Limits for Real and Personal Property, Progress Report for the Period January to June, 1973," Los Alamos Scientific Laboratory report LA-5482-PR (January $1974)$.

3. W. 5. Chepi1, "Erosion of Soil by Wind," USDA Yearbook of Agriculture (U.S. Government Printing office, Washington, D.C. , 1957) pp. 308-314.

4. W. S. Chepil, F. H. Siddoway, and D. V. Armbrust, "Climatic Index of wind Erosion Conditions in the Great Plains," Soil Sci. Soc. Am. Proc. 27, 449-452 (1963).

5. W. S. Chepi1, "Influence of Mnisture on Erodibility of Soil by Wind," Soil Sci. Soc. Proc. 20, 288-292 (1956). 
6. F. Bisal an $1 \mathrm{~J}$. Hsieh, "Influence of Moisture on Erodibility of Soil by Wind," Soil Sci. 102, 143-146 (1966).

7. L. D. Bavor, W. H. Gardner, and W. R. Gardner, Soil Physics (John Wiley \& Sons, Inc., New York, 1972), pp. 474-484.

8. Soil Survey Staff, "Soil Classification, a Comprehensive System - 7 th Approximation," (USDA, U.S. Govt. Printing Office, Washington, D.C., 1960).

9. Soil Survey Staff, "Supplement to Soil Classification, a Comprehensive System - 7th Approximation," (USDA, U.S. Govt. Printing Office, Washington, D.C., 1964).

i0. Soil Survey Staff, "Supplement to Soil Classification, a Comprehensive System - 7th Approximation," (USDA, U.S. Govt. Printing office, Washington, D.C., 1967).

11. H. Jenny, Factors of Soil Formation, a System of Quantitative Pedology; McGraw-Hil1 Book Co., Inc., New York, 1941).

12. H. Jenny and C. D. Leonard, "Functional Relationships Between Soil Properties and Rainfall," Soil Sci. 38, 363-381 $(1934)$.

13. D. P. Franzmeier, "Particle Size Sorting of proglacial Eolian Materials," Soil Sci. Soc. Am. Proc. 34, 920-924 (1970).

14. D. A. Rickert and J. C. F. Tedrow, "Pedologic Investigations on Some Aeolian Deposits of Northern Alaska," Soil Sci. 104, $250-262(1967)$.

15. L. H. Gile, "Fragipan and Water-Table Relationships of Some Brown Podzolic and Low Humic-Gley Soils," Soil Sci. Soc. Am. Proc. 22, 560-565 (1.958).

16. F. Harradine, "Morphology and Genesis of Noncalcic Brown Soils in California," Soil Sci. 96, 277-287 (1963).

17. R. Ulrich, "Soils of the Bery1-Enterprise Area, Utah: Their Origin, Properties, and Classification," Soil Sci. Soc. Am. Proc. 20, 570-574 (1956).

18. T. J. Nimlos and R. C. McConne1, "Alpine Soils in Montana," Soil Sci. 99, 310-321 (1965).

19. F. Harradine, "Comparative Morphology of Lateritic and Podzolic Soils in California," Soil Sci. 101, 142-151 (1966).

20. R. J. St. Arnaud and E. P. Whiteside, "Morphology and Genesis of a Chernozemic to Podzolic Sequence of Soil Profiles in Saskatchewari," Can. J. Soil Sci. 44, 88-99 (1964). 
21. J. E. McClelland, C. A. Mogen, W. M. Johnson, F. W. Schroer, and J. S. Allen, "Chernozems and issociatec Soils of Eastern North Dakota: Some Properties and Topographic Relationships," Soil Sci. Soc. Ani. Proc. 23, 51-56 (1959).

22. H. Smith and L. P. Wilding, "Geresis of Argillic Horizons in Ochraqualfs Derived from Fine Textured Till Deposits of Northwestern Ohio and Southeastern Michigan," Soil Sci. Soc. Am. Proc. $36,808-815$ (1972).

23. R. B. Grossman, J. B. Fehrenbacher, and A. H. Beavers, "Fragipan Soils of Illinois: I. General Characterization and Field Relationships of Hosmer Silt Loam," Soj.l Sci. Soc. Am. Proc. 23, 65-70 (1959).

24. N. Ahmad, R. L. Jones, and A. H. Beavers, "Some Mineralogical and Chemical Properties of the Principal Inorganic Coastal Soils of British Guiana," Soil Sci. 96, 162-174 (1963).

25. J. S. Clark and J. E. Brydon, "Characteristics and Genesis of Concretionary Brown Soils of British Columbia," Soil Sci. 96, 410-417 (1963).

26. M. G. Klages, "Effect of Clay Type and Exchangeable Cations on Aggregation and Permeability of Solonetz Soils," Soil Sci. $102,46-52$ (1966).

27. N. Ahmad and R. L. Jones, "Genesis, Chemical Properties and Mineralogy of Caribbean Grumusols," Soil Sci. 107, 166-174 (1969).

28. H. Kohnke, Soil Physies, (McGraw-Hil1 Book Company, New York, 1968), pp. 81-99.

29. E. P. Whiteside, "Considerations Relative to a Common Particle Size Scale of Earthy Materials," Soil Sci. Soc. Am. Proc. 311, 570-584 (1967).

30. K. Hartge, "The Form and Frequency of Various Particle Size Distribution in Soils," Z. Pflanzenernahr. Dueng. Bodenkd. 107 (1964) in Chem. Abstracts 62 (1965), 8877h.

31. J. K. Syers, M. L. Jackson, V. E. Berkheiser, R. N. Clayton, and R. W. Rex, "Eslian Sediment Influence on Pedogenesis During the Quaternary," Soil Sci. 107, 421-427 (1969).

32. W. D. Chepi1, "Dynamics of Wind Erosion: I. Nature of Movement of Soil by Wind," Soil Sci. $\underline{60}$, 305-320 (1945).

33. W. D. Chepi1, "Dynamics of Wind Erosion: III. Initiation of Soil Movement," Suil Sci. 60, 397-411 (1945). 
34. W. D. Chepi1, "Dynamics of Wind Erosion: III. The Transport Capacity of the Wind," Soil Sci. 60, 475-480 (1945).

35. J. R. Coover and W. C. Moldenhauer, "Some Criteria for Capability Classification of the Soils of the Southern Great Plains of Texas," Soil Sci. Soc. Am. Proc. 21, 641-644 (1957).

36. W. S. Chepil, "Conversion of Relative Field Erodibility to Annual Soil Loss by Wind," Soil Sci. Soc. Am. Proc. 24, 143-145 $(1960)$.

37. W. S. Chepil and N. P. Woodruff," The Physics of Wind Erosion and Its Control," Adv. Agron. 15, 211-302 (1963).

38. M. E. Strong, U.S.D.A. Soil Conservation Service, Albuquerque, NM, personal communication (June, 1973).

39. N. P. Woodruff, Wind Erosion laboratory, Kansas State University, Manhattan, Kansas, personal commication (June, 1973).

40. J. W. Healy: "A Proposed Interium Standard for Plutonium in Soils," Los Alamos Scientific Laboratory report LA-5483-MS (January $19 / 4)$.

41. The Advisory Committee on the Biological Effects of Ionizing Radiations, "The Effects on Populations of Exposure to Low Levels of Ionizing Rad:ation," Division of Medical Sciences, National Academy of Sciences, National Research Council, (November 1972).

42. National Council on Radiation Protection and Measurements, "Review of the Current State of Radiation Protection Philosophy," NCRP Report No. 43, NCRP Publications, Washington, D.C. (January 1975).

43. National Council on Radiation Protection and Measurements, "Basic Radiation Protection Criteria," NCRP Report No. 39, NCRP Publications, Washington, D.C. (January 1971).

44. The International Commission on Radiological Protection, "Recommendations of the International Commission on Radiologica1 Protection," (Adopted September 17, 1965). ICRP Publication 9, (Pergamon Press, London, New York 1966).

45. The International Commission on Radiological Protection, "The Metabolism of Compounds of Plutonium and Other Actinides," ICF.P Report No. 19, (Pergamon Press, Oxford, New York, May $1972)$.

46. The International Commission on Radiological Protection, "Report of ICRP Committee II on Permissible Dose for Internal Radiation (1959), With Bibliography for Biological, Mathematica1 and Physical Data," Health Phys. 3 , 1-380 (June 1960). 
47. National Council on Radiation Protection and Measurements, "Maximum Permissible Body Burdens and Maximum Permissible Concentrations of Radionuclides in Air and in Water for Occupational Exposure," Handbook 69, U.S. Dept. of Commerce, Nationa1 Bureau of Standards (U.S. Govt. Printing Office, June 1959).

48. J. W. Healy, "The Origin of Current Standards," Health Phys. 29, 489-494 (October 1975).

49. International Commission on Radiological Protection, Committee II, "Deposition and Retention Models for Internal Dosimetry of the Human Respiratory Tract," Health Phys. 12, $173-207$ (1966).

50. D. A.. Gillette, I. H. Blifford, Jr., and C. R. Fenster, "Measurements of Aerosol. Size Distributions and Vertical Fluxes of Aerosols on Land Subject to Wind Erosion," J. App1. Meteorol. 11, $977-987$ (September 1972).

51. D. A. Gillette, "On the Production of Soil Wind Erosion Aerosols Having the Potential for Long Range Transport," J. Rech. Atmos. VIII, (3-4) 735-744 (July-December 1974).

52. J. H. Shinn, N. C. Kennedy, J. S. Koval, B. R. Clegg, and W. M. Porch, "Observations of Dust Flux in the Surface Boundary Layer for Steady and Nonsteady Cases," ERDA Symposium Series 38, CONF-740921, Atmospheric Surface Exchange of Pariiculates and Gaseous Pollutants - 1974 Symposium, National Technical Information Service, Springfield, VA.

53. W. S. Chepil and N. P. Woodruff, "Estimations of Will Erodibility of Farm Fields," Agricultural Research Service Production Research Report No. $\overline{2} 5$, USDA (March 1959).

54. L. R. Anspaugh, J. H. Shinn, P. L. Phelps, and N. C. Kennedy, "Pesuspension and Redistribution of Plutonium in Soils," Health Phys. 29, 571-582 (October 1975).

55. G. A. Sehme1 and M. M. Orgil1, "Resuspension Source Change at Rocky Flats," Pacific Northwest Laboratory Annual Report for 1973 to the USAEC Division of Biomedical and Environmental Rescarch, Part 3 Atmospheric Sciences BNWL-1850 Pt 3, 212-214 (Apri1 1974).

56. D. E. Michels, "Diagnosis of Plutonium Reentrained in Air," Dow Chemical, U.S.A., Rocky Flats Division, Report RFP-1927 (Apri1 27, 1973).

57. G. A. Sehmel and F. D. Lloyd, "Particle Resuspension Rates," ERDA Symposium Series 38, CONF-740921, Atmospheric-Surface Exchange of Particulate and Gaseous Pollutants ". 1974 Symposium, National Technical Information Service, Springfield, VA. 
58. G. A. Sehme1 and F. D. Lloyd, "Resuspension Rates from a Circular Field Source," Pacific Northwest Laboratory Annual Report for 1975 to the USERDA Division of Biomedical and Environmental Research, Part 3 Atmospheric Sciences, BNWL-2000, Pt 3, 92-93 (March 1976).

59. D. A. Gillette and I. H. Blifford, Jr., "The Influence of Wind Velocity on the Size Distributions of Aerosols Generated by the Wind Erosion of Soils," J. Geophys. Res. 79 (27), 4068-4075 (September 20, 1974).

60. M. M. Orgil1 and G. A. Sehme1, "Frequency and Diurnal Variation of Dust in the Continerital United States," Pacific Northwest Laboratory Annual Report for 1974 to the USERDA Division of Biomedical and Environmental Research, Part 3 Atmospheric Sciences, BNlL-1950, Pt 3, 226-231 (1975).

61. M. M. Orgill and G. A. Sehmel, "Frequency of Airborne Dust in the Continental United States," Pacific Northwest Juaboratory Annual Report for 1975 to the USERDA Division of Biomedical and Environmental Research Part 3, Atmospheric Sciences, BNWL-2000 Pt 3, 105-108 (March 1976).

62. W. S. Chepil and N. P. Woodruff, "Sedimentary Characteristics of Dust Storms: I I Visibility and Dust Concentration," Am. J. Sci. 225, 104-114 (February 1957).

63. W. M. Porch, "Fast-Response Light Scattering Measurements of Aerosol Suspension in a Desert Area," Atmos. Environ. ㅁ, 897-904 (1974).

64. P. C. Sinclair, "Vertical Transport of Desert Particulates by Dust Devils and Clear Thermals," ERDA Symposium Series 38, CONF-740921, Atmospheric-Surface Exchange of particulates and Gaseous Pollutants 1974 Symposium, National Technical Information Service, Springfield, VA.

65. T. Tamura, "Distribution and Characterization of Plutonium in Soils From Nevada Test Site," in The Dynamics of Plutonium in Desert Environments, Nevada Applied Ecology Group Progress Report NVO-142 (July 1974).

66. R. O. Gilbert, L. L. Eberhardt, E. B. Fowler, E. M. Romney, E. H. Essington, and J. E. Kinnear, "Statistical Analysis of $239-240 \mathrm{Pu}$ and ${ }^{241} \mathrm{Am}$ Contamination of Soil and Vegetation on NAEG Study Sites," in The Radioecology of Plutonium and Other Transuranics in Desert Environments, Nevada Applied Ecology Group Progress Report NVO-153, 339-448 (June 1975).

67. R. O. Gilbert and L. L. Eberhardt, "Statistical Analysis of $\mathrm{Pu}$ in Soil at the Nevada Test Site-Some Results," in The Dynamics of Plutonium in Desert Environments, Nevada Applied Ecology Group Progress Report NVO-142, 51-89 (July 1974). 
68. L. R. Anspaugh and P. L. Phelps, "Results and Data Analysis: Resuspension Element Status Report," in The Dynamics of Plutonium in Desert Environments, Nevada Applied Ecology Group Progress Report NVO-142; 265-310 (Ju1y 1974).

69. P. W. Krey and E. P. Hardy, "Piutoniun in Soil Around the Rocky Flats Plant," USAEC Health and Safety Laboratory Report HASL-235 (August 1, 1970).

70. F. W. Krey, "Remote PJutoniun Contamination and Total Inventories from Rocky Flats," Health Phys. 30, 209-214 (1970).

71. P. Krey, E. Hardy, H. Volchok, L. Toonke1, R. Knuth, M. Coppes, and T. Tamura, "Plutonium and Americium Contamination in Rocky Flats Soil-1973," USERDA Health and Safety Laboratory Report HASi-304 (March 1976).

72. ¿. J. Johnson, "Report to the Board of County Commissioneas of Jefferson County," (September 19, 1975).

73. M. W. Nathans and W. D. Holland, "Analysis of: 239 Pu Farticles Collected Near the Rocky Flats Facility," Trapelo/West Report TLW-6105 (October 25, 1971).

74. H. L. Volchok, R. H. Knuth, and M. T. Klemman, "The Respirabie Fraction of Plutonium at Rocky Flats," Health Phys. 23, $395-396 \quad(1972)$.

75. G. A. Sehme.1 and F. D. Lloyd, "Resuspension of Plutonium at Rocky Flats," Pacific Northiest Laboratory Annual Report for 1974 to the USERDA Division of Biomedical and Environmental Research, Part 3 Atmospheric Sciences, BNWL-1950 Pt 3, 216-221 $(1975)$.

76. Colorado Department of Hea1th, "A Risk Evaluation for the Colorado Plutonium-in-Soil Standard," (January 1976).

77. S. Barr, Los Alamos Sciertific Laboratory, personal communication, 1976 .

78. D. H. Slade, Ed., "Meteorology and Atomic Energy," TİD-24190, USAEC Division of Technica1 Information (July 1968).

79. Westinghouse Electric Corp., "Westinghouse Cheswick Site, Fue1 Development Laboratories Erivironmental Report," (September 1974 ).

80. H. M. Mork, "kedistribution of Plutonium in the Environs of the Nevada Test Site," USAEC Document UCLA-12-590 (UCLA Laboratory of Nuclear Medicine and Radiation Biology), (August 1970). 
81. G. A. Sehme1, "Particle Resuspension From an Asphalt Road Caused by Car and Truck Traffic," Atmos. Environ. 7 (3), 291 309 , (March 1973).

82. G. A. Sehmel, "Particle Resuspension from Truck Traffic in a Cheat Grass Area," Pacific Nortliwest Laboratory Annual Report. for 1975 to the USERDA Division of Biomedical and Environmental Research, Part 3, Atmospheric Sciences, BNlL-2000 Pt 3, 96-98 (March 1976).

83. R. C. Milham, J. F. Schubert, J. R. Watts, A. L. Bonj, and J. C. Corey, "Measured Plutonium Resuspension and Resulting Dose From Agricultural Operations on an 0ld Field at the Savannah River Plant in the Southeastern United States," IAEA/USERDA Internationil Symposium on Transuranium Nuclides in the Environment, Noveriver $17-21,1975$.

84. D. S. Myers, iv. J. Silver, D. G. Coles, K. C. Lamson, D. R. McIntyre, and B. Mendoza, "Evaluation of the Use of S1udge Containing Plitonium as a Soil Conditioner for Food Crops," IAEA/ USERDA International Symposium on Transuranic Nuclides in the Environment, November 17-21, 1975.

85. K. Stewart, "The Resuspension of Particulate Material from Surfaces," in Surface Contamination, R. Fish. Ed., (Pergamon Press, New York, 1967) pp. 151-158.

86. U.S. Atomic Energy Commission Report WASH-1535, proposed final "Environmental Statement, Liquid Metal Fast Breeder keactor Program, Vol. II," (December 1974).

87. F. B. Benson, J. J. Henderson, and D. E. Caldwell, "IndoorOutdour Air Pollution Relationships: A Literature Review," Environmental Protection Agency Publication No. AP-112 (August 1972).

88. H. J. Dunster, "The Concept cf Derived Working Limits for Surface Contamination," in Surface Contamination, B. R. Fish, Fd. (Pergamon Press, Oxford, New York, 1907) pp. 139-147.

89. M. L. Lepow, L. Bruckman, M. Gillette, S. Markowitz, R. Robino, J. Kapish, "Investigations Into Sources of Lead in the Environment of Urban Children," Environ. Res. 10, 415-426 (1975).

90. R. T. Brunski11, "The Relationship Between Surface and Airborne Contanination," in Surface Contamination, B. R. Fish, Ed. (Pergamon Press, Oxford, New York, 1967) pp. 93-105.

91. R. Butterworth and J. K. Donoghue, "Contribution of Activity Released from Protective Clothing to Air Contamination Measured by Personal Air Samples," Hea1th Phys. 18, 319-323 (Apri1 1970). 
92. K. R. Price, "A keview of Transuranic Elements in Soils, Plants, and Animals," J. Environ. Qua1. 2 (1),62-66 (1973).

93. C. W. Francis, "Plutonium Mobility in Soil and Uptake in Plants: A Review," J. Environ. Qual. 2 (1), 67-70 (1973).

94. E. M. Romney, H. M. Mork, and K. H. Larsen, "Persistence of Plutonium in Soils, Plants, and Small Mammals, "Health Phys. 19, 487-491 (1970).

95. R. K. Schulz, G. A. Tompkins, and L. K. Babcock, "Uptake of Plutonium and Americium by Plants from Soils: Uptake by Wheat and Effect of Oxidation State of Plutonium Added to Soils," IAEA/USERDA International Symposium on Transuranium Elements in the Environment, November 17-21, 1975.

96 E. M. Romney, A. Wallace, and R. O. Gilbert, "239-240 Pu and $241 \mathrm{Am}$ Contamination of Vegetation in Aged Fallout Areas," IAEA/ USERDA International Symposium on Transuranium Elements in the Environment, Noyember 17-21, 1975.

97. H. R. McLendon, O. M. Stewart, A. L. Boni, J. C. Corey, K. W. Mcleod, and $\tilde{J}$. E. Pindes, "Relationships Among Plutonium Contents of Soil, Vegetation, and Animals Collected on and Adjacent to an Integrated Nuclear Complex in the Humid Southeastern United States," IAEA/USERDA International Symposium on Trans uranium Nuclides in the Environment, November 17-21, 1975.

98. E. P. Hardy, Jr., USERDA Health and Safety Laboratory Environmental Quarteriy Report for March 1 . June 1, 1976, HASL-306 (July 1, 1976).

99. J. W. Sayre, E. Charney, J. Vostal, and I. B. Pless, "House and Hand Dust As a Potential Source of Childhood Lead Exposure," Am. J. Dis. Child. $127,167-170$ (February 1974).

100. W. Antopol, L. Newman, R. Doering, C. Chryssanthou, and E. Cronkite, "Lead Exposure: Focal Concentrations from Atmospheric Fallout," Mt. Sinai J. Med. NY 41, 250-253 (March-Apri1 1974).

101. P. J. Landigar, S. H. Gehlbach, B. R. Rosenblum, J. M. Shoults, R. M. Candelaria, W. F. Barthe1, J. A Liddle, A. L. Smrek, N. W. Staeh1ing, and J. F. Sanders, "Epidemic I.ad Absorption Near an Ore Smelter," The New England Jour. of Med., 292 (3), 123-129 (January 16, 1975).

102. R. E. Rendall, P. Baily, and C. L. Soskolne, "The Fffect of Particle Size on Absorption of Inhaled Lead," Am. Ini. Hyg. Assoc. J. 36, 207-213 (March 1975). 
103. J. J. Vostal, E. Taves, J. W. Sayre, and E. Charney, "Lead Analysis of House Dust: A Method for the Detection of Another Source of Lead Exposure in Inner City Children," Environ. Health Perjpect. 7 , 91-97 (May 1974).

104. M. L. Lepow, L. Bruckman, R. A. Rubino, S. Markowitz, M. Gijlette, ard J. Kapish, "Role of Airborne Lead in Increased Body Burden of Lead in Hartford Children," Environ. Health Perspect. 7, 99-101 (Nay 1974).

105. G. Ter Haar and R. Aronow, "New Information on Lead in Dirt and Dust as Related to the Childhood Lead Problem," Environ. Health Perspect. 7, 83-89 (May 1974).

106. D. Barltrop, C. D. Strehlow, I. Thorton, and J. S. Webb, "Significance of High Soil Lead Concentrations for Childhood Lead Burdens," Environ. Health Perspect. 7 , 75-82 (May 1974).

107. K. Kostial, I. Simonovic, M. Pisonic, "Lead Absorption from the Intestine in New Born Rats," Nature 233, 567 (October 22, $1971)$.

108. G. B. Forbes and J. C. Reina, "Effect of Age on Gastrointestinal Absorption ( $\mathrm{Fe}, \mathrm{Sr}, \mathrm{Pb}$ ) in the kat," J. Nutr. 102, $647-652(1972)$.

109. P. Robischon, "Pica Practice and Other Hand-Mouth Behavior and Children's Developmental Leve1," Nurs. Res. 20, 4-16 (Jan* uary-February 1971).

110. D. Barltrop, "The Prevalence of Pica," Am. J. Dis. Child. $112,116-123$ (August 1966).

111. P. Lanzkowsky, "Investigation into the Aetiology and Treatment of Pica," Arch. Dis. Child. 34 (174), 140-148 (Apri1 1959).

112. E. M. Layman, F. K. Mil1ican, R. S. Lowrie, L. Y. Takahashi, "Cultural Influences and Symptom Choice: Clay-Eating Custums in Relation to the Etiology of Pica," The Psychological Record 13, 249-257 (1963).

113. The International Commission on Radiological Protection, "A Report of the Task Group on Reference Man," ICRP Publication 23 (Pergamon Press, Oxford, New York, 1975).

114. A. J. Ahlquist, C. J. Umbarger, and A. K. Stoker, "Recent Developments for Field Monitoring of Alpha-Emitting Contaminants in the Environment," presented to Health Physics Society Meeting, San Francisco, Ch, June 28-July 2, 1976.

115. L. R. Anspaugh, J. H. Shinn, and D. W. Wilson, "Evaluation of the Resuspension Pathway Toward Protective Guidelines for 
Soil Contamination with Radioactivity," IAEA/WllO Symposium on Radiological Safety Evaluation to Man and the invironment, My $2 !-24,1974$.

116. U.S. Environmental Protection Agency, "Draft Invironmental Statement-Environmental Radiation protection Requirements for Normal Operation of Activities in the Uranium Fuel Cycle," U.S. Environmertal Protection Agency. Office of Radiation programs, Way 1975.

117. P. W. Durbin, "Metabolism and Biologic Effects of the Transplutonium Elements," in Uranium, Plutonium, Transplutonic Elements, H. C. Hodge, I. N. Stannard, and J. B. Ilursh, Eds., (Springer-Verlag/Ber1in-Heidelberg, 1973).

118. R. L. Thomas and J. W. Healy, "An Appraisal of Available Information on Uptake by Plants of Transplutonium Elements and Neptunium," Los Alamos Scientific Laboratory report LA-6460-MS (August 1976).

119. R. C. Thompson, Pacilic Northwest Laboratory, Richland, WA, personal comnunication, 1976.

120. E. A. Marte11, "Actinides in the Environment and Their Uptake by Man," National Center for Atmospheric Research, Report NCAR-TN/STR-110 (May 1975). 